\title{
ACORDOS INCENTIVADOS \\ UMA CONTRIBUIÇÃO BRITÂNICA NOS CAMINHOS BUSCADOS PELO JUDICIÁRIO BRASILEIRO
}

TESE DE DOUTORADO

Orientador: Prof. Titular José Ignacio Botelho de Mesquita

FACULDADE DE DIREITO DA UNIVERSIDADE DE SÃO PAULO SÃO PAULO 


\title{
ACORDOS INCENTIVADOS
}

\section{UMA CONTRIBUIÇÃO BRITÂNICA NOS CAMINHOS BUSCADOS PELO JUDICIÁRIO BRASILEIRO}

\author{
Tese de Doutorado apresentada à Banca Examinadora da \\ Faculdade de Direito da Universidade de São Paulo, como \\ exigência parcial para a obtenção do título de Doutora em \\ Direito, sob orientação do Prof. Titular José Ignacio Botelho \\ de Mesquita
}


Banca Examinadora 
Agradecimento

Agradeço ao meu estimado Prof. José IGNÁCIO BotelHo DE MESQUITA o incentivo, paciência, as sábias contribuições e, acima de tudo, a confiança em mim depositada. Agradeço ao meu querido pai, José Olavo Amaral Silveira, as inúmeras conversas e o permanente e paternal apoio. 


\section{RESUMO}

O presente trabalho propôs-se a investigar a conveniência e a possibilidade de introdução, no ordenamento brasileiro, de iniciativas à semelhança dos pre-action protocols ("Protocolos") e da Part 36 Offer ("Oferta") do direito inglês, em vigor desde o advento das Civil Procedure Rules, em 1999. Aqueles, uma espécie de procedimento que se desenrola antes do processo judicial, incentivando o diálogo e a troca de informações e produção de prova entre as partes, cujo descumprimento importaria a incidência de multa; esta, uma oferta de acordo cuja rejeição ou aceitação traria consigo consequiências patrimoniais às partes envolvidas na controvérsia, também representada pela aplicação de uma (outra) multa. Embora não indissociáveis, acredita-se que, juntos, potencializam-se mutuamente.

Observaram-se os efeitos práticos da experiência inglesa, contemplando seus pontos fortes e fracos, chegando-se a um balanço positivo. Justificados os méritos dos institutos, entendeu-se possível a implantação de sistemática semelhante no Brasil, feitos certos ajustes. Observou-se, ainda, que um dos grandes méritos dos protocolos é a promoção do acordo informado, não do acordo motivado principalmente pela ineficiência e pela demora na prestação jurisdicional.

Assim, propôs-se a elaboração de protocolos, preferindo-se os específicos ao genérico, incutindo na população e nos operadores do direito a cultura do diálogo e da cooperação na troca de informações. Observaram-se, ainda, os efeitos que a conduta das partes no desenrolar do protocolo geraria dentro do processo.

Propôs-se, ainda, a introdução do que se chamaria de OPAc - Oferta Potencializada de Acordo, à semelhança da Oferta inglesa, mas com conseqüências patrimoniais (multa) calculadas sobre a diferença apurada entre a OPAc e a condenação final, no processo, como forma de criar incentivos suficientes, mas não opressivos.

Unitermos: "pre-action protocols"; "protocolo pré-ação"; "part 36 offer"; OPAc; CPR; acordo; transação; autocomposição; ADR; incentivo; "litigância de má-fé"; "deveres éticos"; disclosure. 


\begin{abstract}
This paper seeks to investigate the desirability and the possibility of introducing, in the Brazilian law, initiatives such as the pre-action protocols ("Protocols") and Part 36 Offer ("Offer") of the English law, in force since the advent of the Civil Procedure Rules in 1999. The former, a kind of procedure that takes place before the judicial proceedings, encouraging the dialogue, the exchange of information and the disclosure of evidence between the parties, and which failure results in the application of a fine; the latter, a settlement offer which rejection or acceptance would entail financial consequences to the parties to the dispute, also represented by the application of a (another) fine. Although not inseparable, it is believed that, taken together, Protocols and Offer enhance each other's effects.
\end{abstract}

The analysis of the practical results of the British experience, considering its strengths and weaknesses, led to a positive balance. Once the merits of those mechanisms have been justified, the implementation in Brazil of a similar systematic - provided certain adjustments are undertaken - was considered possible. It was also observed that one of the great values of the Protocols is promoting well-informed agreements, instead of settlements mainly motivated by the inefficiency and delay of adjudication.

Thus, the drafting of protocols was proposed, preferably the specific over the generic ones, introducing to the people as well as to the legal community a culture of dialogue and cooperation in the exchange of information and evidence. The effects that the conduct of the parties while following the Protocol would generate in the judicial proceedings were also analyzed.

Moreover, we proposed the introduction of the so-called OPAc - Oferta Potencializada de Acordo ("Enhanced Settlement Offer") - similar, in its concept, to the British Offer, albeit bearing financial consequences (fines) calculated over the difference between the OPAc and the amount as per the decision handed down by the judge, in order to create sufficient - but not oppressive - incentives

Key words: "pre-action protocols"; "Part 36 Offer"; OPAc; CPR; agreement; settlement; ADR; incentive; "procedural misconduct"; "ethical duties"; disclosure 


\section{RÉSUMÉ}

Ce travail a l'objectif d'étudier l'opportunité et la possibilité d'introduction, dans le droit brésilien, d'initiatives comme les protocoles préalables à la procédure («Protocols» ou «Protocoles ») et la «Part 36 Offer» («Offre ») de la loi anglaise, en vigueur depuis l'avènement des Règles de Procédure Civile («Civil Procedure Rules ») en 1999. Ceux-la, une sorte de procédure qui a lieu avant la procédure judiciaire, en encourageant le dialogue et l'échange de renseignements et la production de preuves entre les parties, dont l'échec résulte dans une amende; et ceci, une offre de règlement dont le rejet ou l'acceptation entraînerait des conséquences financières pour les parties au différend, également représentées par une (autre) amende. Bien que ces mécanismes ne soient pas inséparables, son utilisation ensemble les potentialise.

Les effets pratiques de l'expérience britannique, compte tenu de ses forces et ses faiblesses, ont été vérifiés et le solde a été positif. Une fois que les mérites des mécanismes ont été justifiés, l'implantation d'un système similaire au Brésil - pourvu que certains ajustements soient faits - a été jugé possible. Encore, on a observé qu'un des grands mérites des protocoles constitue la stimulation d'un accord renseigné, au lieu d'un accord motivé surtout par l'inefficacité et le retard des jugements.

Ainsi, l'élaboration de protocoles a été proposée, préférablement les spécifiques au générique, afin d'inspirer - parmi la population et les opérateurs du droit - la création d'une culture de dialogue et coopération dans l'échange d'informations. Egalement, nous avons observé les effets que la conduite des parties pendant l'étape des protocoles entraînerait sur la procédure judiciaire.

Nous avons encore proposé l'introduction de ce qu'on appellerait OPAc - Offre Potentialisée d'Accord - similaire à l'Offre anglaise, mais avec des conséquences financières (amende), calculées sur l'écart constaté entre l'OPAc et le montant de la condamnation dans la procédure, comme une façon de créer des incitations suffisantes, mais pas oppressantes.

Mots clés: «pre-action protocols»; protocoles préalables à la procédure; «part 36 offer»;

OPAc; CPR; accord; transaction; conciliation; ADR; motivation; «mauvaise conduite dans la procédure»; «litigância de má-fé»; devoirs étiques; disclosure. 


\section{SUMÁRIO}

INTRODUÇÃO AO TEMA

\section{PARTE I \\ REINO UNIDO}

1. CONTEXTO DE SURGIMENTO DAS CIVIL PROCEDURE RULES

2. OS PRE-ACTION PROTOCOLS. 18

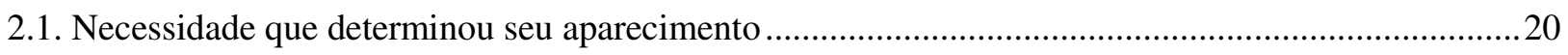

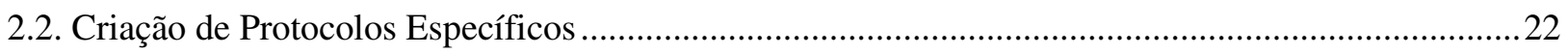

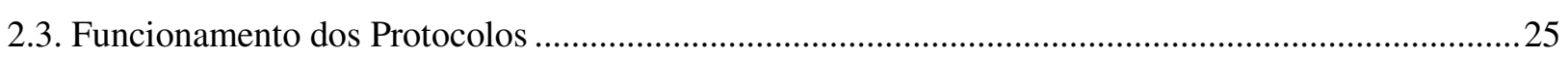

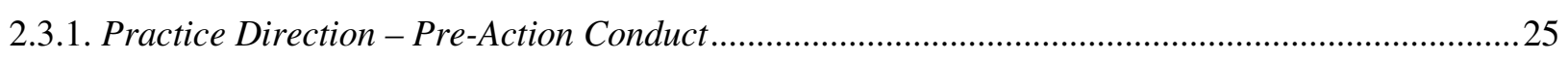

2.3.1.1. Cumprimento e avaliação do cumprimento dos Protocolos ..........................................................27

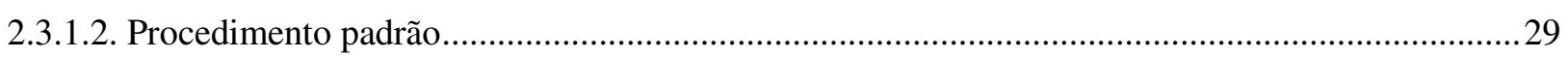

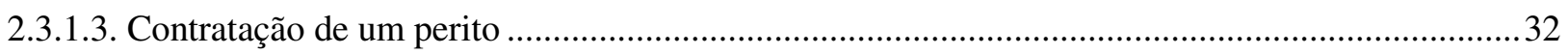

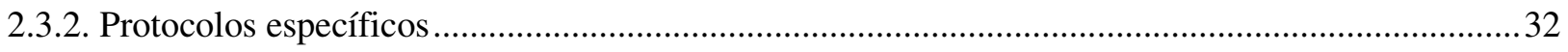

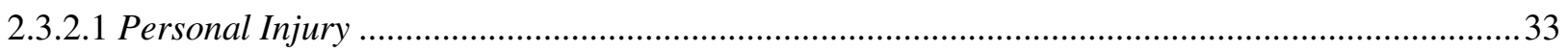

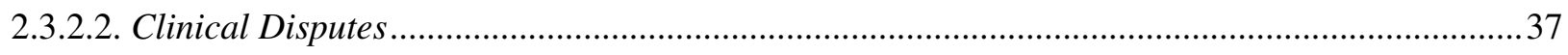

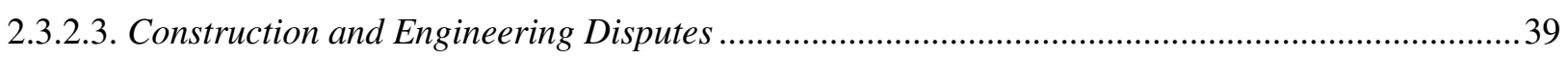

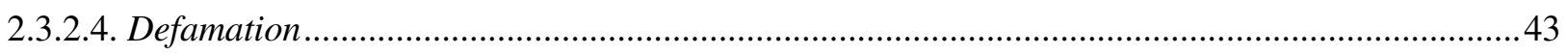

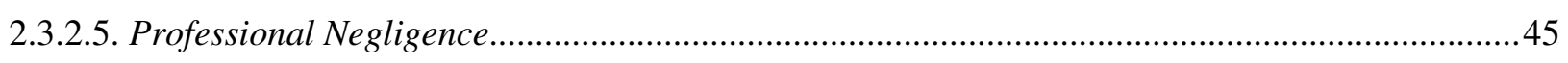

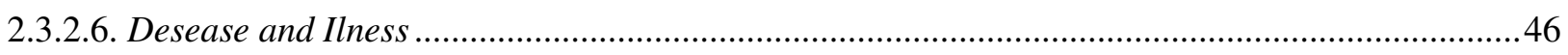

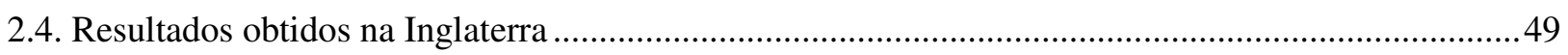

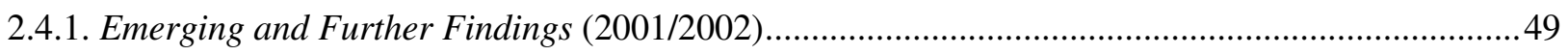

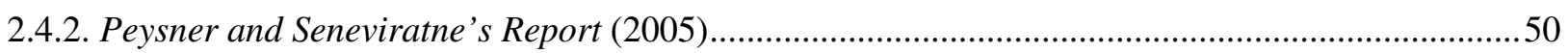

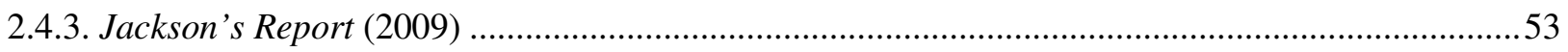

2.4.4. Apontamentos da jurisprudência ................................................................................................57

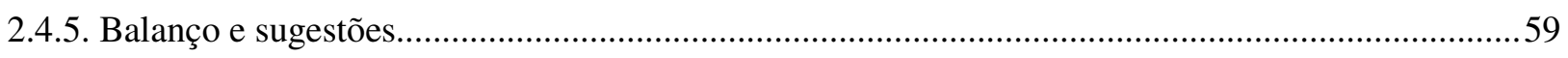

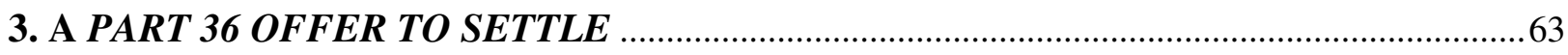

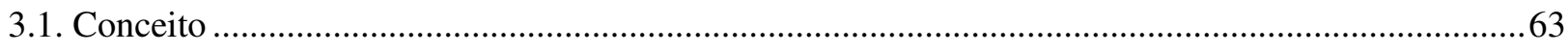

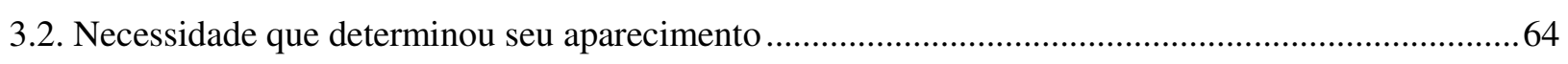




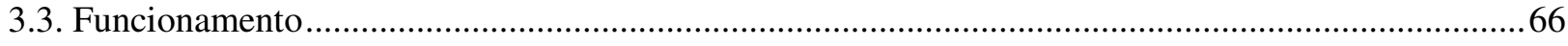

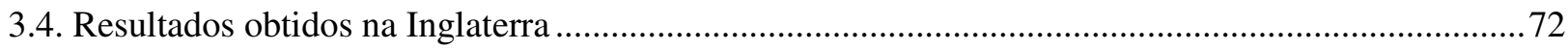

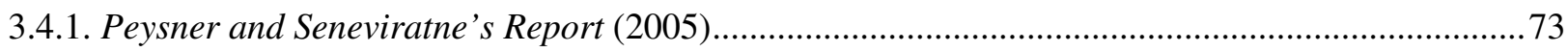

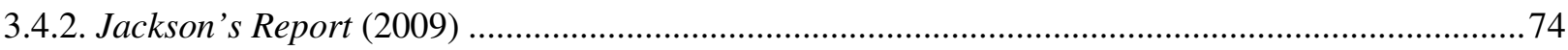

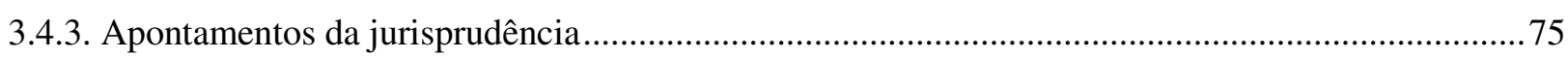

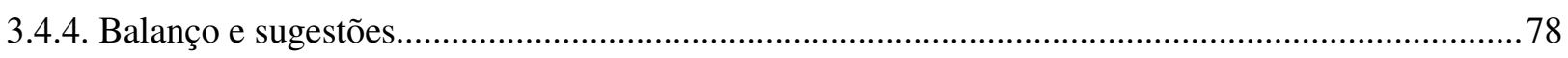

\section{PARTE II}

BRASIL

\section{NECESSIDADES E OBJETIVOS SEMELHANTES (E OBSERVAÇÕES DE ORDEM CULTURAL)}

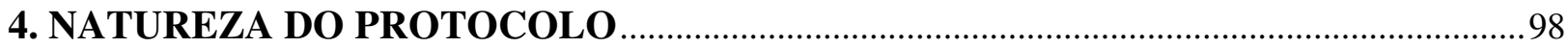

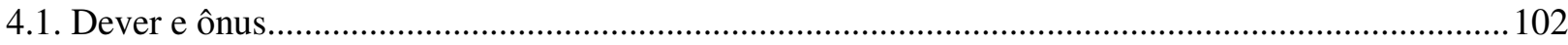

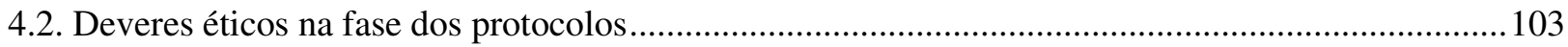

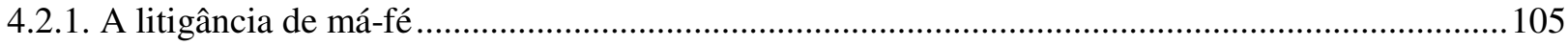

4.3. Necessidade de parâmetros objetivos para o juiz............................................................................... 107

5. PROTOCOLOS: IMPLICAÇÕES DE SUA ADOÇÃO, PANORAMA E

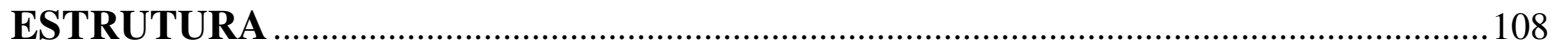

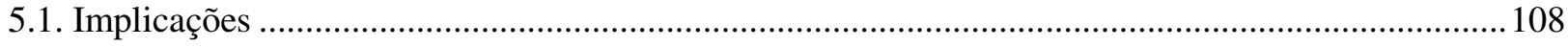

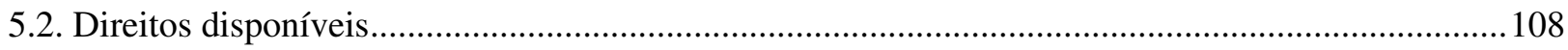

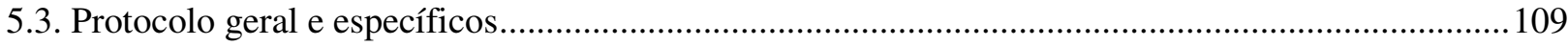

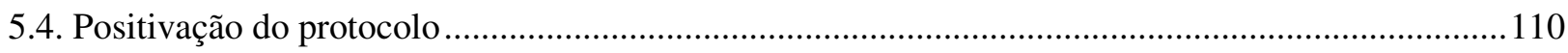

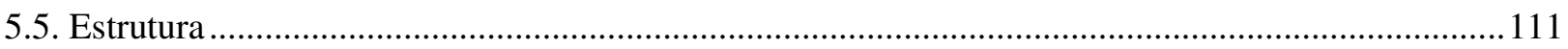

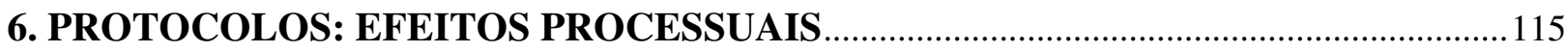

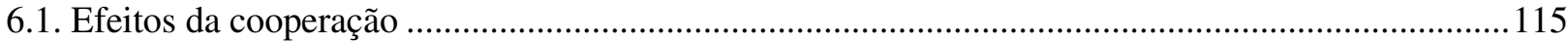

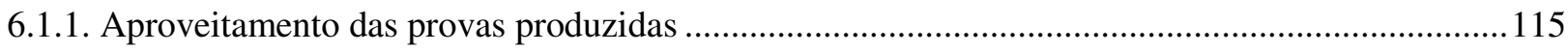


6.2. Efeitos da não-cooperação

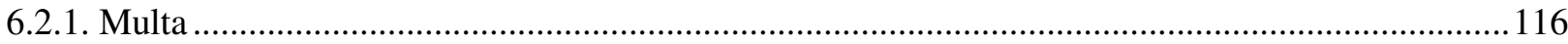

6.2.2. Exibição, em juízo, de documentos omitidos na fase dos protocolos .............................................118

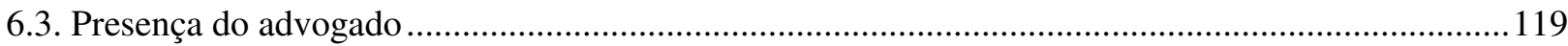

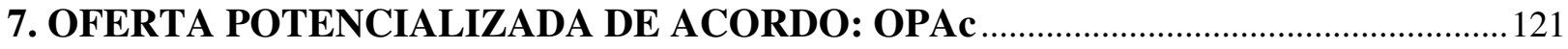

7.1. Notas introdutórias e breve retomada da sistemática da Part 36 Offer .............................................121

7.2. Natureza, disponibilidade de direitos e positivação ........................................................................... 123

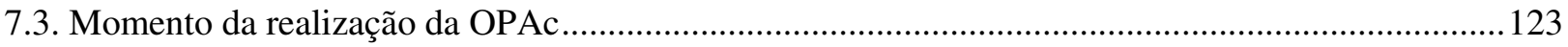

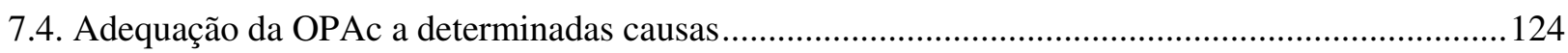

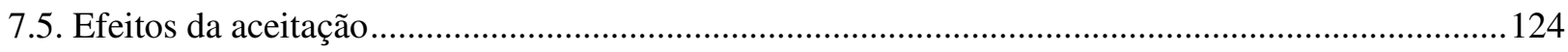

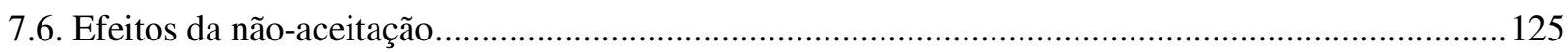

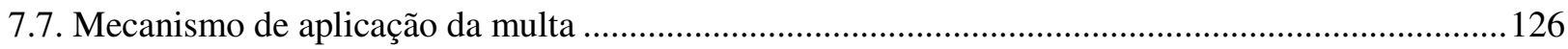

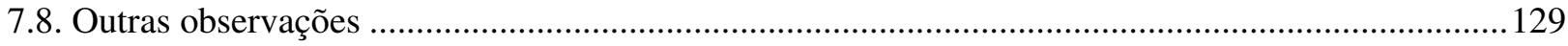

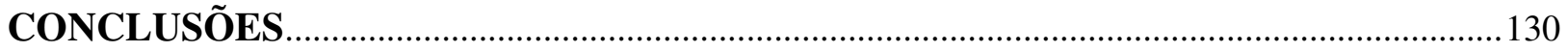

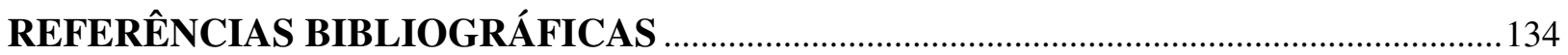

\section{ANEXO}

Pre-Action Protocol for Personal Injury Claims. 


\section{INTRODUÇÃO AO TEMA}

"É nosso dever contribuir para fazer que o direito e os remédios legais reflitam as necessidades, problemas e aspirações atuais da sociedade civil; entre essas necessidades estão seguramente as de desenvolver alternativas aos métodos e remédios tradicionais, sempre que sejam demasiado caros, lentos e inacessíveis ao povo; daí o dever de encontrar alternativas capazes de melhor atender às urgentes demandas de um tempo de transformações sociais em ritmo de velocidade sem precedente"

Essas foram as palavras de MAURO CAPPELLETTI ao abordar a responsabilidade do jurista e ao chamar a comunidade jurídica a pensar formas alternativas de solução de conflitos, especialmente a mediação, a conciliação e a arbitragem. O que se buscará alcançar com o presente trabalho é, em certa medida, uma resposta à conclamação do mestre italiano: propor a adoção de dois mecanismos - aqui entendidos como complementares -, como forma de incentivar as partes a se aproximarem, cooperarem e autocomporem-se.

Este estudo visa, pois, a trazer aos juristas brasileiros detalhes da experiência britânica no tocante a dois institutos distintos: (i) os pre-action protocols (protocolos préação), um procedimento destinado à troca de informações entre as partes antes do início da ação e (ii) a Part 36 offer to settle, oferta de acordo da Parte 36 das Civil Procedure Rules inglesas cuja aceitação ou recusa traz consigo consequiências econômicas ${ }^{2}$. Referidos mecanismos não são indissociáveis, mas se acredita que juntos têm muito mais a oferecer ao jurisdicionado e ao Poder Judiciário, diminuindo o volume de ações ajuizadas e, uma vez verificada a inevitabilidade do ajuizamento da ação, encurtando sua duração, na medida em que se presume já estará mais madura.

Não se trata de falar de métodos alternativos de solução de conflitos da forma como têm até o momento sido abordados, mas sim de buscar algo novo ${ }^{3}$, algo que se vem fazendo além-mar desde há mais de uma década.

\footnotetext{
${ }^{1}$ CAPPELLETTI, Mauro. Os métodos alternativos de solução de conflitos no quadro do movimento universal de acesso à justiça. Revista de Processo, São Paulo, v. 19, n. 74, p. 97, abr./jun. 1994.

${ }^{2}$ Descrição completa desses institutos é oferecida nos Capítulos 2 e 3, da Parte I deste trabalho.

${ }^{3}$ Trata-se de algo novo porque não se tem, no Brasil, notícia de iniciativas semelhantes. No que diz respeito aos protocolos, trata-se de uma série de atos encadeados que devem ser seguidos antes do início da ação, como forma de aproximar as partes e, eventualmente, evitar a ação.
} 
Acredita-se que, no Brasil, um sistema de protocolos semelhante ao que se criou na Inglaterra seria de extremo auxílio para reduzir o volume de ações que são diariamente ajuizadas e afogam o Poder Judiciário, diminuindo a carga de processos que sobre ele pesa. Ademais, isso representaria também uma vantagem ao jurisdicionado, na medida em que as chances de uma composição amigável anterior ao ajuizamento da ação seriam aumentadas (ou mesmo representariam a potencial desistência de propô-la). Por fim, na hipótese de a ação ser de fato ajuizada depois de seguido o protocolo, a causa chegaria ao juiz mais amadurecida e, portanto, é de se supor que seu julgamento seria mais célere e, como conseqüência, menos dispendioso para as partes e para a sociedade.

É verdade que tais mecanismos foram pensados e desenvolvidos para um país que tem uma cultura e um sistema jurídico diferentes, de modo que a sua implantação no Brasil demandará ajustes e a superação de obstáculos.

Por fim, lembre-se que a intenção desses institutos não é de forma alguma obrigar a celebração do acordo, mas facilitá-los: de um lado, através da obrigatoriedade do contato entre as partes - criando uma cultura de cooperação, menos adversarial - e, de outro, através da possibilidade de gerar ganhos para aqueles que considerarem, com seriedade, fazer ou aceitar uma proposta de acordo. Não um acordo qualquer, motivado principalmente por argumentos de demora da prestação jurisdicional, de falência do Judiciário, e sim um acordo informado, ou seja, embasado em conhecimento dos fatos que contituem a controvérsia e da visão que o adversário tem sobre ela.

\footnotetext{
O que se tem no Brasil são, por exemplo, a notificação da lei de locações, para que o contrato não se transforme em contrato com prazo indeterminado, ou, ainda, em relação à compra e venda de imóveis, a exigência imposta pelo Decreto-lei n. 745/69 de que se notifique o promissário comprador para purgar a mora antes que se possa pleitear a adjudicação compulsória do imóvel. Essas são, de fato, ações que podem servir de incentivo para o cumprimento de uma obrigação, o que evitaria o inicio da ação. Embora tais iniciativas tenham o mesmo fim (último) almejado pela implantação de um sistema de protocolos, a eles não se assemelham, na medida em que não se estipula troca de informações ou de documentos como forma de se conhecer melhor a pretensão do potencial oponente, para melhor avaliar os riscos inerentes ao eventual ingresso em juízo. Os protocolos não podem ser reduzidos a uma mera notificação; eles são muito mais do que isso. Alguma semelhança poderia ser encontrada entre o regime dos protocolos e a troca de correspondências que se dá junto a órgãos como o ProCon, por exemplo, que fazem uma espécie de intermediação entre o fornecedor e o consumidor, a qual, quando bem sucedida, pode ter o condão de evitar a ação judicial.

BEDAQUE, discorrendo exatamente sobre mecanismos semelhantes aos protocolos, assinalou que "Tanto Argentina quanto Brasil não prevêem essa fase preliminar (pre-action), muito embora possam os advogados adotar providências nesse sentido, inspiradas na boa-fé. Trata-se, todavia, de procedimento absolutamente facultativo e despido de qualquer regulamentação. Em ambos os países, somente há previsão legal para procedimentos judiciais, ainda que anteriores ao processo principal, mas não inspirados na idéia de conciliação." in BEDAQUE, José Roberto dos Santos. Novas tendências em matéria de fase preliminar. Relatório Síntese. In: GRINOVER, Ada Pellegrini; CALMON FILHO, Petrônio (Orgs.). DIREITO PROCESSUAL COMPARADO. CONGRESSO MUNDIAL DE DIREITO PROCESSUAL, 13. Rio de Janeiro: Forense, 2007. p. 262.
} 
Referindo-se à regulamentação da fase que precede o processo judicial, afirma JosÉ ROBERTO DOS SANTOS BEDAQUE que, embora inexista aqui legislação a respeito:

“(...) o Brasil é receptivo à idéia de regulamentação da fase preliminar. Existe projeto de lei sobre mediação para-processual no processo civil, possibilitando a prevenção ou solução de litígios por terceiro imparcial, escolhido pelas partes. É uma das muitas alternativas na busca de soluções alternativas, tendo em vista a crise por que passa o sistema jurisdicional brasileiro, caracterizado pelo excesso de processos e pela morosidade."

Na Parte I deste trabalho serão apresentados os dois institutos acima referidos, sua origem, seu funcionamento e os resultados obtidos na Inglaterra, na esteira do que escreveu José CARlos BARBOSA MoREIRA ao abordar o tema da importação de modelos jurídicos:

"Ora, entre os postulados básicos da importação de modelos jurídicos -
a par do exame da compatibilidade entre o órgão que se quer
transplantar e o organismo que o vai receber - avulta a investigação
atenta da maneira pela qual o instituto que se pretende importar
funciona praticamente no Estado de origem.".

Não se tem a pretensão de, ao final deste trabalho, sugerir protocolos específicos para o direito brasileiro, dada a vastidão de um trabalho dessa natureza. Ademais, os protocolos ingleses foram desenhados por meio de um esforço conjunto entre profissionais - advogados, associações, juízes, etc. - militantes em determinadas espécies de litígios identificadas como merecedoras de uma iniciativa dessa sorte. Pretender fazer o mesmo neste trabalho seria impensável. Da mesma forma, não se ambiciona propor uma mecânica acabada de incentivos econômicos para que as partes façam ou aceitem propostas uma da outra (à semelhança da Oferta da Parte 36), mas tão somente apontar os caminhos.

O presente estudo visa a trazer ao direito brasileiro uma experiência marcante e positiva no que se refere a uma cultura de cooperação incentivada, relatando, inclusive, as questões e problemas que os institutos geraram e ainda geram além-mar (conforme partes finais dos Capítulos 2 e 3 da Parte I), investigando (e, acredita-se, afastando) potenciais obstáculos para sua implementação no Brasil, bem como propondo sua estruturação no direito brasileiro, o que se fará na Parte II deste estudo.

\footnotetext{
${ }^{4}$ BEDAQUE, José Roberto dos Santos. Novas tendências em matéria de fase preliminar, cit., p. 263.

${ }^{5}$ BARBOSA MOREIRA, José Carlos. A importação de modelos jurídicos. In: processual: $8^{\mathrm{a}}$ série. São Paulo: Saraiva, 2004. p. 265. . Temas de direito
} 
PARTE I

REINO UNIDO 


\section{CONTEXTO DE SURGIMENTO DAS CIVIL PROCEDURE RULES}

Em março de 1994, na Inglaterra, Lord WoOLF $^{6}$ foi nomeado pelo então Lord Chancellor $^{7}$ para liderar uma extensa pesquisa sobre o Judiciário inglês. Seu objetivo era avaliar a situação atual do sistema para em seguida propor reformas.

As medidas propostas por Lord WoOLF visavam a que se: (i) reduzissem o custo e a duração do litígio, através de um maior controle do manejo dos processos a ser feito pelos juízes; (ii) reduzissem a complexidade das normas e se modernizassem terminologias; (iii) removessem distinções desnecessárias de procedimentos; e (iv) promovesse uma cultura de cooperação entre as partes, em oposição à cultura exacerbadamente adversarial que se instalara. Tudo isso com o objetivo de propiciar um melhor acesso dos jurisdicionados à justiça. Um ano mais tarde, concluída a primeira etapa da pesquisa, Lord WoOLF fez publicar o Access to Justice Interim Report ${ }^{8}$ em junho de 1995, no qual ofereceu um panorama geral dos problemas e das mudanças que seriam necessárias para saná-los.

Disse Lord WoOLF sobre a demora na prestação jurisdicional:

"30. Delay is an additional source of distress to parties who have already suffered damage. It postpones the compensation or other remedy to which they may be entitled. It interferes with the normal existence of both individuals and businesses. In personal injury cases, it can exacerbate or prolong the original injury. It can lead to the collapse of relationships and businesses. It makes it more difficult to establish the facts because memories fade and witnesses cannot be traced. It postpones settlement but may lead parties to settle for inadequate compensation because they are worn down by delay or cannot afford to continue."

(...)

"38. Settlements at a late stage of the proceedings involve the parties in substantial additional costs. These late settlements are, however, endemic throughout the system. A settlement at a late stage is better than no settlement at all. But if a case can be settled fairly at an earlier stage this is to the parties' and the courts' benefit and would help to avoid the situation where one party can bring pressure to bear on the other party to settle on unfavourable terms as a result of the burden of costs or the

\footnotetext{
${ }^{6}$ Lord Woolf iniciou sua carreira como advogado, passando mais tarde a juiz eda Corte de Apelação do reino Unido e, posteriormente, a Casa dos Lordes (House of Lords). Assumiu, em 1995, a posição de Lord Chief Justice em em seguida presidiu as Cortes de Inglaterra e do País de Gales.

${ }^{7}$ Ele é o segundo na hierarquia dos Grandes Oficiais do Estado (Great Officers of State) e é nomeado pelo soberano, conforme recomendação do Primeiro Ministro. O Lorde Chanceler é responsável pelo eficiente funcionamento e independência das cortes. Ateriormente, ele era o oficial que presidia a Casa dos Lordes (House of Lords) e o chefe do Judiciário na Inglaterra e no País de Gales, mas o Constitutional Reform Act 2005 transferiu tais papéis para o Lord Speaker e Lord Chief Justice, respectivamente.

${ }^{8}$ ACCESS to justice. By The right honourable the Lord Woolf. Disponível em: $<$ http://www.dca.gov.uk/civil/interim/contents.htm>.
} 
frustration caused by delay."9

A observação feita por Lord WoOLF seria igualmente cabível ao sistema brasileiro, embora o problema sobre custos do processo seja mais acentuado na Inglaterra do que no Brasil. O acordo que se faz porque não se tem mais recursos ou forças para continuar litigando é um acordo potencialmente ruim (ao menos para a parte mais fraca). É quase uma entrega, em oposição a uma calculada e séria avaliação dos fatos, das provas e das conseqüentes chances de êxito de cada uma das partes.

Mais tarde, em julho de 1996, foi publicado o Access to Justice Final Report ${ }^{10}$, com as sugestões formuladas por Lord WoOLF, cuja grande maioria foi implantada por meio das Civil Procedure Rules (CPR), em vigor desde 1999 e que constituíram grande marco no processo civil inglês. Os Pre-Action Protocols e a Part 36 Offer to Settle fizeram parte desse movimento.

O diagnóstico empreendido por Lord WoOLF no seu Access to Justice Final Report identificou que o sistema judicial civil era demasiadamente caro (custos comumente excediam o valor da demanda); lento; desigual (em termos de litigantes lutarem com desigualdade de armas); complexo (em virtude da difícil compreensão das regras por muitos litigantes); adversarial (na medida em que a condução do litígio era dada às partes e as normas eram frequentemente ignoradas por elas e não aplicadas pelos tribunais); e conseqüentemente, penoso e sofrível em razão do justificável medo do desconhecido infundido por cenário tao incerto. Essas foram, em síntese, as palavras de Lord WoOLF no início da Seção 1 de seu relatório.

Lord WoOLF disse visualizar uma nova paisagem para o sistema judicial civil no Reino Unido (“a new landscape”). Grande parte do seu esforço foi no sentido de organizar o sistema em termos de estruturação dos casos dentro das cortes existentes e entre tais cortes, de forma a aparelhá-las corretamente e otimizar os recursos do Judiciário. Além disso, empenhou-se em implementar o case management ${ }^{11}$, modelo mediante o qual os

\footnotetext{
${ }^{9}$ ACCESS to Justice: Interim Report (1995), Lord Woolf. Disponível em: $<$ www.dca.gov.uk/civil/interim/index.htm>. Capítulo 3.

${ }^{10}$ ACCESS to Justice: Final Report (1996), By The Right Honourable the Lord Woolf, Master of the Rolls. July 1996. Disponível em: <www.dca.gov.uk/civil/final/index.htm>.

${ }^{11}$ A expressão "case management" foi traduzida para "gerenciamento de processos" por Paulo Eduardo Alves da Silva, que o definiu da seguinte forma: "O "gerenciamento de processos" pode ser compreendido como o planejamento da condução de demandas judiciais para a mais adequada resolução dos conflitos com o menor dispêndio de tempo e recursos. Está baseado no controle judicial da condução dos feitos e organização da unidade judiciária, e opera basicamente pelo envolvimento imediato do juízo com as
} 
casos seriam efetivamente geridos pelas cortes, o que incluiria detalhar o procedimento (track) a seguir, identificar as questões presentes no caso, decidir de plano algumas delas e estabelecer a ordem através da qual outras seriam resolvidas, fixar cronogramas para que as partes tomassem determinadas providências para o desenrolar do caso, limitar o "disclosure" e a produção de provas periciais. Na visão de Lord WoOLF, isso importaria melhor pensar os recursos a serem alocados a cada caso, o juiz adequado a presidi-lo etc., otimizando gastos das partes e do próprio Judiciário e dificultando manobras das partes para, por exemplo, protrair o caso no tempo.

A inovação mais significativa trazida pelas CPR, ao lado do case management, foi a definição do seu overriding objective ${ }^{12}$ (objetivo supremo), ou seja, o objetivo à luz do qual todas as disposições das CPR devem ser examinadas e obedecidas, objetivo este que há de ser buscado pelas cortes, com o auxílio das partes em litígio. Eis a Parte 1, subitem 1 das CPR:

"O objetivo supremo.

1.1.

(1) As Regras [CPR] são um novo código de processo, com o objetivo supremo de permitir à corte lidar com casos de forma justa.

(2) Lidar com um caso de forma justa inclui, tanto quanto praticável -

a. Certificar-se de que as partes estão em pé de igualdade;

b. Poupar despesas;

c. Lidar com o caso de modo que seja proporcional -

i. Ao volume de dinheiro envolvido;

ii. À importância do caso;

iii. À complexidade das questões;

d. Certificar-se que o caso é manejado de forma expedita e justa; e

e. Alocar ao caso quantidade apropriada dos recursos da corte, levando em consideração a necessidade de alocar recursos a outros casos." 13

questões da lide, estímulo às tentativas de composição amigável das partes, planejamento do fluxo procedimental e organização de estrutura necessária”, SILVA, Paulo Eduardo Alves da. Gerenciamento de processos e cultura de litigância - a experiência do "case management" inglês. In: SALLES, Carlos Alberto de (Coord.). As grandes transformações do processo civil brasileiro: homenagem ao Professor Kazuo Watanabe. São Paulo: Quartier Latin, 2009. p. 636.

${ }^{12}$ In ZUCKERMAN, Adrian A. S. Zuckerman on civil procedure: principles of practice. 2. ed. London: Sweet \& Maxwell, 2006. p. 15-16.

${ }^{13} \mathrm{O}$ texto das CPR foi traduzido livremente. Entretanto, na medida em que a língua inglesa é, hoje em dia, fortemente difundida no Brasil, especialmente dentre os acadêmicos, não se empreenderá, na grande maioria das vezes, a tarefa de tradução de trechos transcritos ao longo do presente trabalho. Segue o texto da seção 1.1 das CPR no original:

"The overriding objective

1.1 
O objetivo supremo nada mais é do que a indicação de princípios que regem o novo código e a nova postura que se pretende fazer adotar, um ideal que deve estar subjacente a cada ato das partes e a cada decisão dos juízes e tribunais.

ADRIAN ZUCKERMAN observa as faces do objetivo supremo e a tensão entre metas (todas trazidas por tal objetivo) que apontam para direções distintas:

"the overriding objective presents the court with specific goals that the court must further in carrying out its case management powers. However, one can hardly fail to notice that these goals are capable of pointing in different directions. Sparing litigant and court resources may be incompatible with expeditious resolution, or it may be at odds with the need to arrive at a correct outcome. Similarly, expedition may be achieved only by investing more resources, or it may only be reached by restricting disclosure and thus running a higher risk of error. (...) The strength of the CPR lies precisely in confronting the inevitable tension between three imperatives: the need for correct outcomes, the need for expeditious resolution, and the practical constraints of court and party resources." 14

(1) These Rules are a new procedural code with the overriding objective of enabling the court to deal with cases justly.

(2) Dealing with a case justly includes, so far as is practicable -

(a) ensuring that the parties are on an equal footing;

(b) saving expense;

(c) dealing with the case in ways which are proportionate -

(i) to the amount of money involved;

(ii) to the importance of the case;

(iii) to the complexity of the issues; and

(iv) to the financial position of each party;

(d) ensuring that it is dealt with expeditiously and fairly; and

(e) alloting to it an appropriate share of the court's resources, while taking into account the need to allot resources to other cases."

${ }^{14}$ In ZUCKERMAN, Adrian A. S. Zuckerman on civil procedure: principles of practice, cit., p. 15-16. 


\section{OS PRE-ACTION PROTOCOLS}

Os chamados pre-action protocols - protocolos pré-ação ${ }^{15}$-, os quais adiante serão chamados, por vezes, apenas de "Protocolos" ou "Protocolo", quando referidos no singular, constituem uma iniciativa introduzida em 1999 que, conforme pesquisas publicadas na Inglaterra $^{16}$, surtiu efeitos bastante positivos no que se refere à diminuição do ajuizamento de ações. De acordo com esses protocolos, que estabelecem procedimentos a serem seguidos pelos interessados em um determinado litígio, o autor deve notificar o adversário da ação que poderá ser contra ele ajuizada e, uma vez feita a notificação, devem iniciar uma troca significativa de informações e documentos a respeito do litígio.

A iniciativa surgiu com Lord WoOLF em seu Access to Justice Interim Report, ao tratar da necessidade de haver um comportamento cooperativo entre as partes assim que se cogitasse sobre a propositura de uma ação. Nesse momento, as partes deveriam fornecer uma à outra informações, documentos e possibilidade de inspecionar determinadas instalações, se esse fosse o objeto da controvérsia. Lord WoOLF escreveu:

"8. Co-operation before the issue of proceedings could result, for example, in an expert being jointly instructed, and this, in turn, might mean that there is no need to issue proceedings. There is no reason, in my view, why a party should not be able to inspect machinery involved in an accident before he starts proceedings. A prospective defendant is generally not obliged to correct a misapprehension under which a potential claimant labours. But in a situation in which a would-be claimant is unaware of vital facts of which his opponent is fully aware and, because his misapprehension is not rectified, the claimant issues proceedings, I see no reason why the court should not take this into account when it is asked to determine what order for costs should be made.",17

Adiante, Lord Woolf semeia a idéia dos Protocolos e convida a comunidade a também pensar sobre o tema:

\footnotetext{
${ }^{15}$ Ao se traduzir protocols por protocolos tem-se em mente não o ato de protocolar, tão freqüente no jargão forense, que indica apresentar a petição, ou o recurso, e receber um comprovante de tal apresentação, qual seja, o protocolo. Aqui, o termo protocolo assemelha-se mais ao protocolo médico ou diplomático, referindo-se a uma série de atos que devem ser seguidos de acordo com regras pré-estabelecidas. Assim, o pre-action protocol, ou protocolo pré-ação, diz respeito à série encadeada de atos que deve ser seguida pelas partes antes de se tornarem partes de um processo, antes que exista uma ação.

${ }^{16}$ As pesquisas serão mencionadas no item 2.4, Parte I deste trabalho.

${ }^{17}$ ACCESS to Justice: Interim Report, cit., Capítulo 19.
} 
"12. In line with my general approach of encouraging more reasonable party behaviour, I invite the appropriate professional bodies, with the participation of relevant groups of court users or their representatives, to draw up guidelines as to pre-proceedings conduct in relation to areas of litigation commonly before the courts. I believe that such guidelines will increase prospects of settlements and, even where there is no settlement, enable proceedings to be disposed of more satisfactorily. (...) The appropriate professional bodies should draw up guidelines for the pre-proceedings conduct of legal representatives." 18 (destaques da transcrição)

Dentre inúmeras características da "nova paisagem" vislumbrada por Lord WoOLF em seu Access to Justice Final Report, as seguintes são de particular interesse ao presente trabalho:

$$
\text { “(...) }
$$

Litigation will be avoided wherever possible.

(a) People will be encouraged to start court proceedings to resolve disputes only as a last resort, and after using other more appropriate means when these are available.

(...)

(d) Protocols in relation to medical negligence, housing and personal injury, and additional powers for the court in relation to pre litigation disclosure, will enable parties to obtain information earlier and promote settlement.

(e) Before commencing litigation both parties will be able to make offers to settle the whole or part of a dispute supported by a special regime as to costs and higher rates of interest if not accepted.

Litigation will be less adversarial and more co operative.

(a) There will be an expectation of openness and co-operation between parties from the outset, supported by pre-litigation protocols on disclosure and experts. The courts will be able to give effect to their disapproval of a lack of co-operation prior to litigation. (...)"19 (destaques da transcrição)

De acordo com Lord IRVINE OF LAIRG, no prefácio que escreveu a um dos diversos Protocolos, a intenção deles é "fornecer um cronograma para a troca de informações relevantes à disputa, através do estabelecimento de padrões para o conteúdo de correspondências. O cumprimento dos Protocolos permitirá às partes formar, mais cedo do

\footnotetext{
${ }^{18}$ ACCESS to Justice: Interim Report, cit., Capítulo 19.

${ }^{19}$ Item 9 da Seção 1 do ACCESS to Justice: Final Report, cit. A indicação da página não foi possível na medida em que a versão do relatório que se usou para a elaboração do presente trabalho foi encontrada na internet, em texto corrido.
} 
que tende a ocorrer hoje, um convencimento informado a respeito dos méritos de suas causas, na medida em que terão, desde cedo, acesso à informação que necessitam.” ${ }^{20}$

Quando publicado o Access to Justice Final Report, Lord WoOLF fez menção àqueles que criticavam a criação de Protocolos sob o argumento de que trariam custos desnecessários e, principalmente, custos que as partes teriam de incorrer desde o início (front-loading of costs). Contra isso, Lord WoOLF ponderou que de fato custos seriam incorridos mais cedo, em comparação com o processo tal como vinha sendo praticado, mas que isso deveria ser apreciado, e não criticado, pois seria exatamente essa característica que iria permitir que se fizessem acordos mais cedo, posto que não é razoável querer incentivar um acordo informado sem que se tenha a obrigação de fornecer documentos e informações, para que se possa avaliar a causa, comercial e financeiramente. Os custos daí advindos são a contrapartida do benefício que se busca. ${ }^{21}$

Monitorar o funcionamento dos Protocolos, sua redação excessiva ou tímida, sua adequação aos casos, etc., seriam todos desafios das entidades envolvidas em cada espécie de litígio e, principalmente, dos juízes, no momento de avaliarem seu cumprimento ou descumprimento e de atribuírem penalidades às partes no último caso.

Além dos diversos Protocolos específicos, que serão mencionados a seguir (item 2.3.2 infra, da Parte I), regulando casos com características próprias, com as CPR entraram em vigor também as chamadas Pre-Action Protocols - Practice Directions, que regulam, de forma genérica, a atuação esperada das partes antes que acionem o Judiciário, disciplinando comportamento pré-ação (o chamado "pre-action behaviour”). Tais PreAction Protocols - Practice Directions foram substituídas em 2008 pela Practice Direction - Pre-Action Conduct.

\subsection{Necessidade que determinou seu aparecimento}

Conforme já explorado, os Protocolos vieram no bojo de um conjunto de mudanças que tiveram por objetivo, dentre outros, criar uma cultura de cooperação entre as partes, incentivando a comunicação e a troca de informações e documentos entre elas desde cedo, estimulando, por exemplo, a contratação conjunta de um perito antes mesmo de iniciada a

\footnotetext{
${ }^{20}$ Item 1.2 da Introdução ao Pre-Action Protocol for Defamation.

${ }^{21}$ ACCESS to Justice: Final Report, cit., Capítulo 10, item 16.
} 
ação, de modo que o acordo informado fosse facilitado e o Judiciário passasse a ser visto como o último recurso dos cidadãos, em vez de ser o primeiro.

Sobre a necessidade dos Protocolos disse Lord WoOLF:

"2. It is a characteristic of our civil justice system that the vast majority of cases are settled without trial, by negotiation between the parties or their legal advisers. There are many more potential claimants who settle their disputes without starting legal proceedings at all. It is my intention to build on this. My approach to civil justice is that disputes should, wherever possible, be resolved without litigation. Where litigation is unavoidable, it should be conducted with a view to encouraging settlement at the earliest appropriate stage."

(...)

4. (...) What is needed is a system which enables the parties to a dispute to embark on meaningful negotiation as soon as the possibility of litigation is identified, and ensures that as early as possible they have the relevant information to define their claims and make realistic offers to settle.

5. In my view, this can only be achieved if the court itself takes more account of pre-litigation activity than has traditionally been the case. Once a protocol has been adopted, the parties' compliance (or failure to comply) with it will be taken into account when the court is dealing with the future conduct of the case. In particular, if one party has unreasonably refused to accept a pre-action offer to settle, that will have consequences in costs once litigation has started."

6. (...) Protocols will also be an important means of promoting economy in the use of expert evidence, in particular by encouraging the parties to use a single expert wherever possible. Unless this happens before the commencement of proceedings, it will frequently be too late because the parties will already have established an entrenched relationship with their own expert." 22 (destaques da transcrição)

Em um ambiente onde imperam a demora na prestação jurisdicional e os altos custos do processo, prescindir da ação ou, se necessária, levá-la a juízo já mais madura, tem méritos.

Haverá quem diga que a implementação desse mecanismo na Inglaterra teve (e se implantado no Brasil teria) por escopo aliviar o Judiciário, o que seria um paliativo, na medida em que o que se deveria buscar seria o aparelhamento apropriado do Judiciário, dando-lhe condições de processar e resolver, com eficiência e correção, as demandas de todos os jurisdicionados.

\footnotetext{
${ }^{22}$ ACCESS to Justice: Final Report, cit., Capítulo 9 - Pre-action Protocols.
} 
Entretanto, o Judiciário, tal como está hoje, por melhor ou pior aparelhado que seja, não deve ser utilizado para resolver disputas que poderiam ser solucionadas de outra forma, ou que poderiam ser solucionadas mais facilmente através do desempenho de uma atividade pré-processual.

\subsection{Criação de Protocolos específicos}

Algumas espécies de casos foram destacadas por Lord WoOLF durante a segunda etapa de sua pesquisa, dentre as quais danos pessoais, negligência médica e profissional, e questões ligadas a locação e posse de imóveis.

Negligência médica (incluindo aí negligência de qualquer profissional da área da saúde), uma sub-espécie da categoria negligência profissional e pertencente também à categoria mais numerosa a ir a julgamento - danos pessoais (personal injury) -, foi destacada pelas seguintes razões: (i) a desproporção entre custos do processo e os danos efetivamente sofridos pelo autor era excessiva, especialmente em causas de pequeno valor; (ii) a demora na resolução do caso era mais preocupante do que em outras espécies de disputas; (iii) casos cujo desfecho poderia ser rapidamente previsto eram debatidos por muito tempo, quando a solução para eles já poderia ter se apresentado logo de início; e (iv) a desconfiança entre as partes e a falta de cooperação era demasiada. Além disso, na maioria dos casos, os custos eram tamanhos que o autor apenas ajuizava a ação se tivesse o apoio do governo, a chamada "legal aid", para custear o processo. Ademais, o prolongamento e os custos da causa são muitas vezes fruto não só da dificuldade intrínseca de estabelecer as questões de mérito que se colocam e de resolvê-las, mas sim do clima de suspeita, de desconfiança, de não-cooperação. Era preciso, portanto, amenizar esse clima.

Afora isso, boa parte das ações envolvendo negligência médica começava porque o autor não conseguia, de outra forma, obter as informações que buscava, fosse do médico, fosse do hospital.

O estabelecimento de Protocolos para ações dessa natureza (assim como é o caso para ações versando sobre outras matérias) visou, portanto, a implementar metas realistas, embora ousadas, no tocante a documentos e informações a serem fornecidos por uma parte à outra, fazer as partes considerarem a possibilidade de contratação de um perito único, bem como dar ao réu a oportunidade, desde logo, de investigar o caso. 
Após o convite que Lord WoOLF fez à sociedade civil - especialmente, a associações que estivessem mais ligadas a determinadas espécies de controvérsias - para que se debruçassem sobre o conteúdo dessas "diretrizes pré-ação", houve de fato um empenho delas para que Protocolos específicos fossem criados, notadamente em áreas que se mostraram de maior preocupação durante a análise que culminou com os Access to Justice Interim e Final Reports.

As associações que participaram ativamente desse processo foram: (i) a Law Society $^{23}$, que auxiliou na criação de um Protocolo para requisição de prontuários médicos e exames; (ii) a Housing Law Practitioners Association e as associações locais representando donos de propriedades para aluguel (landlords); (iii) grupos do setor de construção; e (iv) a Association of Personal Injury Lawyers - APIL e a Association of British Insurers - ABI, dentre outros.

Os Protocolos, frisou Lord Woolf, seriam mais efetivos se fossem acordados, ao menos de forma ampla, por aqueles que tendessem a ser seus usuários mais freqüentes, seja como litigantes seja como representantes destes. No momento da publicação de seu Final Report, Lord WoOLF apontou que muito trabalho já havia sido feito por determinadas entidades, mas se esperava que elas continuassem a conversar entre si com o objetivo de produzir mais Protocolos, suficientes a atender a demanda da sociedade. ${ }^{24}$ Entretanto, disse não esperar fossem criados Protocolos para todos os tipos de litígios, mas sim Protocolos necessários a lidar com problemas específicos em áreas específicas. ${ }^{25}$

Observa-se o seguinte denominador comum entre os Protocolos específicos criados: destinam-se a controvérsias onde se versam sobre, na maioria das vezes, ou pelo menos com maior destaque, questões de fato. Mas não qualquer questão de fato, e sim questões que apresentassem certa homogeneidade nos fatos que seriam debatidos durante a controvérsia. Esse é o caso, pois, de uma batida de carro, de um caso envolvendo negligência médica, da renovação de um contrato de aluguel, dentre outros.

Para questões fáticas muito específicas e complexas, além de pouco homogêneas,

\footnotetext{
${ }^{23}$ A Law Society congrega os solicitors, advogados que estão autorizados a exercer quaisquer poderes inerentes à profissão, exceto representar os clientes perante as cortes de maior hierarquia. Para essa função, devem ser contratados os chamados barristers.

${ }^{24}$ ACCESS to Justice: Final Report, cit., Capítulo 10, item 13.

25،(1) Pre-action protocols should set out codes of sensible practice which parties are expected to follow when faced with the prospect of litigation. They should not cover all areas of litigation, but should deal with specific problems in specific areas, including personal injury, medical negligence and housing." ACCESS to Justice: Final Report, cit., Capítulo 10, Recomendação n. 1.
} 
Protocolos específicos não pareceram uma alternativa produtiva, pois seria praticamente impossível criar um padrão de comportamento, com diretrizes detalhadas para tais questões, na medida em que a intenção de um Protocolo específico é "ensinar" à parte a respeito de qual deve ser a sua conduta antes de ingressar com a ação, que informações deve oferecer e buscar de seu adversário, para que não se perca tempo e dinheiro nesse exercício, para que ele seja o mais eficiente possível.

Ademais, a existência de um padrão de conduta sabido de antemão dá à parte que se encontra ou se encontrará em situação regulada por determinado Protocolo a chance de se aparelhar, de buscar se resguardar e produzir, na medida do possível, o material que poderá ser dela exigido caso uma controvérsia se concretize. Em casos de negligência médica, por exemplo, a entrada em vigor do protocolo específico fez com que os hospitais organizassem melhor as informações de seus pacientes, guardassem melhor seus exames e prontuários, fizessem relatórios mais precisos e, mais do que isso, criassem mecanismos de disponibilização desse material ao paciente mais rapidamente, diante de uma solicitação dessa espécie (e era claro que tal solicitação poderia ocorrer, na medida em que era expressamente determinado no protocolo específico que o paciente poderia pedir e o hospital deveria fornecer esse material). Visto sob esse prisma, a edição do protocolo modificou um padrão de comportamento.

Poder-se-ia objetar que criar toda uma estrutura de atendimento ao Protocolo custa dinheiro. É verdade. Entretanto, mais dinheiro poderia custar não cumprir o Protocolo a contento. Assim, postas na balança as vantagens e desvantagens de se criar tal estrutura, criá-la pareceu economicamente mais vantajoso e, no longo prazo, gerou confiança nos pacientes.

A questão de criação dos Protocolos específicos reside, assim, no reconhecimento da recorrência de determinados tipos de ação, na verificação de que as controvérsias aí verificadas giram em torno de questões de fato que apresentam certa homogeneidade e donde se pode extrair um padrão a respeito das informações e elementos de prova que usualmente são relevantes para resolvê-las. O Protocolo específico vem, pois, da prática, não da teoria. 


\subsection{Funcionamento dos Protocolos}

\subsubsection{Practice Direction - Pre-Action Conduct}

De acordo com os Protocolos, o autor deve dar conhecimento ao réu da ação que poderá ser ajuizada e, uma vez feita a notificação, autor e réu devem iniciar uma troca significativa de informações a respeito do litígio.

Há Protocolos específicos para casos específicos de direito material - que serão detalhados no item 2.3.2 desta Parte I, mas a Practice Direction - Pre-Action Conduct ("Diretriz Prática") ${ }^{26}$, além de servir de guia para os vários tipos de ação, aplica-se a todos eles, ainda que determinada causa encontre abrigo em um Protocolo específico, salvo se este tiver disposição que com ela seja conflitante.

De acordo com mencionada Diretriz Prática, seção 2.1, os Protocolos descrevem a conduta que a corte normalmente esperará das partes antes de iniciada a ação.

Os objetivos dos Protocolos, conforme enunciados pela própria Diretriz Prática são, em tradução livre, os seguintes:

(1) permitir que as partes cheguem a um acordo sem que seja necessário ajuizar a ação; e

(2) auxiliar no manejo eficiente da ação ${ }^{27}$, pelas partes e pela corte, quando esta não puder ser evitada ${ }^{28}$.

Tais objetivos devem ser alcançados através (i) da troca de informações sobre o caso; e (ii) da consideração, pelas partes, do uso de formas alternativas de resolução de controvérsias (Alternative Dispute Resolution - ADR) ${ }^{29}$.

Os Protocolos estabelecem como um processo propriamente dito, que em vez de correr perante o Judiciário, prescinde dele. Dessa forma, poupam-se recursos do Estado na medida em que se diminui o volume de processos a ocuparem juízes e funcionários da

\footnotetext{
${ }^{26}$ Disponível em www.justice.gov.uk/civil/procedurerules_fin/contentes/practice_directions/pd_protocol.htm. ${ }^{27}$ Fala-se em um "manejo mais eficiente do litígio" posto que a observância do protocolo faz com que a causa seja reduzida ao que efetivamente existe de contenda entre as partes, faz com que o caso chegue ao juiz já mais amadurecido, mais depurado.

${ }^{28}$ Practice Direction - Pre-Action Conduct, Seção 1.1 .

${ }^{29}$ Practice Direction - Pre-Action Conduct, Seção 1.2.
} 
Justiça, papel, espaço, etc., podendo tais recursos ser alocados a casos que de fato mereçam a intervenção do Estado. Poupam-se também os recursos das partes, na medida em que, de posse de informações que lhes permitam melhor avaliar suas chances de êxito na Justiça, poderão decidir por nem mesmo ingressar em juízo. E, finalmente, na hipótese de a causa chegar a juízo, as partes já terão razoáveis conhecimentos sobre o que lhes espera, documentos já terão sido produzidos e o processo poderá se desenrolar com mais rapidez.

Lord WoOLF escreveu que a Inglaterra precisava de um sistema que:

"enables the parties to a dispute to embark on meaningful negotiations as soon as the possibility of litigation is identified, and ensures that as early as possible they have the relevant information to define their claims and to make realistic offers to settle. ${ }^{, 30}$ (detaques da transcrição)

Mesmo antes de 1999, quando as CPR entraram em vigor, pode-se dizer que era comum autores enviarem uma carta ao seu futuro adversário antes de iniciarem a ação. $\mathrm{O}$ propósito do Protocolo é levar esse comportamento um passo além e, em particular, requerer respostas formais. ${ }^{31}$ Além disso, as CPR determinam que a corte leve em consideração o comportamento das partes antes de iniciada a ação no momento de ordenar a quem cabem os custos ${ }^{32}$ do processo, conforme detalhado adiante. ${ }^{33}$

${ }^{30}$ ACCESS to Justice: Final Report, cit., p. 107.

31،'Of course, prior to 1999, it was common for the claimants to write letters before action, the purpose of a Protocol is to take that a stage further and in particular to require a formal response.", conforme Martin Thomas (Herberth Smith LLP), em Mondaq Business Briefing de 7 de agosto de 2002. HARRISON, Richard; WILLIAMSON, Ashleigh. Sanctioning non-compliance? Mondaq Business Briefing, Ago/2003. Disponível em:<http://www.accessmylibrary.com/coms2/summary_0286-24078460_ITM>.

${ }^{32}$ Quando na Inglaterra fala-se de "costs" que traduziremos por custos, estão aí abrangidos tanto o que chamaríamos no Brasil de custas do processo, quanto os honorários advocatícios efetivamente gastos por uma parte com seu patrono. Exatamente por essa conta estar em jogo (e por a regra em vigor no direito inglês ser aquela segundo a qual o venido paga os custos do vencedor) é que ao tópico "costs" é devotada tanta atenção na Inglaterra.

${ }^{33}$ Quando da entrada em vigor da Practice Direction - Pre-Action Conduct, em substituição à Practice Direction Pre-Action Protocols, as CPR também sofreram alteração. Em sua seção 3, que trata dos poderes dos juízes, substituiu-se "may" por "will" e acrescentou-se menção expressa à "Pre-Action Conduct" ao prescrever-se que "3.1(4) Where the court gives directions it will take into account whether or not any party has complied with the Practice Direction (Pre-Action Conduct) and any relevant Pre-Action Protocol." Da mesma forma, acrescentou-se a expressão "Practice Direction - Pre-Action Conduct" à Seção 44.3(5), onde se diz que, ao determinar os custos do processo e sobre quem recairão, a corte deve levar em consideração a conduta das partes, o que inclui a conduta antes e durante a ação e, em particular, em que medida as partes cumpriram a Practice Direction - Pre-Action Conduct ou o protocolo específico. Essas alterações são, sem dúvida, forte sinal de que se realmente pretende que as partes observem, antes da ação, a conduta que lhes é proposta e, em não a obedecendo, a corte deve sancioná-las. 
Os Protocolos não são obrigatórios como etapa prévia ao inicio da ação, mas existe uma expectativa de que sejam cumpridos ${ }^{34}$. Ademais, os juízes têm poderes bastantes para impor conseqüências adversas ao não cumprimento dos Protocolos, especialmente em termos de custos (ao que as partes em geral são bastante sensíveis) ${ }^{35}$.

Os Protocolos específicos determinam quais documentos devem ser revelados, os quais são, em regra, apenas aqueles que embasam as alegações da parte, diferentemente do que ocorre no curso da ação judicial, quando a Parte 31 das CPR incide e as partes são obrigadas a oferecer o chamado "standard disclosure". Segundo este, as partes devem dar notícia e posteriormente disponibilizar ao adversário tanto os documentos que fundamentam suas alegações como aqueles que auxiliam o adversário e que prejudicam suas próprias alegações. Esse é um ponto bastante sensível do direito inglês que tende a causar espanto em profissionais que militam em jurisdições que seguem a tradição de civil $l a w^{36}$.

Um dos elementos essenciais dos Protocolos é a troca substancial de informações entre as partes. Se a troca de documentos e informações não for completa e a ação vier de fato a ser proposta, há boas chances de que tal falha seja apontada quando iniciado o processo de disclosure que se desenrola em cada ação judicial e que tem regramento próprio nas CPR. Se assim for, o juiz terá poderes para apenar a parte que não cumpriu devidamente o Protocolo. Há, de fato, Protocolos que exigem trocas mais substanciais do que outras, mas de qualquer forma, o disclosure permeia os Protocolos.

\subsubsection{Cumprimento e avaliação do cumprimento dos Protocolos}

Com o objetivo de permitir ao magistrado posicionar-se frente ao cumprimento ou descumprimento dos Protocolos, existem diversos dispositivos nas CPR que fazem

\footnotetext{
${ }^{34}$ Practice Direction - Pre-Action Conduct - "4.2: The court will expect the parties to have complied with this Practice Direction or any relevant pre-action protocol. The court may ask the parties to explain what steps were taken to comply prior to the start of the claim. Where there has been a failure of compliance by a party the court may ask that party to provide an explanation."

${ }^{35}$ Vide nota 33 supra.

36، The continental european lawyer does not understand how an obligation to give general discovery can be made effective, or enforced (which is much the same thing). Indeed he may ask why his client should provide the opponent with material which is against his interes ${ }^{36}$. On the other hand, the Anglo-Saxon lawyer does not understand how it is possible to arrive at the truth without such an obligation. This position represents a curious kind of role reversal, in which the idealist civil lawyer worries about the pragmatic, and the pragmatic common lawyer worries about the ideal." in MATTHEWS, Paul; MALEK, Hodge M. Disclosure. 2. ed. London: Sweet \& Maxwell, 2001. p. 15.
} 
referência a eles: (i) em qualquer direcionamento que der no processo, o juiz levará em consideração o fato de a parte ter ou não cumprido o Protocolo pertinente (CPR 3.1(4)); (ii) o juiz poderá ordenar que a parte pague ao juízo uma soma em dinheiro se tal parte furtou-se a cumprir o Protocolo que deveria seguir, sem justificativa razoável (CPR 3.1(5)); (iii) o juiz também levará em consideração o cumprimento do Protocolo ao decidir se a parte deve ou não ser liberada de eventual sanção que lhe seja aplicada ao longo do processo, por conta de não ter obedecido as regras que lhe eram aplicáveis, aí incluídos os Protocolos e as practice directions, ou ordens judiciais que lhe eram dirigidas (CPR $3.9(\mathrm{e}))$.

Ao avaliar o cumprimento, o juiz levará em consideração (i) o fato de as partes terem seguido o Protocolo "em substância", atentando menos a deslizes técnicos ou de menor importância; (ii) considerará a proporcionalidade entre os passos seguidos e o tamanho e importância da causa (Diretriz Prática, item 4.3).

No seu item 4.4, prescreve a Diretriz Prática que "The court may decide that there has been a failure of compliance by a party because, for example (...)" (destaques da transcrição).

De acordo com a Diretriz Prática, a corte pode entender que uma parte não cumpriu o protocolo se "não forneceu à outra informações suficientes para que esta compreendesse a causa", "se não agiu dentro do prazo estabelecido e, na ausência de prazo, dentro de um que fosse razoável", "se de forma não razoável recusou-se a considerar meios alternativos de solução de controvérsias", "sem boas razões, não revelou ou exibiu documentos cuja revelação ou exibição foi requisitada”.

Estabelece o item 4.5 que "a corte observará o efeito do descumprimento sobre a parte contrária ao decidir sobre a imposição de sanções."

No caso de o juiz entender que houve descumprimento, as sanções que poderá impor incluirão: (i) a suspensão do processo para que se cumpram etapas que não foram cumpridas; (ii) ordenar que a parte que não o cumpriu pague parte ou a totalidade dos custos do adversário; (iii) ordenar que a parte que não o cumpriu pague os custos de acordo com o princípio da indenização (indemnity basis - mais severo); (iv) se a parte que não o cumpriu for o autor, em favor de quem a sentença tenha sido favorável, ordenar que não receba juros sobre o total ou parte da soma que deverá receber ou que os juros sejam fixados em taxa inferior à que seria fixada se este não fosse o caso; (v) se a parte que não o 
cumpriu for o réu e tenha sido prolatada decisão em favor do autor, ordenar que pague juros sobre o montante a ser recebido pelo autor, a uma taxa superior a que normalmente seria estabelecida, não excedendo $10 \%$ acima dessa taxa. Eis aí um poderoso incentivo para que os Protocolos sejam de fato cumpridos. Daí também vislumbra-se a magnitude da discricionariedade judicial a que as partes estão sujeitas, o que deve ser analisado com cautela.

\subsubsection{Procedimento padrão}

No caso de não haver um protocolo específico incidindo sobre a causa, as partes devem atentar ao procedimento enunciado no item 7 da Diretriz Prática, segundo a qual o autor deve identificar os detalhes do litígio em potencial, por escrito, e enviá-los ao réu através de uma carta pré-ação (“letter before claim”). O réu, por sua vez, deverá respondêla em tempo razoável, por escrito, dando conta de todos os aspectos enumerados pelo autor em sua carta; se apropriado, deverá enviar, antes, uma carta acusando o recebimento da carta pré-ação (item 7.1).

O "tempo razoável” variará de acordo com o assunto. Como regra geral, tem-se que: (i) o réu deve acusar recebimento dentro de 14 dias contados do recebimento da carta pré-ação, a menos que uma resposta completa tenha sido enviada neste período; (ii) se a questão é bastante direta, por exemplo, uma dívida incontroversa, uma resposta completa deverá ser enviada, em 14 dias; (iii) se a questão requer o envolvimento de uma seguradora ou de outro terceiro, ou onde há questões sobre produção de prova, uma resposta completa deverá, em regra geral, ser oferecida em 30 dias; (iv) se o caso for particularmente complexo, requerendo a participação de especialistas, um período maior do que 30 dias poderá ser apropriado; (v) um período de mais de 90 dias para oferecer resposta completa apenas será considerado razoável em casos excepcionais.

O Anexo A à Diretriz Prática apresenta uma descrição detalhada do procedimento na maioria dos casos a que não seja aplicável um protocolo específico. A Anexo B estabelece as informações específicas que deverão ser providenciadas em casos de cobrança de dívida em que o autor é pessoa jurídica e o réu pessoa física (itens 7.3 e 7.4).

Algumas regras gerais também aplicáveis são as seguintes: os documentos apresentados durante o cumprimento dos protocolos não devem ser usados para qualquer 
propósito além da resolução da disputa; embora ADR não seja compulsório, as partes devem sempre considerar tais meios; as partes devem informar de que forma estão financiando seu caso; quando prova pericial for necessária, as partes devem considerar como minimizar seu custo; se o prazo prescricional impuser que a parte inicie a ação sem antes ter cumprido o protocolo, deve ela requerer à corte que suspenda o processo para que os passos indicados pelo protocolo sejam seguidos; no caso de a ação ser ajuizada, o autor deve dizer, no formulário com o qual dá início à ação, se a Diretriz Prática (ou o Protocolo específico, no caso de ser aplicável) foi cumprida.

O Anexo A mencionado acima mencionado destina-se especialmente a casos mais simples.

O autor deve enviar sua carta apresentando detalhes, embora de forma concisa, sobre a questão, de forma a que o réu possa entendê-la e investigá-la sem necessidade de requisitar maiores informações. A carta deve incluir: (i) o nome completo e endereço do autor; (ii) o fundamento da causa (causa de pedir); (iii) um sumário dos fatos sobre os quais se funda a causa; (iv) o pedido do autor; (v) se perda patrimonial é reclamada, como se chegou a soma requerida; e (vi) detalhes de arranjos que tenham sido feitos para financiar a causa. ${ }^{37}$

A carta deve, ainda, (i) listar os documentos sobre os quais o autor pretende fundar suas alegações; (ii) informar qual o ADR que mais lhe parece adequado à questão, se algum lhe parecer, convidando o réu a concordar com tal escolha; (iii) estabelecer a data limite que considera razoável para que o réu ofereça sua resposta completa; (iv) identificar e solicitar cópias de documentos que não estejam em seu poder e aos quais deseje ter acesso. ${ }^{38}$ A menos que o autor tenha certeza de que o réu é representado por um advogado, a carta deve remeter o réu à Diretriz Prática, especialmente à parte que trata das conseqüências do descumprimento e informar ao réu que ignorar a carta poderá ter como resultado a propositura imediata da ação e a responsabilização do réu por custos vir a ser majorada. $^{39}$

Quando o réu for incapaz de fornecer uma resposta escrita completa dentro de 14 dias do recebimento da carta, deve, neste mesmo prazo, enviar ao autor uma carta em que acusa seu recebimento. Ao acusar o recebimento, o réu deve indicar se uma seguradora

\footnotetext{
${ }^{37}$ Diretriz Prática, Anexo A, item 2.1.

${ }^{38}$ Diretriz Prática, Anexo A, item 2.2.

${ }^{39}$ Diretriz Prática, Anexo A, item 2.3.
} 
estará envolvida; a data em que providenciará uma resposta completa; e poderá solicitar mais informações, que possam então permitir-lhe elaborar tal resposta. Se a data sugerida pelo réu é posterior àquela indicada pelo autor em sua carta, o réu deverá justificá-la. Se o réu ou sua seguradora não oferecerem uma resposta completa dentro de 14 dias e a ação for, então, ajuizada pelo autor, é provável que a corte considere que o autor cumpriu o protocolo ("the court is likely to consider that the claimant has complied" - destaques da transcrição ${ }^{40}$ ). Na hipótese de o período de 14 dias não ser suficiente para uma resposta completa porque o réu entende conveniente buscar o conselho de um especialista, deve informar esse fato ao autor ao acusar o recebimento da carta pré-ação, informando também quem buscará tal conselho e quando espera tê-lo, estando então em condições de fornecer a resposta. É razoável que o autor aguarde 14 dias para que o réu busque o conselho desejado. $^{41}$

A resposta do réu deve aceitar ou rejeitar o pedido do autor, no todo ou em parte. Em caso de rejeição, o réu deve: (i) dar suas razões para tanto, identificando quais fatos e quais partes da demanda aceita ou não, e embasando seus argumentos; (ii) dizer se pretende ingressar com uma ação contra o autor a respeito da mesma questão; (iii) indicar se entende que o autor teve culpa no problema que levou à controvérsia e, se caso o faça, informar os fatos em que se fundam suas alegações; (iv) dizer se concorda ou não com o ADR sugerido pelo autor e, em caso de discordância, oferecer suas razões e sugerir outro, ou dizer que entende não haver ADR apropriado ao caso; (v) listar os documentos essenciais em que pretende fundamentar suas alegações; (vi) anexar cópias dos documentos solicitados pelo autor ou informar porque tais cópias não serão disponibilizadas; e (vii) identificar e requerer cópias de documentos relevantes que não estejam em seu poder e aos quais deseja ter acesso. ${ }^{42}$

Se nem réu nem seguradora, quando for o caso, apresentarem resposta completa dentro do prazo estabelecido pelo autor (ou do prazo que tenha sido informado ao autor pelo réu por ocasião da carta em que acusou recebimento da carta pré-ação) e o autor ajuizar a ação, é provável que a corte considere que o autor cumpriu o protocolo.

\footnotetext{
${ }^{40} \mathrm{O}$ trecho destacado convida mais uma vez a se pensar sobre a discricionariedade que o juiz tem ao apreciar o cumprimento dos Protocolos.

${ }^{41}$ Diretriz Prática, Anexo A, itens 3.1 a 3.6.

${ }^{42}$ Diretriz Prática, Anexo A, itens 4.1 e 4.2.
} 
Entretanto, se o autor entender por ajuizar a ação antes de expirado o prazo solicitado pelo réu, o juiz considerará se o prazo solicitado fora ou não razoável. ${ }^{43}$

O autor deverá, por seu turno, fornecer os documentos solicitados pelo réu ou informar porque não poderá disponibilizá-los. Se o réu houver reconvindo, o mesmo processo acima descrito se desenrolará, dessa vez com os pólos invertidos.

\subsubsection{Contratação de um perito}

Nos casos em que seja necessária a contratação de um perito, o Anexo C à Diretriz Prática estabelece que as partes devem considerar a melhor forma de minimizar os custos dessa contratação. Devem, assim, considerar a possibilidade de contratarem um perito conjunto ("a single joint expert"), que será pago por ambas as partes, ou um perito acordado (“an agreed expert"), o qual será acordado por ambas, mas pago por apenas uma delas.

Se a primeira alternativa não se consumar, a parte que deseja obter o laudo pericial deve fornecer à outra uma lista dos peritos no determinado ramo de expertise e, dentro de 14 dias do recebimento dessa lista de peritos, a segunda parte poderá fazer suas objeções à referida lista. Se restarem um ou mais peritos sem objeção, a primeira parte deverá contratar um deles. Se todos sofrerem objeções, a primeira parte poderá contratar um perito de sua livre escolha. A atitude das partes em contratar ou rejeitar nomes de peritos será levada em consideração pelo juiz se a ação for levada ao Judiciário. ${ }^{44}$

\subsubsection{Protocolos Específicos}

Existem dez Protocolos específicos já em vigor na Inglaterra. São eles: (i) Personal Injury; (ii) Clinical Negligence; (iii) Construction and Engineering Disputes; (iv) Defamation; (v) Professional Negligence; (vi) Judicial Review; (vii) Desease and Iness; (viii) Housing Disrepair; (ix) Possession Claims based on Rent Arrears; (x) Possesion

\footnotetext{
${ }^{43}$ Diretriz Prática, Anexo A, itens 4.3 e 4.4.

${ }^{44}$ Diretriz Prática, Anexo C, itens 3 a 6. Vê-se, pois, que o Judiciário tem amplos poderes para avaliar a conduta das partes e atribuir-lhes penalidades no caso de entender que foram inadequadas.
} 
Claims based on Mortgage or Home Purchase Plan Arrears in respect of Residential Property. Não se tratará de todos eles, pois isso tomaria o tempo do leitor desnecessariamente. ${ }^{45}$

\subsubsection{Personal Injury}

O Protocolo Pré-Ação para Demandas Relativas a Danos Pessoais ("Pre-Action Protocol for Personal Injury Claims" ou "PAPPI") veio a lume em 26 de abril de 1999, sendo um dos primeiros e talvez um dos mais detalhados de todos os atualmente em vigor.

$\mathrm{O}$ protocolo se inicia pelas chamadas Notes of Guidance ("Notas de Direcionamento"), que indicam a que casos ele se destina: acidentes em rodovias, escorregamentos e acidentes no trabalho que tenha danos pessoais como um de seus elementos, com valor que o conduza ao fast track ${ }^{46}$. A corte, por sua vez, espera que as partes cumpram o protocolo tanto quanto possível, como por exemplo no que se refere ao envio da letter of claim $^{47}$, ao intercâmbio de informações e aos peritos (PAPPI 2.4).

As Notas de Direcionamento trazem diversas disposições. Uma delas refere-se ao caso de o réu ter contratado seguro e, assim, ter pouco incentivo para cumprir o protocolo, posto que o desfecho da ação lhe é indiferente. Nesses casos, o protocolo prescreve que desde logo a letter of claim deve ser repassada ao segurador e que, se o segurado falhar nessa tarefa, em certos casos a cobertura do seguro pode vir a ser afetada.

Outra refere-se ao fato de que nem a letter of claim nem a resposta do réu tem status de statements of case do autor e do réu - peça hábil para que autor e réu exponham suas razões em juízo. Assim, se o statement of case do autor não confere com a letter of claim, não pode o réu valer-se disso para desacreditar o autor, posto que eventos ocorridos

\footnotetext{
${ }^{45} \mathrm{O}$ primeiro dos Protocolos aqui mencionados (Personal Injury) é inserido como 'Anexo' ao final do presente trabalho, para referência do leitor.

${ }^{46}$ As causas que vem a juízo, na Inglaterra, são alocadas a uma de três vias (tracks): small claims track, fast track e multi-track, partindo de um procedimento bastante simplificado para as ações alocadas ao small claims track, com disclosure limitado e chegando a um procedimento bastante completo e extenso nas ações alocadas ao multi-track. As regras de alocações são bastante intrincadas e detalhadas, de modo que descrevê-las não é pertinente ao escopo deste trabalho. Entretanto, de forma bastante superficial e genérica, pode-se dizer que ações de valor inferior a $£ 5.000,00$ são alocadas ao small claims track, ações de valor entre $£ 5.000,00$ e $£ 15.000,00$ são alocadas ao fast track e ações de valor superior a $£ 15.000,00$ são alocadas ao multi-track.

${ }^{47}$ Letter of claim era a nomenclatura conferida pela Practice Direction Pre-Action Protocol à atual letter before claim, expressão usada pela Diretriz Prática atualmente em vigor.
} 
entre o envio da letter of claim e o ajuizamento da ação podem tê-lo levado a fazer mudanças no seu pedido. Contudo, se não há eventos que justifiquem tal mudança, tem a corte liberdade para apená-lo (PAPPI 2.13).

O Protocolo inicia-se por estabelecer como deve ser a letter of claim. Prescreve que ela deve ser enviada ao réu em duas cópias: uma para o réu e a segunda para ser encaminhada por este ao seu segurador, caso possua $\mathrm{um}^{48}$. A letter of claim deve conter: (a) clara narração dos fatos em que se baseia o pedido; (b) natureza dos danos sofridos; e (c) quaisquer perdas patrimoniais incorridas. Ainda, em casos de acidente de veículo, devese especificar o hospital em que o autor foi socorrido. O protocolo também prevê que o autor dê notícia ao réu de qualquer "conditional fee agreement - CFA" em vigor" ${ }^{49}$ (PAPPI 3.1).

Os autores e seus advogados, no caso de terem sido contratados - o que, frise-se, não é obrigatório sequer na ação - são incentivados a usar o formulário padrão que faz parte do Protocolo como Anexo A, permitindo-se, obviamente, adaptações ao caso concreto.

Informações suficientes devem ser prestadas ao réu para que este possa avaliar, ainda que de forma genérica, os riscos presentes, evitando o mal que o decurso do tempo representa.

O réu tem 21 dias para responder à letter of claim, prazo que se inicia a partir da data de postagem da carta que identificou o segurador ${ }^{50}$. Transcorridos os 21 dias sem resposta do réu ou da sua seguradora, o autor é autorizado a iniciar a ação (PAPPI 3.6).

O réu, ou a seguradora, desde que tenha acusado recebimento da letter of claim, terá um prazo máximo de 3 meses, contados da data de ciência da potencial ação, para se inteirar sobre o caso, buscando conhecer em pormenores os fatos e as circunstâncias que os motivaram, enfim, para investigar a questão. Até o fim deste prazo, o réu, ou a seguradora, deverá responder à letter of claim indicando se nega sua responsabilidade pelo evento noticiado na carta e, se o fizer, deve dar suas razões, incluindo uma versão alternativa dos fatos narrados pelo autor. Se, no curso da investigação acima referida, o autor se der conta

\footnotetext{
${ }^{48} \mathrm{Se}$ o segurador for conhecido pelo potencial autor, a carta deve ser encaminhada diretamente a ele (PAPPI 3.4).

${ }^{49} \mathrm{O}$ CFA é o acordo entre parte e seu advogado por meio do qual este apenas faz jus a um prêmio, caso a parte seja vencedora na ação. Mais uma vez, vê-se aqui a importância dos costs no processo civil inglês, mas a eles não nos deteremos posto que não fazem parte do escopo deste trabalho.

${ }^{50}$ Não há previsão de prazo para o envio da identificação do segurador.
} 
de que o valor da causa supera o valor das causas que devem seguir o fast track, deve imediatamente noticiar o fato ao réu.

Se o réu negar sua responsabilidade, “deve anexar à letter of reply documentos em seu poder que sejam relevantes para a questão que se coloca entre as partes, e cuja revelação normalmente seria ordenada pela corte, seja no chamado "pre-action disclosure" ou no "disclosure during proceedings". Uma lista de documentos que podem ser considerados relevantes para casos de danos pessoais está indicada no Anexo B ao PAPPI.

Antes que qualquer das partes contrate um perito, a parte que entende necessária a perícia deve oferecer ao seu adversário uma lista com o nome de um ou mais profissionais cuja especialidade considere adequada ao caso (PAPPI 3.15). A parte contrária tem 14 dias para impugnar um ou todos os nomes propostos. Se pelo menos um nome for mutuamente aceitável $^{51}$, o autor deverá contratar e formular quesitos ao perito (o que se denomina “instruct the expert”) (o Anexo C ao PAPPI contém uma instruction letter que pode ser usada como modelo). Se todos os nomes propostos pelo autor forem rejeitados pelo réu, cada um poderá então contratar um perito de sua escolha ${ }^{52}$. Caberá à corte, caso a ação seja ajuizada, decidir se o comportamento das partes de não indicar um perito mutuamente aceitável foi uma iniciativa não razoável (PAPPI 3.18).

Caso um perito já tenha sido contratado pelo autor e o réu a ele não se oponha, não poderá fazer uso de evidências de seu próprio perito, a menos que (a) o autor concorde, (b) a corte o permita, ou (c) o relatório do perito contratado pelo autor tenha sido alterado e o autor não disponibilize o relatório original.

Na hipótese de ter sido acordado um perito entre as partes, estas podem submeterlhe questões escritas sobre o seu laudo (PAPPI 3.20). Os custos do perito mutuamente acordado serão em regra arcados pelo autor, mas os custos de responder a questionamentos subseqüentes serão normalmente arcados pela parte que formular tais questionamentos.

As partes devem considerar, o quanto antes, se os danos sofridos pelo autor podem ser remediados por reabilitação e, para tanto, podem valer-se do Rehabilitation Code, Anexo D ao PAPPI.

O Código de Reabilitação é endossado pela maioria das associações de seguradoras e dos advogados militantes na área de danos pessoais, mas não é compulsório e, de modo

\footnotetext{
${ }^{51} \mathrm{O}$ perito mutuamente aceitável não se confunde com um perito conjunto ("joint expert”).

${ }^{52}$ As Notas de Direcionamento prevêem que, no caso de a ação vir a ser ajuizada, um laudo médico deve ser anexado à ação (PAPPI 2.14).
} 
algum é a única forma de as partes endereçarem a questão da reabilitação. O Código é fruto da percepção de que quanto mais cedo o tratamento adequado for oferecido ao autor - portanto, mesmo antes de a ação ser composta entre as partes -, maiores serão as chances de que sua recuperação seja mais rápida e eficaz. Assim, as seguradoras, diz o Código, entendem que muitos benefícios podem ser alcançados se desde logo forem disponibilizados fundos para o tratamento do autor. Dessa forma, seguradora e réu são encorajados a cuidadosamente considerar os benefícios de uma avaliação precoce das necessidades do autor, bem como o meio pelo qual tais necessidades poderiam ser mais convenientemente atendidas.

É claro que a seguradora apenas terá chances de avaliar tais necessidades se a ela forem fornecidos elementos suficientes. A menos que os danos já tenham sido constatados por meio de um laudo médico já providenciado pelas partes, tal avaliação deverá ser feita por um médico ou clínica independente tanto do autor quanto do réu. Este laudo não poderá ser usado numa ação subseqüente ${ }^{53}$ e é objeto de sigilo profissional (item 6.2 do Código de Reabilitação).

Uma lista padrão de documentos a serem exibidos ao longo do cumprimento do protocolo ("Standard Diclosure List") é trazida pelo Anexo B do PAPPI, separada por espécie de ação de danos pessoais.

No caso de Road Traffic Accidents (RTA), por exemplo, documentos que comprovem a manutenção do veículo (caso seja alegado defeito nele); na hipótese de ser alegado defeito na rodovia, documentos que comprovem que seu administrador cumpriu determinações de segurança prescritas pela lei e fez os testes que dele seriam razoavelmente exigidos para se certificar de que as condições da rodovia eram perfeitas para uso, relatórios de inspeção de suas condições de uso, relatório de queixas a respeito do estado da rodovia, registros de outros acidentes ocorridos no trecho onde teve lugar o acidente em discussão.

Para pedidos que envolvam acidentes em local de trabalho, cópia do livro de registro de acidentes, do relatório de primeiros socorros, do relatório do supervisor do acidente, outros relatórios de acidentes anteriores que demonstrem negligência, relatório de cumprimento, pelo réu, de disposições relativas à segurança no trabalho, treinamento dos empregados quanto a esta.

\footnotetext{
${ }^{53}$ Discorda-se dessa previsão. Com efeito, uma das propostas deste trabalho diz respeito à aproveitabilidade, na ação judicial, das provas produzida no curso do protocolo.
} 
A lista padrão de disclosure é extensa e bastante específica caso leis e regulamentos próprios apliquem-se ao caso, na hipótese de, por exemplo, a atividade desenvolvida demandar uso de vestimenta e aplicação de treinamento específicos, for intrinsecamente danosa à saúde, etc. Na maioria das vezes, os documentos solicitados referir-se-ão ao cumprimento do regulamento específico.

Percebe-se que, no caso do PAPPI, muito do que tem que ser revelado pelo réu pode lhe ser prejudicial e, assim, ajudar a embasar as alegações do autor. Este é um traço característico do processo de disclosure inglês, que normalmente tem lugar quando a ação é ajuizada ${ }^{54}$.

\subsubsection{Clinical Disputes}

O Protocolo Pré-Ação para a Resolução de Disputas Clínicas ("Pre-Action Protocol for the Resolution of Cinical Disputes" ou "PAPCD") foi fruto do trabalho do chamado Clinial Disputes Forum, um fórum de debate formado em 1997, resultante do Access to Justice Report elaborado por Lord WoOLF, que empreendeu diversas consultas junto aos mais importantes participantes do "sistema médico-legal", dentre eles executivos do National Health System (NHS), o Departamento de Saúde do Reino Unido e a Law Society (associação que congrega os solicitors $^{55}$ ). O objetivo maior deste Protocolo é encontrar formas menos adversariais e mais eficientes em termos de custos para resolver controvérsias que digam respeito a serviços de saúde e tratamento médico.

Em nota introdutória ao Protocolo, fez-se um alerta e um apelo: o aumento progressivo de litígios envolvendo hospitais, médicos (inclusive os chamados "General Practitioners," ou "GPs"), dentistas e outros profissionais da saúde e o clima de desconfiança crescente pode seriamente prejudicar o relacionamento de tais profissionais com os pacientes, desnecessariamente prolongar controvérsias e desviar para os custos com o processo aqueles recursos que poderiam ser alocados ao tratamento de pacientes. Para que esse cenário mude, contudo, é preciso que os profissionais da saúde aceitem que pacientes têm direito a explicações e a reparações em caso de negligência, de modo que

\footnotetext{
${ }^{54}$ Vide nota 36 supra.

${ }^{55}$ Solicitors são os advogados que trablaham sozinhos ou reunem-se em escritórios de advocacia (law firms), desempenhando toda a sorte de trabalhos jurídicos exceto a representação do cliente junto às cortes de mais alta hierarquia. A associação que os congrega denomina-se Law Society.
} 
uma abordagem excessivamente defensiva por parte dos profissionais da saúde não é favorável à rápida e eficiente resolução de controvérsias, com pacificação.

O Protocolo visa, especialmente, a (i) oferecer previsibilidade sobre o tempo necessário a que se percorra o procedimento estabelecido; e (ii) padronizar as informações relevantes, incluindo documentos, registros e prontuários, que deverão ser reveladas à parte contrária. Na medida em que a possibilidade e prontidão na resposta a ser oferecida pelo profissional da saúde ou pela instituição que tratou do paciente variam de acordo com inúmeros fatores, o protocolo tende a ser suficientemente amplo e flexível para aplicar-se a toda a gama de serviços de saúde, públicos ou privados.

O Protocolo é dividido em princípios gerais e em passos propriamente ditos, os quais referem-se à seqüência de atos que se recomenda seja seguida.

Dentre os princípios gerais estão: fazer com que os profissionais da saúde invistam em pessoal treinado para auxiliar pacientes que experimentaram um comportamento negligente ou um resultado adverso no tratamento; desenvolver um modelo de governança que possibilite a manutenção correta de registros e prontuários dos pacientes; permitir que resultados adversos sejam prontamente investigados e que os pacientes sejam plenamente informados de suas opções, dentre outros. Pacientes, por outro lado, devem reportar suas insatisfações o quanto antes (até para que a colheita de documentos e o contato pessoal com membros da equipe que os atendeu seja mais eficiente e certo) e devem, sempre, considerar métodos alternativos de solução de controvérsias.

Antes de enviar a letter of claim, o paciente normalmente precisará ter tido acesso aos documentos que lhe dizem respeito e ao seu tratamento. Para solicitar esse documentos, o paciente deve ser tão preciso e específico quanto possível no que se refere ao momento em que se deu seu atendimento, quem o tratou, etc. O réu deverá fornecer tais registros em até 40 dias da data de recebimento de seu pedido e por isso poderá cobrar uma taxa de $£ 10,00$, de acordo com a Lei de Acesso a Registros de Saúde de 1990 (Access to Health Records Act 1990), além de despesas com fotocópias e postagem. O autor deverá informar desde logo se deseja receber uma estimativa dos custos de fotocópia de tais registros antes de que lhe sejam enviados. Se o réu não puder cumprir o prazo estipulado deverá informar o autor a respeito do atraso e, além disso, quais as providências que estão sendo tomadas para saná-lo. 
Na hipótese de o autor não receber os registros solicitados em 40 dias, poderá ele solicitar à corte que o réu os apresente ("order for pre-action disclosure") e, obviamente, a corte poderá, como é de praxe em se tratando de protocolos, aplicar sanções em termos de alocação de custos do processo quando o caso for julgado, se levado a juízo.

Ao receber os registros solicitados, o autor poderá melhor avaliar seu caso. Em chegando à conclusão de que existem fundamentos para uma demanda contra o réu, deverá enviar-lhe a letter of claim, contendo (i) um claro resumo dos fatos em que se baseia a causa, incluindo o resultado adverso que alega ter ocorrido; (ii) descrição da negligência que atribui ao réu; (iii) descrição dos danos causados, condição presente e prognóstico; (iv) os danos patrimoniais e uma estimativa do que pretende demandar do réu, com a descrição de como chegou a tal valor; (v) a cronologia dos fatos, para casos mais complexos; e (vi) referência a documentos que estejam em poder do hospital/médico.

A ação não deverá ser ajuizada em menos de 3 meses contados da data da letter of claim, a menos que isso seja necessário para evitar a prescrição da ação ${ }^{56}$.

Dentro de 14 dias a contar do recebimento da letter of claim, o réu deverá acusar seu recebimento, indicando quem será o responsável por lidar com a questão. A carta resposta deverá ser enviada em até 3 meses da data da letter of claim. Nela, o réu poderá aceitar ou recusar as alegações do autor. Neste caso, o réu deverá fornecer sua versão dos fatos e os documentos que a embasam.

É freqüente que em casos versando sobre controvérsias médicas seja necessária a participação de um perito. Entretanto, o Protocolo não oferece diretrizes sobre como a nomeação dos peritos deve se dar, em que momento as partes devem trocar seus laudos, etc. O Protocolo frisa, contudo, que a intenção das Civil Procedure Rules é implementar uma cultura menos adversarial e, assim, a nomeação conjunta de peritos deve ser considerada pelas partes.

\subsubsection{Construction and Engineering Disputes}

O Protocolo Pré-Ação para Demandas Relativas a Construção e Engenharia ("PreAction Protocol for Construction and Engineering Disputes" ou "PAPCE") entrou em

\footnotetext{
${ }^{56} \mathrm{~A}$ suspensão ou não da ação neste caso nao é disciplinada pelo Protocolo.
} 
vigor em 2 de outubro de 2000. Como nota introdutória, aplica-se ele a demandas que tratem de negligência profissional praticada por arquitetos, engenheiros e "quantity surveyors" ${ }^{\circ 7}$.

O PAPCE não é aplicável a casos em que (i) se deseje incluir tutela de urgência; (ii) a ação a ser proposta objetive o "summary judgement" respeito aos mesmos temas recentemente julgados sob a égide do $1996 \mathrm{Act}^{59}$.

Notas sobre cumprimento e proporcionalidade feitas por este protocolo repetem as orientações gerais da Diretriz Prática: a corte observará o cumprimento do protocolo na sua substância. Diz, ainda, que observará o efeito do não cumprimento sobre a parte inocente ${ }^{60}$. Pequenos desvios, como atrasos em providenciar informações, por exemplo, não serão entendidos como descumprimentos. Ademais, a corte espera que os atos de cumprimento do Protocolo sejam proporcionais à demanda. Assim, o Protocolo não deve ser usado como uma estratégia para gerar custos e trabalho desnecessário à parte contrária. Por fim, o protocolo não impõe às partes que revelem uma à outra todos os detalhes e provas que embasam as alegações feitas, como seria necessário na hipótese de a ação ser de fato ajuizada. $^{61}$

O objetivo geral do protocolo é permitir que (i) autor e réu tenham fornecido um ao outro informações suficientes para que saibam a natureza do caso de cada qual; (ii) cada parte tenha tido a oportunidade de considerar a versão do outro, podendo aceitá-la ou rejeitá-la, total ou parcialmente, o mais cedo possível; (iii) haja mais contato entre as partes antes do ajuizamento da ação; (iv) haja maior troca de informações entre as partes; (v) as partes possam investigar as questões colocadas antes de ajuizar a ação ("better pre-action investigation”); (vi) as partes tenham formalmente se encontrado pelo menos uma vez com a intenção de definir as questões colocadas, concordando que sejam elas as questões a

\footnotetext{
${ }^{57}$ Quantity surveyors são profissionais que trabalham no ramo de contruções e ocupam-se de seus custos.

${ }^{58}$ Nos termos da Parte 24 das CPR.

${ }^{59}$ Housing Grants, Construction and Regeneration Act 1996.

${ }^{60}$ Esta era uma prescrição que constava da Practice Direction - Pre-Action Protocol, mas não foi repetida na Diretriz Prática.

${ }^{61}$ Decisões judidiais têm demonstrado a intenção das cortes de conferir seriedade no desempenho das atividades prescritas pelo Protocolo, sancionando seu descumprimento através de ordens relativas a custos, que são proferidas logo que a ação é iniciada (em vez de o serem ao final do processo). Nesse sentido, vejase as seguintes decisões: Charles Church Developments Ltd v Stent Foundations Ltd [2007] EWHC 855 (TCC), Callery v Gray (No.1) [2001] EWCA Civ 1117; [2001] 1 W.L.R. 2112. Daejan Investments Ltd v Park West Club Ltd [2003] EWHC 2872 (TCC); [2004] B.L.R. 223. McGlinn v Waltham Contractors Ltd [2005] EWHC 1419 (TCC); [2005] B.L.R. 432. Cundall Johnson \& Partners LLP v Whipps Cross University Hospital NHS Trust [2007] EWHC 2178 (TCC). Alfred McAlpine Capital Projects Ltd v SIAC Construction (UK) Ltd [2005] EWHC 3139 (TCC); [2006] B.L.R. 139. Orange Personal Communications Services Ltd v Hoare Lea (a firm) [2008] EWHC 223 (TCC).
} 
serem debatidas, e explorar alternativas para sua solução; (vii) as partes estejam numa posição em que sejam capazes de fazer acordos satisfatórios antes de recorrem ao Judiciário; e (viii) os processo seja resolvido de forma mais eficiente se de fato a ação for ajuizada.

O autor ou seu advogado deve enviar ao réu (ou réus) uma cópia da letter of claim, a qual deverá conter as seguintes informações: (i) o nome e endereço do autor; (ii) o nome e endereço de cada potencial réu; (iii) um resumo claro dos fatos em que a demanda se baseia; (iv) os dispositivos de lei e/ou do contrato em que a demanda se baseia; (v) a natureza da medida buscada (se, por exemplo, tratar-se de um pedido de indenização, o detalhamento de como se alcançou a quantia reclamada, como foi feito o cálculo da multa contratual, etc.); (vi) nos casos em que uma demanda tenha sido noticiada ao réu no passado e por ele rejeitada, os motivos pelos quais o autor acredita que referida rejeição não foi acertada; (vii) os nomes de quaisquer peritos (experts) já contratados pelo autor (com quesitos já formulados) e de cujo laudo pretende se valer, identificando as questões que serão endereçadas pelo perito.

Dentro de 14 dias do recebimento da letter of claim, o réu deve acusar seu recebimento por escrito e poderá indicar o nome e endereço de sua seguradora (se houver). Se o réu não acusar o recebimento da letter of claim dentro do prazo estipulado, o autor poderá dar inicio à ação imediatamente.

Se o réu desejar fazer objeções à demanda do autor sob o fundamento de que: (i) a corte não tem jurisdição; (ii) o caso deva ser direcionado à arbitragem; ou (iii) o réu indicado na letter of claim é parte ilegítima, tais objeções deverão ser formuladas em até 28 dias do recebimento da letter of claim ("notice of objection”). Deixar de levantar quaisquer dessas questões neste momento não prejudicará o direito do réu de fazê-lo se e quando a ação for iniciada, mas a corte poderá considerar tal comportamento no momento em que arbitrar custos. Nos casos em que um notice of objection for feito, o réu não será obrigado a respeitar as previsões a seguir, mas no caso de o réu retirar sua objeção, a seção seguinte será imediatamente aplicável e os prazos serão contados como se a letter of claim houvesse sido recebida no momento em que for dada a notícia da retirada da objeção.

No caso de não serem feitas as objeções acima, ou de serem feitas apenas em relação a parte da demanda, as demais determinações do Protocolo deverão ser 
cumpridas $^{62}$. Assim, no mesmo prazo de 28 dias acima assinalado (ou em outro que tenha sido acordado entre as partes, mas nunca superior a 3 meses), o réu deverá enviar ao autor uma letter of response ("carta resposta"), a qual deverá conter a seguintes informações: (i) os fatos colocados na letter of claim com os quais o réu concorda e, se não concordar, a base para tanto; (ii) os pedidos inseridos na letter of claim, também fornecendo o embasamento para o caso de delas discordar; (iii) se a demanda é aceita total ou parcialmente, se as indenizações, outros valores ou extensão de prazo solicitadas são aceitas ou rejeitadas e, se rejeitadas, sob qual fundamento; (iv) no caso de ser alegado que o autor participou da negligência alegada, os fatos que embasem tal alegação; (v) se o réu pretende acionar o autor também e, se este for o caso, prover o autor com as mesmas informações que deveriam constar da letter of claim que seria enviada pelo réu ao autor; (vi) os nomes de quaisquer peritos (experts) já contratados pelo réu e de cujo laudo pretende se valer, identificando as questões que serão endereçadas pelo perito.

No caso do item (v) acima, o autor deverá providenciar uma resposta ao réu em prazo igual ao assinalado ao réu para resposta da letter of claim. Se o autor não receber a resposta dentro do prazo acordado, poderá dar inicio à ação imediatamente.

Dentro de 28 dias contados do recebimento, pelo autor, da resposta enviada pelo réu, ou, na hipótese de o autor pretender responder à reconvenção, após o recebimento, pelo réu, da resposta enviada pelo autor, as partes deverão encontrar-se.

O objetivo dessa reunião (denominada "Pre-Action Meeting") será possibilitar que as partes concordem sobre quais são as questões presentes no caso, bem como identifiquem a causa fundamental de discordância sobre tais questões e, assim, considerem em que medida e de que forma tais questões podem ser resolvidas sem recurso ao Judiciário e, se o ajuizamento da ação for inescapável, de que forma ela pode ser conduzida eficientemente, assim atendendo ao objetivo supremo identificado no início deste trabalho.

O Protocolo estabelece expressamente não ter a intenção de prescrever em detalhes como deve se dar o encontro entre as partes, mas toma a liberdade de estabelecer diretrizes. Dentre elas e, mais precisamente, em relação às pessoas que devem estar presentes na

\footnotetext{
${ }^{62}$ A respeito do cumprimento do protocolo, decidiu-se em Cundall Johnson and Partners LLP $v$ Whipps Cross University Hospital NHS Trust [2007] EWHC 2178 (TCC) que "On the facts of the case, the claimant had not complied with the requirements of the Protocol as the claimant's solicitors had never sent a letter summarising the contractual basis of the claim for additional fees. The defendant could not become liable to send a response letter under para 4.3 prior to receipt of a proper letter of claim."
} 
reunião, estabelece que devem estar presentes: (i) o próprio autor no caso de ser pessoa física e, se pessoa jurídica, seu representante legal, com poderes para transigir; (ii) o advogado de cada parte, se um houver sido contratado; (iii) o representante legal da seguradora, no caso de sua existência ter sido revelada; e/ou (iv) a parte a quem efetivamente incumbia a obrigação, no caso de sub-contratados, por exemplo.

As partes devem considerar resolver a disputa que se coloca entre elas através de métodos alternativos de solução de controvérsias. Entretanto, se o recurso a tais métodos mostrar-se impossível e se existir alguma questão para cuja solução é provável que a contratação de um perito seja necessária, as partes devem empenhar-se para chegar a um acordo sobre como as questões a serem abordadas pelo perito deverão ser definidas, se há possibilidade de se nomear um perito conjunto e, em caso positivo, quem será ele. Além disso, as partes devem empenhar-se para, na medida do possível, definir a extensão da troca de documentos entre elas, com o objetivo de poupar custos; e como deve ser conduzido o litígio, com vistas a minimizar custos e demoras.

Qualquer parte poderá ser inquirida pela corte (e sempre terá a liberdade de falar espontaneamente) e deverá revelar: (i) se e quando alguma reunião ocorreu e quem estava presente; (ii) a identidade de uma ou mais partes que se tenha recusado a participar e os motivos dessa recusa; (iii) se não houve qualquer reunião, a razão disso; (iv) quaisquer acordos alcançados entre as partes; e (v) o fato de métodos alternativos de soluções de controvérsia terem ou não sido considerados ou acordados.

Por fim, se cumprir com os procedimentos estabelecidos no protocolo significar a prescrição da ação, o autor poderá ajuizar a ação sem cumprir o Protocolo, mas deverá solicitar à corte que lhe dê diretrizes quanto ao procedimento a ser adotado. A corte, nessa ocasião, considerará determinar ou não a suspensão do processo para que o Protocolo então seja cumprido.

\subsubsection{Defamation}

Em vigor desde 2 de outubro de 2000, o Pre-Action Protocol for Defamation (“Protocolo Pré-Ação de Difamação"), ou PAPD ressalta, em sua nota introdutória, que ações de difamação tem características específicas, sendo uma delas a importância do 
tempo. Quase que invariavelmente, o autor buscará reparação imediata e/ou pedido de desculpas como parte do processo de restaurar sua reputação.

O autor deve notificar o réu a respeito da potencial demanda tão cedo quanto possível. A letter of claim deverá conter as seguintes informações: (i) nome do autor; (ii) detalhes suficientes da publicação ou veiculação que contém as palavras das quais o autor se queixa e, se possível, uma cópia de referida publicação ou programa veiculado; (iii) as incorreções ou falta de embasamento das palavras de que se queixa o autor, de modo a que possa o réu entender as alegações formuladas; (iv) a reparação buscada; e, quando possível, (v) o detalhamento dos danos causados ao autor pela veiculação das referidas palavras. Por fim, é importante que o autor faça constar da letter of claim o significado que ele atribui a tais palavras.

O réu deve oferecer sua resposta à letter of claim tão logo quanto razoavelmente possível ("reasonably possible"). Se o réu entender que será incapaz de responder satisfatoriamente dentro de 14 dias (ou em período menor, conforme especificado na letter of claim), deverá especificar a data até a qual pretende responder.

A resposta deverá incluir o seguinte: (i) se, e em que medida, a causa é aceita ou rejeitada e se mais informações são necessárias; (ii) se a causa for aceita total ou parcialmente, o réu deverá indicar as reparações que está disposto a oferecer; (iii) se mais informação é necessária, o réu deve precisar que informação é essa e por que dela necessita; e (iv) se a causa é rejeitada, o réu deve explicar os motivos da rejeição, indicando os fatos que embasam tal rejeição. Ademais, é desejável que o réu diga, ainda, qual o significado que atribui às expressões em questão.

Por fim, ressalta-se no Protocolo que as partes devem buscar resolver sua querela através de formas alternativas, citando-se a mediação, a negociação, e o direcionamento da causa ao Press Complaints Commision, um órgão independente que lida com reclamações do público voltadas ao editorial de jornais e revistas, frisando que as partes podem ser questionadas em juízo sobre o porquê de o assunto não ter sido decidido de forma alternativa. Entretanto, o Protocolo reitera que as partes não podem jamais ser obrigadas a recorrer a qualquer forma de resolução alternativa de controvérsias ${ }^{63}$.

\footnotetext{
${ }^{63}$ Em Halsey v Milton Keynes NHS Trust Steel v Joy, 2004, a Corte de Apelação rechaçou a hipótese de condenação, em custos, da parte que se recusou a tentar a mediação.
} 


\subsubsection{Professional Negligence}

O Protocolo Pré-Ação de Negligência Profissional ("Professional Negligence PreAction Protocol" ou "PNPAP") entrou em vigor em 16 de julho de 2001 e destina-se aos casos em que o profissional a ser demandado por negligência não pertença nem ao setor de construção nem ao setor de saúde, para os quais há Protocolos específicos.

A letter of claim deve ser enviada assim que o autor entender que há motivos para ajuizar uma ação contra o réu. A carta deve conter o relato dos fatos, as alegações feitas contra o profissional e a relação de causa e efeito entre o comportamento do profissional e os danos causados ao autor, bem como uma estimativa desses danos, com detalhes do cálculo e, ainda, o pedido (se indenização ou se outra forma de reparo). O autor deve fazer com que acompanhem a carta todos os documentos que embasem suas alegações. Afora isso, o autor deve também indicar o nome do perito, se um já houver sido contratado (e a ele formulado quesitos) e deve solicitar que uma cópia da carta seja imediatamente enviada ao segurador do réu, se houver.

Por fim, o Protocolo faz uma ressalva especifica, que não se verifica na maioria dos Protocolos (embora seja prática corrente em todos): ele não tem o status de Statement of Case (o equivalente à petição inicial no Brasil). Entretanto, na hipótese de a letter of claim e o Statement of Case (no caso de a ação ser ajuizada) diferirem significativamente, a corte pode decidir, a seu exclusivo critério, impor sanções ao autor. O mesmo se dá entre e carta resposta e a defesa.

Dentro de 21 dias do recebimento da letter of claim, o réu deve acusar seu recebimento. Nos 3 meses que se seguirem à data em que o recebimento da letter of claim for acusado, o profissional deverá investigar o caso e, se tiver problemas para cumprir o prazo, o profissional deverá informar ao autor o que está fazendo para agilizar o processo e quando espera ter as informações necessárias. $\mathrm{O}$ autor não deve negar ao réu extensões de prazo que sejam justificáveis.

Uma vez empreendida a investigação necessária, o réu deve enviar ao autor: (i) uma carta-resposta; ou (ii) uma carta de acordo; ou (iii) ambas.

A carta resposta deverá conter a aceitação ou recusa das alegações do autor, total ou parcial. Se houver recusa, deverá o réu fornecer sua versão dos fatos, bem como os documentos que a fundamentam. Se o réu precisar de mais informações ou documentos 
para poder formar sua posição, deverá solicitá-los ao autor. A carta de acordo, por sua vez, conterá a proposta de acordo do réu.

Se a carta resposta negar a letter of claim e não tiver sido enviada carta de acordo, o autor poderá desde logo ajuizar sua ação. Em qualquer outra circunstância, as partes deverão iniciar tratativas, com a intenção de concluí-las em até 6 meses contados da data em que foi acusado o recebimento da letter of claim. Se a contenda não for resolvida dentro desse período, as partes poderão acordar uma extensão desse prazo, identificando os pontos que já se encontram resolvidos e os que ainda pendem de solução. Caso não concordem com um prazo adicional, o autor poderá ajuizar a ação. Quando possível, o autor deve, com pelo menos 14 dias de antecedência, dar notícia ao réu de que irá ajuizar a ação.

Quanto à contratação de peritos, se o autor obteve um laudo pericial antes de enviar a letter of claim, o profissional (o réu) terá igual direito de obter um laudo antes de enviar a carta resposta ou a carta de acordo. Se, por outro lado, o autor não houver obtido prova pericial antes de enviar a letter of claim, as partes são encorajadas a nomear um perito conjuntamente, concordando sobre a forma de pagamento dele e sobre como deve conduzir seu trabalho. Caso a nomeação conjunta não seja possível, as partes são livres para contratar cada qual seu perito, frisando que, a todo momento, o Protocolo (e as Notas de Direcionamento) reforça que as partes devem ter ciência de que os gastos alocados ao caso devem ser proporcionais ao valor em disputa, e também por isso a nomeação conjunta é incentivada.

\subsubsection{Desease and Ilness}

\section{a) Introdução}

O Protocolo Pré-Ação para Demandas Relacionadas a Doenças ("Pre-Action Protocols for Desease and Ilness Claims" ou "PAPDIC") entrou em vigor em 8 de dezembro de 2003 e destina-se a todos os casos de danos pessoais que sejam resultado de doenças (adquiridas no ambiente de trabalho ou em virtude do consumo de determinado produto), e não de acidentes. O cronograma e os detalhes nele estabelecido podem se mostrar inapropriados a depender da doença em questão e dessa forma alterados pela parte que assim o considerar, mas se esse for o caso, tal parte deve comunicar tal evento à parte 
contrária e estar preparada para justificar sua conduta em juízo, caso a ação venha a ser proposta.

Em nota introdutória, o Protocolo se diz ser um código de boas práticas. Da mesma forma que em outros Protocolos específicos, obter registros profissionais pode ser algo importante na investigação da demanda que o autor cogita propor, especialmente em demandas ligadas a doenças ocupacionais. Tais documentos devem ser providenciados em até 40 dias, sem custo. Na hipótese de não ser possível providenciar as informações e os documentos solicitados nesse prazo, o réu deve ao menos fornecer detalhes das providências que está tomando para resolver o problema.

Se o réu ou sua seguradora não providenciar as informações solicitadas ou não fornecer explicações que justifiquem eventual demora, o autor poderá solicitar em juízo uma ordem para obtenção de provas prévia (“order for pre-action disclosure”).

Caso o autor decida não ir adiante, deve imediatamente informá-lo ao réu.

Se o autor decidir ir adiante, assim que tenha informações suficientes a embasar uma demanda, deve enviar duas letter of claim para o réu, uma delas devendo ser repassada à seguradora.

Existe um formato padrão de letter of claim, cujo uso é aconselhado. Não é necessário que o autor anexe à letter of claim provas médicas, mas é sugerido que o faça na grande maioria dos casos. A carta deve narrar os fatos com a máxima precisão possível, fornecendo documentos que os comprovem, para que o réu e/ou sua seguradora possam avaliar o caso, inclusive em termos de valores.

O réu deve acusar o recebimento da letter of claim dentro de 21 dias a contar da data de sua postagem, identificando a seguradora (se houver) e quem será o responsável por lidar com o caso. Deve, ainda, apontar eventuais omissões observadas na letter of claim. Se o recebimento não for acusado dentro do prazo estabelecido, o autor poderá ajuizar a ação.

Em 3 meses contados da data em que acusou o recebimento da letter of claim, o réu ou a seguradora deverá enviar ao autor sua resposta, na qual aceitará ou negará as alegações contra si feitas. No caso de negá-las, o réu deverá anexar à resposta documentos relevantes que estejam em seu poder e que seriam provavelmente requisitados pela corte no caso de o caso ser levado a juízo, seja previamente ou no curso da ação. 
A contratação de peritos será normalmente necessária em casos dessa natureza. $\mathrm{O}$ Protocolo não pretende dar orientações especificas sobre como tal ou tais peritos devem ser nomeados e por quem, mas, da mesma forma que outros Protocolos, frisa que há de se atentar ao custo que isso representa em relação à magnitude da controvérsia.

Nos momentos em que as partes concordarem em nomear um único perito, uma das partes deve apresentar à outra uma lista com o nome de um ou mais peritos. Dentro de 14 dias, esta parte poderá apresentar objeções a um ou mais dos peritos sugeridos, devendo a parte que sugeriu seus nomes escolher dentre aqueles contra os quais não foram opostas objeções. Na hipótese de todos os nomes da lista terem sido rechaçados, cada parte deverá nomear seu perito. Caberá à corte, no caso de a demanda ser proposta, avaliar se o comportamento das partes (ao não chegarem a um acordo sobre um único perito) foi razoável ou não.

Se uma das partes não fizer objeções ao perito já nomeado, não poderá fazer uso de prova pericial produzida por outro perito, salvo se (i) a parte contrária não se opuser, (ii) o juiz assim decidir, ou (iii) se o laudo do perito nomeado tiver sido alterado e a parte que o contratou não estiver disposta a revelar o laudo original.

Qualquer das partes poderá enviar, ao perito escolhido de comum acordo, questões escritas sobre o laudo produzido, as quais deverão ser respondidas separadamente a cada uma das partes.

Os honorários do perito escolhido de comum acordo geralmente serão arcados pelo autor; os honorários do perito que responder perguntas serão arcados pela parte que as fizer. Quando o réu aceitar a responsabilidade pelos danos alegados pelo autor, quaisquer relatórios médicos que tenham sido produzidos em razão do protocolo, e que sirvam de base para a alegação de cada uma das partes, deverão ser revelados à parte contrária.

O Protocolo fala expressamente das ofertas de acordo sob a égide da Part 36 das $\mathrm{CPR}$, prevendo que sempre que uma oferta for feita, a parte que a fizer deve fornecer à parte contrária todo o material necessário para que avalie a oferta de maneira apropriada. Diz, ainda, que antes de que a ação seja ajuizada, o laudo pericial deve ser enviado à parte contrária, devendo-se conceder a esta no mínimo 21 dias para que considere tal laudo e avalie a possibilidade de acordo. 


\subsection{Resultados obtidos na Inglaterra}

De 1999 para cá, uma década se passou e já houve oportunidades de avaliação da mudança de comportamento das partes e da adoção de uma cultura de acordos.

Algumas pesquisas que buscaram aferir o impacto das CPR no processo civil inglês, o impacto dos protocolos no comportamento dos litigantes, bem como o resultado dessa mudança são relatadas abaixo e ajudam a visualizar a "nova paisagem".

\subsubsection{Emerging and Further Findings (2001/2002)}

Na primeira dessas pesquisas, intitulada Emerging Findings, An Early Evaluation of the Civil Justice Reforms, de março de 2001, e coordenada pelo Department of Constitutional Affairs (DCA) do Reino Unido, os efeitos dos Protocolos foram positivamente descritos:

"3.15. Early indications show that the introduction of Pre-Action Protocols has been key in encouraging a new settlement culture. A survey of their members by the Association of Personal Injury Lawyers showed that $48 \%$ of respondents felt that earlier settlement had been reached and $33 \%$ of cases avoided litigation." ${ }^{64}$

Em pesquisa posterior, denominada Further Findings - A Continuing Evaluation of the Civil Justice Reforms, de agosto de 2002, indica o DCA que:

"3.17 The Clinical Disputes Forum conducted a survey of over 100 users of the Clinical Negligence Protocol and reported the findings in September 2001. These are very positive and indicate that the main objectives of the protocol are being met:

*Better communication ${ }^{65}$

\footnotetext{
${ }^{64}$ EMERGING Findings. An early evaluation of the civil justice reforms, March 2001. Disponível em: $<$ http://www.dca.gov.uk/civil/emerge/emerge.htm>.

${ }^{65}$ Trata-se, de fato, de inserir a prática da comunicação entre as partes, sem que para isso precisem de um terceiro, privado ou público. Em um primeiro momento, a adequação à norma pode ser puramente interesseira, isto é, movida pelo temor da sanção que pode vir a ser aplicada se o protocolo for descumprido. Entretanto, com o passar do tempo, espera-se que um novo modelo de inter-relação entre partes se instale e deite raízes. Sobre a mediação, instituto que guarda alguma relação com o que aqui se apresenta, escreveu ANA CECÍlIA ROLAND GUEDES PINTO: "o objetivo básico é que os envolvidos desenvolvam um novo modelo de inter-relação que os capacite a resolver ou discutir qualquer situação em
} 
* Better exchange of information
* Earlier investigation by defendants
* Improved opportunities for settlement

3.18 In an article published in Legal Action in October 2001, Suzanne Burn referred to this survey. She wrote that the responses: 'indicated particularly that defendants are carrying out better and earlier investigations, there is more co-operative behaviour, the protocol provides better opportunities for pre-action settlement, and the statements of case are more focused when litigation is necessary."

\subsubsection{Peysner and Seneviratne's Report (2005)}

John Peysner e MARy SEneviRATne, professores da Nottingham Law School e da Nottingham Trent University, respectivamente, a pedido do DCA elaboraram um estudo intitulado "The Management of Civil Cases: the courts and the post-Woolf landscape", o qual foi publicado em novembro de 2005.

De acordo com este estudo:

"There was a general view that co-operation between the parties and the court was significantly better post-CPR, although one district judge felt that a better way of expressing it was "compliance" rather then cooperation.

"The protocols had certaily helped to produce a more co-operative environment, because of the consequences of non-compliance. This was called "forced" co-operation by some judges, which nevertheless eventually becomes habitual conduct. The protocols had also made it easier to obtain disclosure, which improved co-operation.

"The co-operative approach inculcated by the protocols also applied to practice areas which did note have specific protocols (...)." 67

Citando o depoimento de um entrevistado que usualmente representa requerentes, continuam os autores da pesquisa:

que haja a possibilidade de conflito. É, pois, uma proposta educativa e de desenvolvimento de habilidades sociais no enfrentamento de situações adversas. In: PINTO, Ana Cecília Roland Guedes. O conflito familiar na justiça: mediação e o exercício dos papéis. Revista do Advogado, São Paulo, v. 62, p. 69, mar. 2001.

${ }^{66}$ FURTHER Findings. A continuing evaluation of the civil justice reforms, March 2001. Disponível em: $<$ http://www.dca.gov.uk/civil/reform/ffreform.htm>.

${ }^{67}$ PEYSNER, John; SEVIRATNE, Mary. The management of civil cases: a snapshot. Civil Justice Quarterly, v. 312, p. 12-13, 2006. Disponível em; <http://www.dca.gov.uk/research/2005/9_2005_full.pdf>. 
"Well, in my experience it is much easier to get disclosure. We will normally get more or less full disclosure now before we issue [proceedings] which means that if liability is denied we can take a view as to whether or not, based on the documents, it is worth issuing proceedings. ${ }^{68}$

Um dos problemas de forma geral identificados, contudo, disse respeito à medida de discricionariedade que era dada ao juiz pelo objetivo supremo (overriding objective), especialmente pela falta de decisões amparadas no novo regime a guiarem a ação das partes e de seus representantes (como é de praxe acontecer quando existe uma mudança estrutural da magnitude da introduzida pelas CPR).

Sobre disclosure, a pesquisa identificou o seguinte:

“(...) our interviewees reported that the disclosure regime was working well and specific disclosure applications were much reduced from the position before the introduction of the CPR. The one exception was in relation to pre-issue applications. If the prospective defendant does not produce documents, such as inspeciton reports and contractual documents, timeously or at all during the pre-action protocol phase, then the prospective claimant's solicitor can issue a specific disclosure application. In general, this was working well and contributing to diversion from litigation, by giving the claimant's solicitor material that established either that there was no claim or that there was a claim leading to settlement during the pre-action protocol phase." 69

Houve manifestações de advogados de autores no sentido de que em diversos casos os réus dizem não concordar com as alegações feitas pelo autor durante a fase de cumprimento dos protocolos, mas não apresentam a documentação que embasa tal discordância. Assim, os autores têm que requisitar referidos documentos repetidamente e, muitas vezes, recorrem ao Judiciário para requerer uma ordem de "pre-action disclosure", a qual, uma vez atendida, pode, de fato, fazer-lhes mudar de idéia e entender que sua ação não tem chances de prosperar, não devendo nem mesmo ser proposta. É fato, contudo, que requisições de "pre-action disclosure" podem muitas vezes servir de instrumento de pressão sobre os potenciais réus e de fonte de receita para os advogados dos autores, em se tratando de casos com pouquíssimas chances de sucesso (já de antemão assim identificadas). ${ }^{70}$

\footnotetext{
${ }^{68}$ PEYSNER, John; SEVIRATNE, Mary. The management of civil cases: a snapshot, cit., p. 13.

${ }^{69}$ PEYSNER, John; SEVIRATNE, Mary. The management of civil cases: a snapshot, cit., p. 21.

${ }^{70}$ PEYSNER, John; SEVIRATNE, Mary. The management of civil cases: a snapshot, cit., p. 21.
} 
Os autores do estudo identificam uma alta taxa de acordos:

"Judges noted that the vast majority of cases settle, and we were told of settlement rates of 60\% or more. (...) Solicitors noted that the majority of claims are settled pre-issue, and that this is a direct result of the Rules (...). Claims are thus set out in more detail, and all the evidence is put to the other side, in accordance with the pre-action protocol. The solicitors get the documentation earlier, so they can make a more informed view of the evidence. Also, defendants, the insurers, realise that litigation is expensive, so they are being more pro-active, making more sensible offers, unlike the pre-CPR days when 'there was a philosophy of let's litigate and fight'. The Rules are definitely working from the point of view of the claimant's lawyers."

Os estudo observa, contudo que as reformas do CPR geraram uma antecipação de custos ("front loading of costs") que seriam normalmente incorridos durante o processo, na medida em que os Protocolos, dentre outras mudanças trazidas pela CPR, forçavam as partes a se dedicarem mais ao caso desde logo, o que, por óbvio, significava tempo delas, de seus advogados e de eventuais peritos contratados:

"Prior to the CPR, the natural history of a personal injury claim involved very limited work prior to issue of a writ in the High Court or particulars of claim in the County Court. After issue, there was a gradual and escalating exchange of information (allegations, documents, experts' reports and witness statements) normally leading to settlement. Post-CPR much of this exchange occurs before issue and, accordingly, many cases settle during or at the end of the protocol period. The CPR has 'frontloaded them,", 72

Adicionalmente, reportou-se na pesquisa que as partes não podem ajuizar uma ação "com segurança" sem que antes tenham percorrido os Protocolos, o que lhes gera custos. Por fim, houve quem dissesse que fazer acordos depois de implementados os Protocolos tornou-se mais difícil, na medida em que é pouco provável que os advogados recomendem o acordo sem que antes todas as informações requeridas pelos Protocolos tenham sido trocadas, por medo de que sejam acusados de negligência por recomendar um acordo por menos do que seu cliente faria jus. Em contrapartida, em épocas pré-CPR, "a boa prática recomendava a completa troca de informações, mas ela não era exigida e, assim, tal medo não se impunha.",73

\footnotetext{
${ }^{71}$ PEYSNER, John; SEVIRATNE, Mary. The management of civil cases: a snapshot, cit., p. 35.

${ }^{72}$ PEYSNER, John; SEVIRATNE, Mary. The management of civil cases: a snapshot, cit., p. 56.

${ }^{73}$ PEYSNER, John; SEVIRATNE, Mary. The management of civil cases: a snapshot, cit., p. 56.
} 


\subsubsection{Jackson's Report (2009)}

Em 2008, o Master of the Rolls indicou Lord Justice JACKSON ${ }^{74}$ para elaborar um estudo que revisasse o sistema de custos na Inglaterra, haja vista a preocupação de que continuassem bastante elevados. A coleta de dados começou em janeiro de 2009 e, em maio, Lord Justice JACKSON publicou seu relatório preliminar, intitulado Review of Civil Litigation Costs ("Revisão de Custos").

Da mesma forma como havia sido observado por PEYSNER e SEVIRATNE, os Protocolos seriam um dos ingredientes a gerar antecipação dos custos normalmente incorridos pelas partes durante o processo judicial. Entretanto, houve consenso de que "settlements based upon a fuller understanding by parties of their opponents' cases are more likely to be fair." 75 De fato, observa-se na Revisão de Custos uma acentuada diminuição das ações propostas após a edição das $\mathrm{CPR} .^{76}$

O relatório indicou que, em causas versando sobre danos pessoais, seguradoras raramente cumpriam os Protocolos e que, para incentivar o cumprimento, sanções deveriam ser aplicadas mais eficazmente; muitas vezes, os autores iniciavam a ação apenas para promover negociações.

Outra observação pertinente referiu-se à possibilidade de pedir ao juiz que a parte revele alguma informação ou exiba documento antes de iniciada a ação que versará sobre a questão de direito material aparentemente controvertida, o chamado pre-action disclosure. ${ }^{77}$ Queixam-se os advogados dos réus de que os autores constantemente fariam pedidos de revelação de documentos ao juiz, mesmo em casos de mínimas quebras do protocolo pertinente, e mesmo em casos bastante fracos; advogados de autores, em contrapartida, reclamam que os réus reteriam informações necessárias a propiciar a correta avaliação do potencial de êxito da causa:

\footnotetext{
74 Juiz na Corte de Apelação do Reino Unido.

${ }^{75}$ JACKSON, Lord Justice Rupert. Review of civil litigation costs: preliminary report. May 2009. Disponível em: <http://www.judiciary.gov.uk/about_judiciary/cost-review/index.htm>.

${ }^{76}$ JACKSON, Lord Justice Rupert. Review of civil litigation costs: preliminary report, cit., p. 57.

${ }^{77}$ De acordo com as CPR, o pre-action disclosure tem lugar quando (i) a parte que detém a posse de certo documento provavelmente será parte na ação, se ela for intentada pela parte que requer a ordem de "predisclosure"; (ii) se o documento está no âmbito do que seria revelado se a ação houvesse sido ajuizada; e (iii) se a revelação de tal documento é desejável para que (a) o processo seja resolvido justamente; (b) a resolução da controvérsia pelas partes, sem a necessidade de ação, seja facilitada; ou (c) se poupem despesas.
} 
"I am told by personal injury defence solicitors that pre-action disclosure has become a "cottage industry", in which claimant solicitors frequently pursue applications and claim costs on the basis of minor protocol breaches; such applications are even made in weak cases that are not pursued further. The complaint by defence solicitors is that these applications generate costs to no useful purpose. The position of claimant solicitors is that defence solicitors frequently withhold information or documents that are necessary for the claim to be assessed or progressed." ${ }^{, 78}$

A maioria dos profissionais consultados (especialmente advogados de autores em ações por danos pessoais) mostrou-se apreensiva com a falta de sanção ao não cumprimento dos Protocolos e, afora isso, com o fato de que a penalidade para tal descumprimento apenas seria verificada após o julgamento, ou seja, muito tempo depois do evento, o que retiraria parte de sua força. Assim, sugeriu-se que a notícia do descumprimento do protocolo pudesse ser levada ao juiz desde logo e que este imediatamente sancionasse a parte faltosa. ${ }^{79}$

Um parênteses: é questionável o acerto da sugestão de que as partes venham a juízo para pedir a aplicação de sanções à parte que descumpriu o protocolo, posto que isso escancararia as portas do Judiciário aos litigantes em potencial. Preferível, talvez, fosse incentivar a parte a, frente ao descumprimento da parte adversa, ingressar com a ação propriamente dita.

A respeito de grandes disputas comerciais ("large commercial claims"), o Relatório de Custos apontou o seguinte:

"There should continue to be no pre-action protocol for Commercial Court cases. In complying with the more general Practice Direction Protocols (replaced with effect from 6th April 2009 by the Practice Direction on Pre-action Conduct) the parties should exercise constraint in pre-action procedures. The claim and response letters should be concise. Only essential documents should be supplied on each side. In appropriate cases it should be permissible to commence proceedings without following the pre-action procedures." 80

\footnotetext{
${ }^{78}$ JACKSON, Lord Justice Rupert. Review of civil litigation costs: preliminary report, cit., p. 392.

79 “'17.33 Breaches of pre-action protocols. Most of the practitioners are concerned that breaches of pre-action protocols usually go unpunished. Such matters are usually dealt with at the end of the case, when people have forgotten the details of the pre-action skirmishes. It would be best if applications could be made to the court pre-action to deal with any failure to comply with the protocols." JACKSON, Lord Justice Rupert. Review of civil litigation costs: preliminary report, cit., p. 130.

${ }^{80}$ JACKSON, Lord Justice Rupert. Review of civil litigation costs: preliminary report, cit., p. 278.
} 
A narrativa acima indica que para casos mais complexos um protocolo detalhado (especificando documentos ou categorias de documentos) não seria recomendável. Ademais, na medida em que casos mais complexos têm maior intercâmbio de documentos e informações, gerando mais custos, especialmente despesas com honorários advocatícios, existe uma preocupação de que os trabalhos, e por conseguinte os custos, sejam restringidos ao estritamente necessário. Por fim, o último trecho da narrativa levanta alguma inquietação sobre como se ter previsibilidade sobre qual caso deveria e qual não deveria observar os Protocolos. E previsibilidade é algo que falta no direito hoje; diminuir seu nível entende-se seja algo extremamente desaconselhável.

Ainda a respeito de disputas comerciais mais complexas ${ }^{81}$, houve profissionais que se manifestassem pela desnecessidade do protocolo, argüindo que eles foram importantes na promoção de uma conduta de maior cooperação entre as partes, mas que, uma vez que esta cultura já se firmou, os protocolos seriam desnecessários, sendo portanto partidários de um regime mais flexível, em que não houvesse protocolos formais, mas em que as partes fossem encorajadas a trocar informações antes de iniciar o litígio. Neste caso, o juiz deveria ter o poder de sancionar as partes que entendesse não terem cooperado de maneira razoável, o que inclui a revelação de documentos importantes para a compreensão da causa. $^{82}$

Mencionou-se, ainda, que é preciso permissão do juiz para que o laudo produzido durante o cumprimento do protocolo seja aduzido em juízo como prova, o que se entende seja tópico bastante delicado.

Em suma, as opiniões submetidas a Lord Justice JACKSON a respeito dos Protocolos não foram unânimes. Aqueles que os felicitaram disseram que os Protocolos:

(i) prestam enorme auxílio na troca de informações desde logo, o que facilita que se chegue a acordos antes do que normalmente aconteceria;

(ii) os custos incorridos são preferíveis a se ter surpresas na ação; e

\footnotetext{
81 "Overall, the Woolf reforms brought a change in the adversarial culture, but instruments such as the preaction protocols which have brought this about for some types of litigation have less impact in heavy commercial and other complex litigation." CRANSTON, Ross. Complex litigation: the Commercial Court. Civil Justice Quarterly, v. 190, p. 206, 2007. Cranston justifica sua posição ao sustentar que neste tipo de caso (complexo), imperam no comportamento do advogado que os patrocina a cooperação, a cortesia, o profissionalismo, o empenho em conversar informalmente com a parte adversa para tentar resolver a controvérsia que, dentre outras, são qualidades críticas para a bem sucedida condução do caso.

${ }^{82}$ JACKSON, Lord Justice Rupert. Review of civil litigation costs: preliminary report, cit., p. 295.
} 
(iii) evitam que se desgastem relações existentes (comerciais ou não), o que é frequentemente o caso quando o litígio é levado a juízo.

Os que os criticaram, sublinharam que:

(i) eles levam a forte antecipação de custos;

(ii) são uma distração;

(iii) não há nada que o réu possa fazer se o autor indevidamente prolongar a duração do Protocolo;

(iv) o juiz não tem qualquer poder para agir e controlar a etapa de cumprimento dos protocolos e, quando o litígio chega a juízo, já terá sido tarde demais para se evitar abusos;

(v) ações desenvolvidas antes da ação são nela duplicadas (ex: o statement of case - espécie de petição inicial - é a letter before claim reformulada.)

(vi) sanções pelo descumprimento do protocolo não são impostas como deveriam ${ }^{83}$;

(vii) o modelo vislumbrado por Lord WoOLF previa maior controle dessa etapa;

(viii) litigantes de outros países tem dificuldade em entender o porquê de se ter que fazer tanto antes mesmo de a ação ser iniciada e se sentem frustrados com o processo;

(ix) existe um medo de que a previsão contida na Diretriz Prática, no sentido de que se requisitem mais documentos, seja usada de forma opressiva (a chamada "fishing expedition");

(x) a insistência de que as partes considerem ADR pode significar perda de tempo e de dinheiro; e

(xi) os Protocolos não são fáceis de serem usados pelas próprias partes, sem o auxílio de advogados ("not user friendly for litigants in person").

Por fim, Lord Justice JACKSON faz a seguinte ponderação: o objetivo dos Protocolos é facilitar a troca de informações e documentos, alcançando, tanto quanto possível, a autocomposição entre as partes antes de iniciada a ação. Poucos rejeitariam tal objetivo. Existe, entretanto, uma preocupação no sentido de que alguns dos Protocolos

\footnotetext{
${ }^{83}$ Nesse sentido, apontou-se o voto de Ramsey Justice in Charles Church Developments Ltd $v$ Stent Foundations Ltd [2007] EWHC 855 (TCC) "the courts should generally deal with the cost consequences of failure to comply with a pre-action protocol at an early stage".
} 
estejam se tornando contra-producentes e gerando mais custos do que poupando. ${ }^{84}$ As questões a serem consideradas agora, uma década depois das CPR, são: a simplificação de alguns protocolos ou detalhamento de outros; custos incorridos nesta etapa e a recuperabilidade ou não deles; sanções mais efetivas para o caso de descumprimento; alternativas para quando a etapa de cumprimento do Protocolo se tornar demasiadamente longa. ${ }^{85}$

Vê-se, portanto, que o movimento agora existente é de aperfeiçoamento dos Protocolos, visto que entendidos como uma medida que trouxe contribuições positivas. Não se fala, jamais, em sua abolição ou retração.

\subsubsection{Apontamentos da jurisprudência}

Questão de bastante destaque na jurisprudência inglesa, mas de pouca relevância para este estudo é a de se identificar a quem cabem os custos incorridos na fase préprocessual $^{86}$.

Em Ian McGlinn v Waltham Forest Contractors Ltd (1) Huw Thomas Associates (2) DJ Hartigan \& Associates Ltd (3) (2005) ${ }^{87}$, todo o procedimento previsto no Protocolo de Construção e Engenharia havia sido cumprido. Por fim, o autor ajuizou a ação contra os réus, mas, contra um deles, (um arquiteto), não inscreveu na "petição inicial" todos os pedidos que havia feito quando do início da fase de cumprimento dos Protocolos. Tal réu dizia haver gasto, até aquele momento, quase $£ 20.000,00$. Assim, no bojo da ação, seu advogado requereu que seu cliente fosse reembolsado pelos custos incorridos durante o cumprimento dos Protocolos.

Ao decidir, o Juiz Coulson QC invocou (i) o Supreme Court Act 1981, seção 51 ('the costs of and incidental to the proceedings shall be in the discretion of the court'),

\footnotetext{
${ }^{84}$ JACKSON, Lord Justice Rupert. Review of civil litigation costs: preliminary report, cit., p. 474 . Lord Jackson fala inclusive de sua experiência profissional, onde teve chance de testemunhar mais de $£ 1.000 .000,00$ serem gastas ao longo do cumprimento de um protocolo e, ainda, observar que uma letter of claim pode chegar a ter 350 páginas.

${ }^{85}$ Lord Justice JACKSON termina por afirmar que entende serem os protocolos um dos assuntos mais difíceis de seu estudo, de modo que convida todos os interessados a exprimirem sua opinião. JACKSON, Lord Justice Rupert. Review of civil litigation costs: preliminary report, cit., p. 475.

Diz-se pouco relevante para este trabalho porque nao se tem (e não se sugere qualquer mudança nesse aspecto), no Brasil, regime de custos que se assemelhe ao inglês.

${ }^{87} 3$ All E.R. 1126.
} 
donde concluiu que os custos incorridos por qualquer das partes em cumprimento a qualquer Protocolo eram suscetíveis de serem considerados "custos incidentes à ação"; e (ii) o julgamento da Corte de Apelação em Callery v Gray $(2001)^{88}$, no qual Lord WoOLF considerou a recuperabilidade de custos na hipótese de a questão ser resolvida sem que fosse iniciada a ação e, ademais, disse que '(2) Where an action is commenced and a costs order is then obtained, the costs awarded will include costs reasonably incurred before the action started, such as costs incurred in complying with a Pre-action Protocol.'

Assim, Coulson QC entendeu que tais custos eram em tese recuperáveis, a depender da visão da corte sobre serem ou não considerados "incidentais à ação".

Por fim, exarou que:

\begin{abstract}
"Save in exceptional circumstances, costs incurred by a defendant at the stage of a Pre-Action Protocol, in dealing with and responding to issues which were subsequently dropped from the action when the proceedings were commenced, could not be costs "incidental to" those proceedings. It would be contrary to the whole purpose of the Pre-action Protocols, which are themselves such an integral part of the CPR, if claiming parties were routinely penalised if they decided not to pursue claims in court which they had originally included in their Protocol claim letters. The whole purpose of a Pre-action Protocol procedure is to narrow issues and to allow a prospective defendant, wherever possible, to demonstrate to a prospective claimant that a particular claim is doomed to failure. ${ }^{89}$
\end{abstract}

Em resumo, antes de McGlinn, se o réu fosse bem sucedido na ação e a corte exercesse sua discrição ao ordenar que a parte contrária pagasse seus custos, os custos de responder às questões trazidas na ação seriam recuperados, aí incluídos também os custos incorridos anteriormente à ação. ${ }^{90}$ Foi em McGlinn que se apresentou pela primeira vez a questão dos custos incorridos para responder a alegações do autor que não superaram a fase dos Protocolos.

\footnotetext{
${ }^{88}$ [2001] EWCA Civ 1117.

${ }^{89}$ Apud, NEWMAN, Paul. How much will it cost me? Construction Newsletter, p. 2, 2005. COULSON QC frisou: "Accordingly, unless the circumstances were exceptional and thereby gave rise to some sort of unreasonable conduct, costs incurred by a defendant at the Pre Action Protocol stage in successfully persuading a claimant to abandon a claim (either in whole or in part) were not costs incidental to any subsequent proceedings if, in those subsequent proceedings, such claims did not feature at all. Consequently, such costs were not recoverable under s.51 of the Act.”, in 3 All E.R. 1126.

90 "It was clear on the authority of In re Gibson's Settlement Trusts and Callery v Gray that if the defendant was successful in the action and the court was in favour of exercising its discretion to grant it costs that the costs of responding to those issues that were pursued in the proceedings could be recovered and those costs would include the costs incurred pre-action. However, it was not until McGlinn's case that the issue of whether the costs of responding to those issues that were not pursued could be recovered was addressed." RICHARDS, Greg. Damned if you do, damned if you don't. Cons. Law, v. 17, n. 13, 2006.
} 
Tal decisão foi criticada, especialmente pelos advogados de réus potenciais em disputas da mesma natureza, alegando que se essa fosse a orientação dos tribunais, não haveria nada que refreasse os impulsos do autor que desejasse aventurar-se em demandas especulativas ou exageradas, fazendo o potencial réu dispender tempo e recursos para defender-se, a final chegando-se a uma situação em que o autor entendesse por não acionar tal réu em juízo. ${ }^{91}$

Além da recuperabilidade dos custos incorridos na fase pré-processual, a jurisprudência inglesa tem se debruçado sobre a necessidade de se conferir efetividade aos protocolos através da imposição consistente de sanções ${ }^{92}$.

\subsubsection{Balanço e sugestões}

Juízes e estudiosos são unânimes em reconhecer as vantagens que os Protocolos trouxeram, criando, inclusive, uma cultura de maior cooperação entre as partes, através da troca de informações e documentos, conforme o padrão de comunicação estabelecido pela Diretriz Prática e pelos Protocolos específicos. Tal mudança de comportamento, que teve (e provavelmente ainda tem) sua maior causa nas conseqüências adversas que o descumprimento dos Protocolos pode trazer, tem sido refletida na celebração de maior número de acordos entre as partes e, quando tal não ocorre, na chegada ao Judiciário de causas mais maduras.

Contudo, assim como em tudo o mais, os Protocolos não são apenas beleza e contentamento. Citem-se, nesse sentido, alguns riscos que trazem em si.

Existe, por exemplo, o risco de que a má-fé de uma das partes a faça retardar o cumprimento do Protocolo ou mesmo a faça negar-se a cumpri-lo, de modo que é preciso

\footnotetext{
${ }^{91}$ Referindo-se a McGlinn: "However, the decision is harsh on defendants - it potentially creates a no win situation for them. A claimant chooses to incur the cost of making allegations at the pre-action stage. However, the defendant often does not have a choice and must respond to each claim made against it in order to protect its business and reputation and to avoid the penalties for non-compliance with the Protocols. In doing so the defendant invariably incurs some costs. A defendant is damned if it does not respond to claims made against it at the pre-action stage - given the penalties given for non-compliance with the Protocols and the effect that failure to respond may have on its business or reputation - and it is damned for its compliance with the Protocols by incurring costs that cannot be recovered if those claims do not proceed.". Por fim, diz que a decisão favorece os autores. RICHARDS, Greg. Damned if you do, damned if you don't, cit.

${ }^{92}$ Conforme nota 61 supra.
} 
haver limites rígidos para o comportamento das partes durante essa fase, sob pena de deixar-se a parte bem-intencionada a mercê de seu oponente.

Além disso, há o risco de que uma das partes leve a outra a incorrer em altos custos desde o início do surgimento da controvérsia, ou o risco de que os custos incorridos na fase de Protocolos não sejam aproveitados na ação judicial, se proposta.

Há o risco, também, de a parte que o inicia ter como objetivo apenas adentrar nos assuntos do seu adversário, sem qualquer intenção de propor uma ação - são as chamadas fishing expeditions.

Há o risco de que as conseqüências desfavoráveis não sejam uniforme e constantemente aplicadas pelo juiz. O jurisdicionado precisa de previsibilidade. Entretanto, para que a segurança e a previsibilidade que o jurisdicionado tanto preza sejam preservadas, importante é que o juiz tenha critérios bem definidos. Assim, e apenas como um exemplo dessa previsibilidade, da mesma forma que os atos de manifestação das partes no processo tem momento e prazo para acontecer, prazo esse muitas vezes curto, também é recomendável que os Protocolos os tenham.

A experiência dos Protocolos tem sem dúvida um saldo positivo, mas, como se vê, não é sem defeitos. Assim, avaliar os defeitos observados na Inglaterra e tentar encontrar formas de corrigi-los (ou pelo menos amenizá-los) é uma dos objetivos do presente trabalho.

$\mathrm{Na}$ Inglaterra, uma das ferramentas de auxílio das partes ao cumprirem os Protocolos é o chamado "pre-action disclosure", de acordo com o qual, em certas ocasiões, a parte pode vir a juízo requisitar uma ordem para que outra parte exiba determinado documento, sempre tendo em mente uma ação que potencialmente surgirá.

Louvando, em regra, o pre-action disclosure, NEIL ANDREWS aponta:

"In general it can be suggested that legal systems will do well to promote pre-action disclosure, as an adjunct to the encouragement of settlement, especially to assist the disputant to make a more solid assessment of the dispute's merits" 
Entretanto, ANDREWS menciona também que existem restrições a esse direito, calcadas principalmente na vedação das "fishing expeditions" $"$ e da violação à intimidade e à confidencialidade, especialmente daqueles que não serão partes na ação.

No Brasil, existe trabalho recente do Professor Flávio LuIZ YARSHELl, em que aventa a possibilidade (e a adequação) de algo semelhante ao pre-action disclosure, defendendo a existência de um direito autônomo à antecipação da prova (mediante ação judicial), um direito que prescindiria do requisito de urgência e seria apenas indiretamente vinculado a uma ação posterior, como forma de possibilitar que as partes obtivessem mais elementos para poderem avaliar com mais propriedade o caso e as chances de êxito que teriam na hipótese de a demanda ser ajuizada ${ }^{94}$.

Conforme aponta YARSHELL, as partes podem sem dúvida trocar elementos probatórios espontanemante desde sempre, pré-constituindo provas. Entretanto, a ação probatória autônoma de que fala teria lugar nas hipóteses em que não há o concurso de vontade de todas as partes e, mais, no caso de a intervenção do juiz ser relevante para que a prova obtida tenha eficácia em processo a ser futuramente proposto.

Sem se fazer a crítica ou o elogio da ação autônoma proposta por YARSHELL, a idéia dos Protocolos é semelhante - fazer com que as partes tenham a maior quantidade possível de elementos para avaliar o caso e decidir se vale ou não a pena propor uma ação ou se a melhor alternativa é a autocomposição -, mas tem seu espectro de atuação integralmente fora do processo judicial. Além disso, em vez de valer-se apenas da boa vontade das partes, visam os Protocolos a criar um padrão de comportamento cujo cumprimento ou descumprimento acarrete conseqüências às partes, positivas ou negativas, respectivamente, como forma de incentivá-las ao cumprimento.

Ademais, se o cumprimento do Protocolo implicasse enxurrada de ações de antecipação da prova, parte do seu objetivo - aliviar o Judiciário - teria sido posta de

\footnotetext{
${ }^{93}$ Essa regra foi reafirmada pela Corte de Apelação no contexto de "commercial wrongs", conforme julgamento em Black vs Sumitomo Corporation ([2002] 1 WLR 1562, CA.), mas que em casos de danos pessoais em que a vítima busca documentos de seu empregador, a abordagem dos tribunais tende a ser mais liberal., cfr. ANDREWS, Neil. The pre-action phase. General Report - Common Law. In: GRINOVER, Ada Pellegrini; CALMON FILHO, Petrônio (Orgs.). DIREITO PROCESSUAL COMPARADO. CONGRESSO MUNDIAL DE DIREITO PROCESSUAL, 13. Rio de Janeiro: Forense, 2007 p. 227.

${ }^{94}$ YARSHELL, Flávio Luiz. Antecipação da prova sem o requisito da urgência, e direito autônomo à prova. São Paulo: Malheiros Ed., 2009.
} 
lado $^{95}$. Os Protocolos devem conferir às partes um padrão de conduta que elas possam cumprir por si sós; que não requeira a ação do juiz, ainda que o recurso a ele seja inafastável. As partes devem assimilar que aquilo que deveriam fornecer uma à outra no processo, devem fornecer desde já.

Por fim, tem-se que a imposição de um padrão de conduta às partes, de um roteiro propriamente dito, parece ser mais efetiva na medida em que se trate de questões específicas, onde se sabe qual a mecânica da relação de direito material existente entre autor e réu e, assim, quais as informações e documentos que devem ser trocados para que os fatos objeto da controvérsia sejam apurados. Por esse motivo, inclina-se a comunidade jurídica inglesa por preferir Protocolos específicos a um Protocolo genérico, posto que este não teria a habilidade de gerar um roteiro de conduta preciso para as partes, possivelmente acarretando dispêndio excessivo de tempo e de recursos. Os Protocolos específicos têm, na sua grande maioria, gerado contribuições importantes para a promoção de acordos entre as partes, pelo que são aclamados na Inglaterra.

\footnotetext{
${ }^{95}$ Como já se observou, a Inglaterra faz uso do pre-action disclosure, inclusive durante a fase de cumprimento dos Protocolos. Neste particular, acredita-se que o sistema a ser importado para o Brasil nao deva fazer uso de tal recurso.
} 


\section{A PART 36 OFFER TO SETTLE}

\subsection{Conceito - linhas gerais}

$\mathrm{Na}$ Inglaterra, os custos do processo são alocados entre as partes com base no chamado "indemnity principle", de acordo com o qual a parte perdedora deve pagar os custos do seu adversário (aí incluídos os gastos com seu advogado), limitados a custos razoavelmente incorridos e razoáveis em valor (reasonably incurred and reasoble in amount).

A situação do réu costuma ser mais desvantajosa do que a do autor, pois de acordo com o indemnity principle, considera-se como vencedor o autor que ganha qualquer parte do que pediu, independentemente de quão mínima seja em comparação ao quanto requerido na ação. Assim, um autor que estivesse confiante em recuperar determinado valor, sentir-se-ia tentado a inflar sua ação, prolongar o processo e não controlar seus custos, sabedor de que poderia recuperá-los se conseguisse ao menos uma pequena porção do que requerera.

Para proteger o réu de tal desvantagem, de há se muito criou o sistema de payment into court (depósito em juízo), que nada mais é senão uma oferta de acordo. Se o autor a rejeitar e, mais tarde, quando a ação for julgada, não obtiver mais do que lhe fora ofertado pelo réu, fica responsável pelo pagamento dos seus próprios custos, bem como por aqueles incorridos pelo réu.

Foi devido à extrema dificuldade de se prever os custos de um processo - dado que podem envolver não só os seus próprios custos, mas também os da parte contrária -, que se pensou em um mecanismo cuja finalidade seria diminuir a exposição das partes a eles. É verdade que o incentivo a aceitar o acordo funciona proporcionalmente à exposição a, e à imprevisibilidade de custos a que a parte esteja sujeita. Em um país como a Inglaterra, onde os custos são altos e imprevisíveis, um sistema de proteção como esse é indispensável e frequentemente usado pelas partes.

A Parte 36 das CPR manteve o conceito subjacente ao payment into court, alterando seu mecanismo e expandindo-o: substituiu-se o efetivo depósito em juízo por 
uma carta proposta ${ }^{96}$ e permitiu-se que o autor também dela fizesse uso, proposta essa cuja não aceitação importaria reflexo sobre os custos a que estaria sujeito uma vez findo o processo. De acordo com a Parte 36, se o autor aceitar a oferta do réu, fará jus a que este arque com os custos que ele, autor, incorreu até aquele momento. Se recusar a oferta, arrisca-se a ter que pagar os custos do réu da data da oferta em diante, no caso de, julgada a ação, não ganhar mais do que lhe havia sido ofertado pelo réu.

Nos termos da Parte 36, o autor pode fazer uma oferta de valor inferior ao que pediu na ação. Se o réu a aceitar, o autor terá direito ao valor da oferta, mais os custos que incorreu até aquele momento. Se declinar, e o autor ao final ganhar mais do que havia oferecido, terá direito a recuperar custos de acordo com o indemnity basis (mais favorável a ele do que o standard basis), segundo o qual fará jus a juros sobre os custos e o valor que lhe foi conferido por sentença, como forma de recompensa pelo desnecessário ônus de ter que fazer face a todo um processo judicial. ${ }^{97}$

A Part 36 Offer (como é chamada essa oferta) não significa admissão de responsabilidade ou reconhecimento de que os argumentos da parte contrária sejam melhores ou piores. Ela não pode ser usada contra a pessoa que fez a oferta, exceto para o fim de determinar a incidência de custos, de modo que não deve ser comunicada à corte incumbida de julgar o caso até que o julgamento termine.

\subsection{Necessidade que determinou seu aparecimento}

Conforme mencionado desde o início, foi a intenção de Lord WoOLF desenvolver mecanismos que promovessem uma cultura de cooperação e de composição amigável entre as partes desde cedo e, em regra, incentivos econômicos são os que mais surtem efeitos na promoção de qualquer conduta.

\footnotetext{
${ }^{96}$ Conforme Calderbank $v$ Calderbank [1975] 3 All ER 33, cujo entendimento foi mais tarde reiterado em Crouch v King's Healthcare NHS Trust [2005] 1 All ER 207.

${ }^{97}$ The Rule now uses the expressions more advantageous than a Defendant's Part 36 offer and at least as advantageous to the Claimant as the proposals contained in a Claimant's Part 36 offer. Different consequences follow. In particular the entitlement, unless the court considers it unjust, to the enhancement provisions of $\mathrm{r} 36.14(3)$ are not available to the Defendant.

These provisions are designed as an incentive to encourage Claimants to make and Defendants to accept appropriate offers of settlement. Such incentive would be deprived of effect unless the non-acceptance of that which ultimately proves to have been a sufficient offer ordinarily will advantage the Claimant in the respects set out in the rule . . . " Comentários à regra no White Book Service 2007."
} 
Lord WoOLF disse:

"My aim is to increase the emphasis on resolution otherwise than by trial." $" 98$

Da forma como antes manejada, a oferta de acordo era restrita ao réu, demandava o depósito do valor ofertado, estava adstrita a ações cujo objeto fosse a cobrança de dívidas ou requerimento de indenização e não permitia que se propusesse acordo sobre um parte da demanda apenas. A intenção de Lord WoOLF foi ampliar esse cenário. Eis alguns dos argumentos para tais mudanças, conforme presentes no seu Access to Justice Interim Report:

“5. (...) Written offers of this kind should be capable of being made either in respect of the whole case or of one or more issues. Not having to make a physical payment into court will simplify the operation of a more flexible system on these lines. It will also relieve the court administration of the burden of managing the monies paid into court." 99 (destaques da transcrição)

Antecipando críticas sobre a insegurança que acarretaria não se ter o valor ofertado desde logo depositado em juízo, Lord WoOLF argumentou:

"6. This will mean that the party accepting the offer will not have the security, which he has at present, of being able to take the money out of court. As against this, it must be remembered that the party who succeeds at trial has no security for his judgment. To require payment into court can prevent a party who does not have the means to make a payment from making a sensible offer to settle which it would be reasonable for the other party to accept. Assuming that the other party would not recover more by continuing with the proceedings, from his point of view it is better to accept an offer, even though it may be difficult to enforce, than to continue with the proceedings and to obtain a judgment which would also be incapable of being enforced. And if he accepts an offer which is then not met, that may be a useful warning not to waste good money in further pursuit of what may be fruitless litigation." $"$ (destaques da transcrição)

E, ainda, sobre a oferta feita antes de iniciada a ação:

"17. It is the intention that offers should be able to be made and in fact be made before the commencement of proceedings. The other side would be expected to co-operate and to provide voluntary disclosure if necessary

\footnotetext{
${ }^{98}$ ACCESS to Justice: Interim Report, cit., Capítulo 24.

${ }^{99}$ ACCESS to Justice: Interim Report, cit., Capítulo 24.

${ }^{100}$ ACCESS to Justice: Interim Report, cit., Capítulo 24.
} 
before the commencement of proceedings. If a party does not do so, the court will have discretion to take this into account when deciding the appropriate order to make. Where an offer is made before proceedings, the costs incurred prior to the proceedings would be subject to the same principles." 101

É claro que existem inúmeras nuances e pontos de atenção em um sistema como esse, como, por exemplo, as ofertas de último minuto, as ofertas feitas sem que a parte contrária tivesse efetiva oportunidade de avaliá-las, ou sem que se tivesse dado à parte contrária material suficiente para verificar os argumentos do adversário, etc. É de se notar, portanto, que as conseqüências da oferta dependerão significativamente do grau em que se deu a troca de informações e documentos entre elas.

Eis aí, portanto, a intrínseca relação entre o sistema de Protocolos, que dão as diretrizes sobre o que uma parte deve dizer e mostrar à outra, e a possibilidade de se fazer uma oferta de acordo informada, séria e consciente, que não signifique apenas uma armadilha à parte contrária.

\subsection{Funcionamento}

A Parte 36 das Civil Procedure Rules disciplina ofertas de acordo e conseqüências advindas de uma oferta que observe seus termos, e por isso denominada Part 36 Offer. Neste Capítulo e nos seguintes, a Part 36 Offer (tal como disciplinada e praticada no direito inglês) será referida apenas como "Oferta".

Para que seja considerada uma Oferta, deve ela obedecer aos seguintes requisitos: (a) ser feita por escrito; (b) explicitar que se trata de uma Oferta; (c) estabelecer um período de não menos do que 21 dias pelo qual o réu será responsável pelos custos do autor no caso de a Oferta ser aceita; (d) explicitar se a Oferta contempla toda a demanda ou parte dela (e que parte); e (e) dizer se está levando em conta qualquer pedido que tenha sido feito pelo réu ao autor. A depender do caso, a Oferta deverá obedecer a requisitos ainda mais específicos e, ainda, poderá ser feita uma Oferta tratando apenas da alocação de responsabilidade, não da quantificação da indenização, por exemplo (CPR 36.2).

${ }^{101}$ ACCESS to Justice: Interim Report, cit., Capítulo 24. 
O chamado "Período Relevante" é o enunciado no item (c) acima, que será de no mínimo 21 dias, podendo ser extendido pelo acordo das partes. No caso de a Oferta ter sido feita a menos de 21 dias do julgamento, o Período Relavante se encerrará com o fim do julgamento (podendo o juiz designar outra data para o término de tal período) (CPR 36.3(1)).

A Oferta pode ser feita a qualquer momento: antes do início da ação e mesmo em grau de apelação (CPR 36.3(2)). Uma Oferta que propõe o pagamento ou o recebimento de determinada quantia será considerada como já tendo computado os juros aplicáveis até a data do término do Período Relevante (21 dias ou outro período acordado entre as partes ou 21 dias após a Oferta ser feita, no caso de feita com menos de 21 dias de antecedência em relação ao início do julgamento) (CPR 36.3(3)).

As consequiências da Oferta, que serão em breve apontadas, só se aplicam aos custos incorridos em primeira instância (CPR 36.3(4) $)^{102}$.

Antes que o Período Relevante se encerre, o ofertante pode, mediante envio de notificação à sua contraparte, alterar os termos da Oferta (para que sejam mais vantajosos a si) ou pode inclusive retirá-la, desde que o juiz dê permissão para tanto ${ }^{103}$. No caso de o Período Relevante já ter expirado, e desde que o receptor da oferta não tenha dado ciência ao ofertante de que a aceitou, tal retirada ou mudança nos termos da oferta prescindirá da autorização do juiz (CPR 36.3(5)(6)(7)).

\section{Disposições específicas atinentes à Oferta feita pelo réu.}

Salvo as hipóteses constantes dos itens 36.5(3) (ação de danos pessoais envolvendo pagamento de prestações periódicas) e 36.6(1) (provisional damages ${ }^{104}$ ), a Oferta feita pelo réu deverá implicar o pagamento de um valor total, de uma só vez (a single sum of money) que, se aceita, deverá ser feito em 14 dias. O réu pode oferecer efetuar o pagamento dentro de período superior a 14 dias da data de aceitação da Oferta, mas nesta hipótese não será mais considerada uma Oferta, com as conseqüências próprias a ela nos termos da Part 36

\footnotetext{
${ }^{102}$ As partes podem também fazer Ofertas em grau de apelação, onde os custos em jogo serão os incorridos em segunda instância.

${ }^{103}$ Conforme a Practice Direction 36, a permissão deve ser buscada junto a um juiz que não o juiz do caso.

${ }^{104}$ Provisional damages é a indenização paga para a pessoa que teve algum dano pessoal que pode agravar-se no futuro. Assim, o juiz lhe concede a possibilidade de, dentro de certo período de tempo, voltar ao Judiciário para nova avaliação dos danos sofridos, desde que decorrente do mesmo evento que gerara a primeira indenização.
} 
das CPR, a menos que seja aceita (CPR 36.4(2)). Se o réu entender que pode ter dificuldades em fazer o pagamento em 14 dias, sempre poderá solicitar ao autor que com isso concorde, não podendo, contudo, impor-lhe a espera.

$\mathrm{Na}$ hipótese de ações de danos pessoais reclamando lucros cessantes (future pecuniary loss), aplica-se o disposto na regra 36.5. Nesse sentido, tem-se a possibilidade de uma Oferta para pagar ou para aceitar receber, no que se refere aos lucros cessantes: (i) uma soma total, pronta e acabada (lump sum); (ii) pagamentos periódicos; ou (iii) ambos. Na hipótese de não se tratar de lucros cessantes, a Oferta apenas poderá contemplar a hipótese de uma soma total, pronta e acabada (CPR 36.5(3)).

Se a Oferta contempla apenas um valor global (lump sum), deve obviamente indicálo, podendo também indicar qual parte da soma oferecida é relativa aos lucros cessantes e qual parte é relativa aos demais danos. É, ainda, necessário indicar qual parte da Oferta refere-se a lucros cessantes a serem pagos (ou aceitos) em parcelas periódicas, especificando suas datas e se são ou não reajustáveis. Por fim, na hipótese de pagamento em parcelas, deve-se informar como será assegurada a continuidade dos pagamentos (CPR 36.5(4) (a) a (d)). Seja qual for o caso, sempre que a Oferta contemplar uma soma global e pagamento em parcelas, o ofertando apenas poderá aceitar a Oferta como um todo. Quanto aos pagamentos em parcelas, o autor deve, dentro de 7 dias, requerer ao juiz uma decisão (award) nesse sentido, de modo que os pagamentos das parcelas vincendas seja assegurado (CPR 36.5(7)).

Uma Oferta pode, inclusive, contemplar pedido de provisional damages. Neste caso, a Oferta deve especificar que: (a) o valor oferecido pretende satisfazer o pedido, assumindo que os danos sofridos pela pessoa não levarão às doenças ou aos agravamentos indicados na Oferta, (b) que a Oferta é condicionada a que o ofertado possa requerer indenização pelo agravamento de sua condição dentro de um determinado limite temporal; e (c) qual é tal limite. Se aceitar a Oferta, o indivíduo deve, dentro de 7 dias, requerer ao juiz uma decisão (award) nesse sentido (CPR 36.6(5)).

Tem-se por realizada ou por alterada a Oferta na data em que seu destinatário recebe-a ou recebe a notificação de alteração de seus termos (notice is served on the offeree) (CPR 36(7)). Dentro de 7 dias contados de sua realização, o destinatário da Oferta pode solicitar esclarecimentos a seu respeito, os quais deverão ser prestados em até 7 dias contados do recebimento da solicitação. Caso não responda, quem solicitou os esclarecimentos pode requerer ao juiz que ordene o ofertante a fazê-lo. 


\section{Aceitação}

A Oferta é tida por aceita quando a notificação da aceitação for entregue ao ofertante (CPR 36.9(1) $)^{105}$. Pode ela ser aceita a qualquer tempo (tenha ou não o ofertante feito uma Oferta diferente subsequentemente), a menos que o ofertante notifique a parte contrária de que a retirou (CPR 36.9(2)). Dessa forma, as partes devem monitorar o valor de suas Ofertas em relação ao desenrolar do caso, de modo a modificá-las se estiverem altas ou baixas demais frente às provas trazidas à baila.

Entretanto, em alguns casos a permissão do juiz poderá ser necessária. São eles: (a) Ofertas feitas por alguns dentre vários litisconsortes passivos, em que o autor deseja continuar litigando contra os demais litisconsortes ou em que o autor deseja encerrar o litígio contra tais demais litisconsortes, mas estes não consentem (CPR 36.12); (b) o Período Relevante tenha expirado e valores já tenham sido pagos ao autor, os quais devem ser deduzidos da Oferta; (c) o julgamento já se tenha iniciado, dentre outros. A menos que as partes tenham chegado a um acordo quanto a custos, quando a corte conceder permissão para a aceitação da Oferta deverá também regular a distribuição dos custos do processo, podendo aplicar as conseqüências próprias da Oferta, nos termos desta seção das CPR. A menos que as partes concordem, a Oferta não poderá ser aceita no período entre o fim do julgamento e a prolação da sentença.

\section{Conseqüências da aceitação da Oferta quanto a custos}

Na hipótese de a Oferta ser aceita dentro do Período Relevante, o autor fará jus aos custos que incorreu no processo até o momento da entrega da notificação da aceitação ao ofertante. Quando (a) a Oferta do réu disser respeito apenas a parte do pedido e, (b) no momento da aceitação (feita dentro do Período Relevante) o autor abrir mão do saldo da ação, o autor fará jus aos custos incorridos até o momento em que notificar o ofertante a respeito da aceitação da Oferta, a menos que o juiz ordene diferentemente. Caso o valor dos custos não seja acordado entre as partes, será determinado pelo juiz em base padrão (on the standard basis). ${ }^{106}$

\footnotetext{
${ }^{105}$ Neste caso, a notificação de aceitação deve ser protocolada nos autos da ação em curso (Practice Direction Part 36 - 3.1), se houver ação em curso.

${ }^{106}$ De acordo com o CPR 44.4(2), quando o valor dos custos deve ser avaliado de acordo com o standard basis, a corte apenas permitirá custos que sejam proporcionais ao assunto discutido e, tendo dúvidas sobre a razoabilidade dos custos incorridos, decidi-los-á em favor da parte pagante. Em contrapartida, quando os custos são avaliados de acordo com o indemnity basis, dúvidas sobre proporcionalidade do quanto foi incorrido frente ao objeto da causa devem ser resolvidas em favor da parte que receberá os custos (CPR 44.2(3)).
} 
Nos casos em que se aceite a Oferta (a) feita menos de 21 dias antes do julgamento ou (b) feita após ter expirado o Período Relevante, e as partes não acordem sobre a responsabilidade pelos custos, o juiz decidirá a esse respeito (CPR 36.10(4)). Quando se tratar do item (b) acima (e a menos que o juiz decida de forma diferente), o autor fará jus aos custos do processo até a data em que o Período Relevante houver expirado; e o ofertante será responsável pelos custos do destinatário da Oferta desde a data em que o Período Relevante tenha expirado até a data de aceitação (CPR 36.10(4)).

\section{Efeitos da aceitação da Oferta}

Se a Oferta for aceita a ação será suspensa. Se uma Oferta parcial for aceita, a ação será suspensa quanto a tal parte; se a Oferta for parcial, mas o autor abrir mão do seu saldo, a responsabilidade por custos será decidida pelo juiz, a menos que as partes tenham chegado a um acordo quanto a custos também (CPR 36.11(3)). Se a aprovação do juiz for necessária para que a transação vincule as partes, a suspensão ocorrerá quando ocorrer a aprovação (CPR 36.11(4)).

A suspensão, contudo, não afetará o poder do juiz de fazer cumprir os termos da Oferta ou de lidar com quaisquer questões relativas a custos (inclusive juros sobre os custos) (CPR 36.11.(5)).

Quando for aceita Oferta de (ou que inclua) soma única de dinheiro (lump sum), tal soma deverá ser paga ao autor, a menos que as partes tenham acordado de forma diversa, dentro de 14 dias (a) da aceitação; ou (b) da data em que o juiz conceder provisional damages ou pagamento em parcelas periódicas, se estes forem os casos (CPR 36.11(6)). $\mathrm{Na}$ hipótese de não ser paga em 14 dias (ou outro prazo que tenha sido acordado entre as partes), o juiz proferirá sentença a respeito do valor não pago (CPR 36.11(7)). Quando a seção (6) acima não se aplicar, i.e., não se tratar de Oferta de soma única, e a parte alegar que a Oferta não foi cumprida, tal parte poderá compelir a outra a honrar os termos da Oferta sem a necessidade de ingressar com nova demanda (CPR 36.11(8)).

À aceitação de uma Oferta feita por um ou alguns de vários réus aplica-se a seguinte disposição: se a responsabilidade dos réus é subsidiária, o autor pode aceitar a Oferta desde que descontinue a ação em relação aos demais réus e esses consintam, por escrito, com a aceitação da Oferta pelo autor. Se a responsabilidade dos réus é solidária, o autor pode aceitar a Oferta e continuar com a demanda contra os demais réus, se o direito 
lhe autorizar. Nos demais casos, o autor deve solicitar ao juiz autorização para aceitar a Oferta.

\section{Restrições à revelação da Oferta}

A Oferta será tratada como "sem prejuízo" (without prejudice) ${ }^{107}$, exceto quanto a custos. A realização de uma Oferta não deve ser comunicada ao juiz até que este tenha proferido sua decisão (CPR 36.13(2)). Tal previsão não se aplica, contudo, (a) quando o réu tenha alegado no processo que, antes mesmo de o autor iniciá-lo, fez Oferta que abarcava todo o pedido, incondicionalmente; (b) quando o processo foi suspenso como resultado da aceitação da Oferta - CPR 36.11; ou (c) quando ofertante e destinatário da Oferta tenham assim acordado, por escrito.

\section{Conseqüências no tocante a custos após o julgamento}

A regra (CPR 36.14(1)) aplica-se quando, uma vez proferida a decisão pelo juiz:

(a) o autor não obtém decisão mais favorável do que a Oferta feita anteriormente pelo réu (ex: o réu oferece $£ 10,00$ e o juiz condena-o a $£ 9,00$ ); ou

(b) o autor obtém decisão tão favorável quanto a Oferta que anteriormente ele mesmo fizera ao réu (ex.: o autor diz que aceita $£ 10,00$ e o juiz condena o réu no mesmo valor).

No caso do item (a) acima, o juiz entenderá (a menos que considere injusto fazê-lo, i.e., que o autor convença-o disso) que o réu faz jus ao ressarcimento de seus custos desde a data em que o Período Relevante expirou, bem como juros sobre tais custos (CPR $36.14(2))$.

No caso do item (b) acima, o juiz entenderá (a menos que considere injusto fazê-lo, i.e., que o réu convença-o disso) que o autor faz jus:

(a) a juros sobre o total do valor da condenação a uma taxa não superior a $10 \%$ acima da taxa base (a taxa usada pelo Banco da Inglaterra) para parte do ou para todo o período a partir do término do Período Relevante;

\footnotetext{
${ }^{107}$ Conforme o glossário das próprias CPR, “as negociações com vistas a uma solução são geralmente conduzidas sem prejuízo, o que significa que as circunstancias em que o conteúdo dessas negociações pode ser revelado ao juiz são muito restritas", in GLOSSARY. Disponível em: <http://www.justice.gov.uk/civil/procrules_fin/menus/glossary.htm>.
} 
(b) aos seus custos conforme o indemnity basis desde a data em que se encerrou o Período Relevante; e

(c) juros sobre esses custos em taxa não excedente a $10 \%$ da taxa base (CPR $36.14(3))$.

Ao considerar se a aplicação das regras acima (CPR 36.14(2) e (3)) é injusta ou não, o juiz levará em conta todas as circuntâncias do caso ${ }^{108}$, incluindo:

(a) os termos da Oferta;

(b) o estágio do processo no qual a Oferta foi feita, inclusive quão antes de o julgamento começar;

(c) a informação disponível às partes ao tempo da realização da Oferta; e

(d) a conduta das partes em relação a dar ou a recusar-se a dar informações com fins a proporcionar que a Oferta fosse feita ou avaliada (CPR 36.14(5)).

Os parágrafos (2) e (3) dessa regra não se aplicam à Oferta que:

(a) tenha sido retirada;

(b) tenha sido alterada de modo a que seus termos fossem menos vantajosos ao seu destinatário e este tenha alcançado a última Oferta;

(c) tenha sido feita em período inferior a 21 dias antes do julgamento, a menos que o juiz tenha abreviado o Período Relevante (CPR 36.14(6)).

Ainda que apenas a Oferta (assim considerada, como se disse anteriormente, a oferta da Parte 36) tenha consequiências próprias quanto a custos, a CPR 44.3 ordena que o juiz leve em conta a existência de ofertas ao decidir sobre custos.

\subsection{Resultados obtidos na Inglaterra}

$\mathrm{Na}$ Inglaterra, é voz corrente entre os militantes e operadores do direito que o instituto da Part 36 Offer potencializa os acordos, trazendo às partes incentivos econômicos para ouvirem uma à outra e considerarem, com seriedade, eventuais ofertas.

\footnotetext{
${ }^{108} \mathrm{Em}$ Rosalind Huck v Tony Robson (2002), a Corte de Apelação decidiu que "a judge would be entitled to exercise his discretion and refuse indemnity costs where an offer was purely a tactic to secure the benefit of Pt 36".
} 
Conforme o CEDR - Centre for Dispute Resolution Civil Justice Audit, em pesquisa de abril de 2000, "74\% of external lawyers (those not practising in a firm which dealt with its own litigation) felt that Part 36 made settling cases easier" ${ }^{\prime 109}$. Freshfields, um dos maiores escritórios de advocacia da Inglaterra, publicou pesquisa intitulada "Civil Justice Reforms One Year On - Freshfields Assess Their Progress" a respeito dessa reforma, na qual dizia: "the preliminary indications are that Part 36 offers are being made in practice on a regular basis (particularly by claimants) (...). Evidence suggests that preaction offers are being widely used by both potential claimants and potential defendants" 110 , o que sugere que há uma atitude mais conciliatória das partes e de seus advogados.

Existe, contudo, quem entenda ser o mecanismo perigoso:

"The Part 36 regime, and the sanctions available to the court, of course have an important place. But there is need for care. In litigation, where the stakes can already be very high, there is a difference between creating a climate where a disciplined and sensible approach by parties towards settlement is encouraged, and creating a climate which creates undue pressure to settle regardless of merits." 11 (destaques da transcrição)

Assim, é um desafio encontrar uma mecânica que financeiramente incentive o acordo e que, ao mesmo tempo, não constitua pressão indevida sobre qualquer das partes.

\subsubsection{Peysner and Seneviratne's Report (2005)}

A impressão geral apontada pela pesquisa ${ }^{112}$ foi no sentido de que o funcionamento e as implicações da Part 36 Offer, aí incluídas as sanções a ela atribuídas, eram eficazes, embora fossem tidas como complicadas e, portanto, difíceis de serem explicadas aos clientes. $^{113}$

Ressaltou-se, contudo, a existência de uma potencial tensão no mecanismo:

\footnotetext{
${ }^{109}$ EMERGING Findings. An early evaluation of the civil justice reforms, cit., p. 12.

${ }^{110}$ EMERGING Findings. An early evaluation of the civil justice reforms, cit., p. 12.

${ }^{111}$ TRYING Woolf. Law Society Gazette, p. 13, abr. 2000.

${ }^{112}$ Trata-se do mesmo estudo mencioado no item 2.4.2 supra.

${ }^{113}$ PEYSNER, John; SEVIRATNE, Mary. The management of civil cases: a snapshot, cit., p. 2.
} 
"One problem was highlighted with the system, in that if the offers are made early, one side may not be in possession of the relevant information, and this creates problems for solicitors in discharging their duty with proper care towards their clients." 114

Por fim, o estudo indicou que não houve sugestões específicas de alterações no mecanismo da Part 36, mas que seria o momento de revisitá-la, pensando na possibilidade de diminuir sua complexidade. Isso levaria a se cogitar sobre o maior incremento dos custos e juros adicionais como forma de torná-los incentivos mais vigorosos, aumentando a probabilidade de auto-composição. Entretanto, indica uma preocupação de especial relevo: esse exercício é difícil, posto que "seria inapropriado colocar muita pressão no litigante para que fizesse um acordo versando sobre uma causa que ele, litigante, acredita terá uma solução favorável se levada a julgamento. Os incentivos e desincentivos do mecanismo deveriam ser mais profundamente explorados nesta revisão." 115 (destaques da transcrição)

\subsubsection{Jackson's Report (2005)}

Conforme o estudo empreendido por Lord JACKSON e seus assessores, enunciado no item 2.4.3 supra, "The procedure for offers contained in CPR Part 36, including claimants' offers (one of Lord WoOLF's many innovations) has by common consent been a considerable success". 116

O Relatório de Custos não se deteve muito sobre os resultados da Parte 36, exceto por afirmar que em regra geral funciona bem e incentiva o acordo. Além disso, mencionou que, embora às vezes produzindo resultados cruéis, evitava controvérsias baseadas em argumentos de "razoabilidade" e "conduta". 117

Por fim, acentuou que muitas das contribuições recebidas durante sua pesquisa apontavam para a necessidade de reversão da decisão tomada pela Corte de Apelação em $B A A$ vs Carver $^{118}$, em 2008, visto que teria introduzido um grau indesejável de incerteza à

\footnotetext{
${ }^{114}$ PEYSNER, John; SEVIRATNE, Mary. The management of civil cases: a snapshot, cit., p. 39.

${ }^{115}$ PEYSNER, John; SEVIRATNE, Mary. The management of civil cases: a snapshot, cit., p. 40.

${ }^{116}$ JACKSON, Lord Justice Rupert. Review of civil litigation costs: preliminary report, cit., p. 1.

${ }^{117}$ JACKSON, Lord Justice Rupert. Review of civil litigation costs: preliminary report, cit., p. 476 . Isso porque, com uma regra clara, não haveria espaço para que se reclamassem outras conseqüências, sob o argumento de que a conduta da parte havia sido razoável, por exemplo.

${ }^{118}$ Carver v BAA Plc [2008] EWCA Civ 412.
} 
Part 36 e, ademais, teria colocado pressão indevida para que autores aceitassem Ofertas, mesmo quando as considerassem baixas. ${ }^{119}$

\title{
3.4.3. Apontamentos da jurisprudência
}

Sobre o que significaria "more advantageous", julgamento relevante foi o proferido em Carver v BAA, onde se colocou a seguinte questão: se o julgamento superou a Oferta feita pelo réu, mas a diferença entre a Oferta e o valor advindo da decisão judicial for ínfima (no caso £51,00), as conseqüências em termos de alocação de custos devem permanecer ou o juiz tem liberdade para verificar se a vantagem clamada (a situação 'more advantageous') de fato ocorreu? O Juiz KNIGHT QC optou pela última, decidindo que a autora deveria pagar os custos do réu desde o momento em que se findara o prazo para aceitação da última oferta feita por este. A autora, então, recorreu à Corte de Apelação, que manteve a decisão do juiz:

\begin{abstract}
"[32] It follows that Judge Knight was correct in looking at the case broadly. He was entitled to take into account that the extra 551 gained was more than off set by the irrecoverable cost incurred by the Claimant in continuing to contest the case for as long as she did. He was entitled to take into account the added stress to her as she waited for the trial and the stress of the trial process itself. No reasonable litigant would have embarked upon this campaign for a gain of £51."
\end{abstract}

No caso, a autora pedira muito mais do que o razoável (muito mais do que a final recebeu), o réu fizera várias propostas de acordo ao longo do desenrolar do caso, mas a autora em nenhum momento dedicara-se a negociar, a fazer contra-propostas. Essas foram circuntâncias levadas em consideração pela corte ao reputar que o julgamento, embora $£ 51,00$ acima da Oferta, nao havia sido "more advantageous" à autora. Essa decisão sugeriu a necessidade de haver uma margem indeterminada para se ter o julgamento como mais vantajoso do que a Oferta. A pergunta que a corte se fez foi: "was it worth the fight?".

\footnotetext{
${ }^{119}$ JACKSON, Lord Justice Rupert. Review of civil litigation costs: preliminary report, cit., p. 476.

${ }^{120}$ [2008] All ER (D) 295 (Apr). Para a Corte, "The claim was pursued and became exaggerated, and the claimant had to bear ultimate responsibility for the manner in which her claim was conducted on her behalf."
} 
No acórdão, a Corte afirmou que a Part 36 Offer aplica-se a ações cujo objeto seja pagar quantia ou não (“money claims or non-money claims"). Em ações cujo objeto não seja apenas pagamento, os critérios de comparação são ainda mais subjetivos e fluidos, de modo que todas as circunstâncias do caso devem ser consideradas. ${ }^{121}$

O julgamento da Corte de Apelação em Carver levantou questões acerca da imprevisibilidade das conseqüências da Part 36 Offer e das conseqüências perniciosas que tal imprevisibilidade traria ao jurisdicionado. Nesse sentido, comenta ADRIAN ZUCKERMAN:

"The efficacy of the system in ensuring fair treatment and in promoting settlement crucially depends on the predictability of the consequences of offers made under CPR 36. (...) Unfortunately, the costs consequences of CPR 36 are considerably less predictable than they were under the former system. This is mainly due to the fact that the discretionary element in making costs orders is far stronger under the CPR."

Assim, continua ZUCKERMAN, dizendo que em muitos casos:

"a party may have been successful in bettering the opponent's offer and yet be denied costs, or even be ordered to pay those of the opponent."122

A decisão da Corte de Apelação em Carver não foi reafirmada na maioria dos julgamentos que a ela se seguiram, sob o argumento de que os fatos em Carver eram muito particulares (especialmente o fato de a autora não ter se dedicado minimamente a negociar).

Em Morgan v UPS ${ }^{123}$, a decisão a favor do autor foi minimamente mais vantajosa do que a Oferta antes feita a ele pelo réu, mas como o autor tinha se disposto a negociar, a corte decidiu que o julgamento havia sido "mais vantajoso ao autor" e ordenou ao réu que pagasse seus custos. Assim, embora a Corte de Apelação tenha distinguido Morgan v UPS de Carver v BAA, não aplicando assim a conclusão a que se chegara em Carver v BAA, os princípios enunciados neste julgamento permanecem.

\footnotetext{
121، In the context of the new Pt 36, where money claims and non-money claims were to be treated in the same way, 'more advantageous' was an open textured phrase. It permitted a more wide-ranging review of all the facts and circumstances of the case in deciding whether the judgment was worth the fight." [2008] All ER (D) 295 (Apr).

${ }^{122}$ ZUCKERMAN, Adrian A. S. Zuckerman on civil procedure, cit., p. 958-959.

${ }^{123}$ Morgan v UPS [2008] EWCA Civ 1476.
} 
Entende-se, contudo, conforme opiniões de vários setores da comunidade jurídica reportadas por Lord JACKSON, que o julgamento em Carver v BAA deveria ser revertido, posto que gera insegurança demasiada nas partes, o que sem dúvida prejudica o mecanismo da Oferta, baseado que é na previsibilidade das consequiências que atrai. Assim, "more advantageous", em ações para pagamento de quantia, significa financeiramente melhor, qualquer que seja o valor em que a sentença exceda a Oferta.

Outra questão rcorrente nos tribunais ingleses é a que se refere à retirada da Oferta pelo ofertante. De acordo com Flynn v Scougall, a corte pode entender que a Oferta foi retirada, mesmo que o ofertante não o tenha feito formalmente, quando as circunstâncias do caso mudaram de tal forma ("sufficient change in circumstances") que uma Oferta tal qual a que está na mesa seria impensável ${ }^{124}$.

O Department for Constitutional Affairs to Reino Unido lançou, em 12.01.2006, uma Consulta Pública (Consultation Paper 02/06) indicando uma série de sugestões para a reformulação da Part 36. Uma das propostas dizia respeito à remoção do requisito da permissão judicial para que a parte pudesse aceitar a Oferta feita por seu adversário fora do Período Relevante. $^{125}$

A resposta à Consulta Pública foi publicada em 01.08.2006 (CP(R)02/06) e neste ponto específico indicou que: "Embora a maioria das respostas concordem com a proposta de remoção do requisito da permissão do juiz, a margem foi bastante estreita. Análises das respostas mostraram que parte dos que não concordaram com a proposta fizeram-no porque sentiam que o juiz deveria reter a habilidade de decidir sobre custos se estes não houvessem sido acordados." 126 Subentende-se da resposta que a motivação dos que reputam necessária a permanência do requisito da permissão não reside, propriamente, na possibilidade de que a corte oponha-se à aceitação tardia.

\footnotetext{
${ }^{124}$ Flynn v Scougall [2004] EWCA Civ 873, conforme McQUATER, John. The future of Part 36: Part 3. Journal of Personal Injury Law, 2009.

${ }^{125}$ A Consulta se justificava: "This is because a permission requirement implies a possibility of refusal and it is unclear why the court should ever do this. Parties should be encouraged and assisted to settle cases, not hindered.". PART 36 of the civil procedure rules: offers to settle and payments into court". Consultation Paper (CP 02/06), p. 15. Department for Constitutional Affairs, Jan. 2006. Disponível em: $<$ http://www.dca.gov.uk/consult/civilproc36/civilprocrules_part36.pdf>.

${ }^{126}$ Conforme resposta à Consulta. PART 36 of the civil procedure rules: offers to settle and payments into court. Response to consultation paper (CP(R) 02/06) p. 6. Department for Constitutional Affairs, Ago. 2006. Disponível em: <http://www.dca.gov.uk/consult/civilproc36/response0206.pdf>.
} 
Outras questões foram colocadas em consulta pública e o resultado desse processo culminou com a reformulação parcial da Parte 36 em abril de $2007^{127}$.

\subsubsection{Balanço e sugestões}

É voz corrente que o mecanismo da Oferta potencializa a promoção de acordos e por isso é louvado pelos juristas ingleses. Entretanto, mesmo aqueles que a reputam uma importante ferramenta na engrenagem do atual processo civil, fazem críticas ou pelo menos indicam pontos de atenção no que tange ao instituto.

Sobre eles, cite-se a possível pressão indevida para que se proponham ou aceitem acordos, sem que a parte disponha de elementos para avaliá-lo, especialmente quando propostos sem que as informações ou documentos relevantes para a correta e completa compreensão da controvérsia tenham sido expostos por uma parte à outra.

O tempo da proposta e o arcabouço de informações trocadas são algumas das inúmeras variáveis que podem fazer com que as consequiências normalmente atribuíveis à Oferta sejam injustas no caso concreto.

Para dar conta dessas variáveis possíveis e evitar injustiças, é conferido ao juiz inglês o poder de não aplicar, a depender das circunstâncias do caso, as conseqüências que a Parte 36 especialmente prescreve. Nesse sentido, ao considerar se a aplicação da CPR 36.14(2) e (3) é injusta ou não, o juiz levará em conta todas as nuances do caso, incluindo:

(a) os termos da Oferta;

(b) o estágio do processo no qual a Oferta foi feita;

(c) a informação disponível às partes ao tempo da realização da Oferta; e

(d) a conduta das partes em relação a dar ou a recusar-se a dar informações com fins a proporcionar que a Oferta fosse feita ou avaliada.

Tem-se, assim, que o elemento discricionário é forte, mas inescapável, posto que não parece haver meios de disciplinar esse mecanismo de forma a dar plena conta dessas variáveis, prescindindo do juiz. Para se garantir a previsibilidade do mecanismo, é

${ }^{127}$ O mecanismo descrito no item 3.3 já contempla a Parte 36 tal qual alterada em 2007. 
necessário, contudo, que decisões como a proferida em Carver $v B A A$ não sejam proferidas.

Embora a Parte 36 contemple Ofertas realizadas em ações cujo objeto seja obrigação de pagar quantia (money claims), ou obrigação de fazer ou não fazer (non-money claims), o fato é que os exemplos doutrinários e os julgados daquele país tratam, em sua grande maioria, de money claims. Para se aferir que o julgamento foi mais vantajoso em uma money claim, basta comparar a oferta, atualizada, com o valor da condenação. Para se aferir a mesma vantagem em uma non-money claim, a tarefa é mais complicada e mais sujeita a gerar controvérsias, pois ainda que se possa subdividir o pedido e avaliar se para este ou aquele pedido a decisão judicial fora mais ou menos vantajosa que a Oferta, conferir pesos aos pedidos seria tarefa inglória e fadada à provocar a discórdia. 
PARTE II BRASIL 


\section{NECESSIDADES E OBJETIVOS SEMELHANTES OBSERVAÇÕES DE ORDEM CULTURAL)}

Há, no Brasil, a mesma necessidade que se viu na Inglaterra e que motivou a criação dos Protocolos e da Oferta? Busca-se no Brasil objetivo igual ou semelhante ao que se buscou na Inglaterra? Incentivar os acordos entre as partes e semear a idéia de que o Judiciário não deve ser o primeiro, mas o último recurso das partes é algo percebido como meritório e importante também no Brasil?

Os objetivos dos Protocolos, conforme enunciados pela própria lei inglesa, são:

(1) permitir que as partes evitem o litígio judicial através da celebração de um acordo antes que a ação judicial seja iniciada; e

(2) auxiliar no manejo eficiente do litígio, quando este não puder ser evitado,

tudo isso através do encorajamento a que as partes troquem informações sobre a controvérsia que entre elas surgir.

O objetivo da Oferta $^{128}$ é o primeiro acima enunciado, mas a possibilidade de se fazer uma Oferta (i.e., uma proposta de acordo com conseqüências patrimoniais) é resultado da informação que as partes trocaram e da idéia que formaram sobre suas respectivas chances de êxito caso a controvérsia fosse levada ao juiz e fosse objeto, ao final, de uma sentença. Embora na Inglaterra a Oferta possa ser feita a qualquer momento, as conseqüências adversas descritas no item 3.3 da Parte I deste trabalho podem ser modificadas pelo juiz caso entenda que seria injusto aplicá-las e, um dos fatores que se considerará nessa análise será o momento em que a Oferta foi feita. Assim, entende-se que uma Oferta feita quando ainda não se tinha elementos para avaliá-la não deverá implicar as mesmas conseqüências, para a parte que não a aceitou, que a Oferta feita quando informações relevantes já houvessem sido trocadas. Daí, pois, estarem ambos os institutos, Protocolos e Oferta, intrinsecamente ligados.

A grande necessidade observada na Inglaterra dizia respeito a promover o acesso à justiça, baixando os custos do processo, diminuindo demoras injustificadas e facilitando acordos entre as partes, por meio de um maior contato entre elas desde logo. Aqui, custo

\footnotetext{
${ }^{128}$ Conforme estabelecido em capítulo precedente, a Part 36 Offer to Settle será aqui referida como Oferta (com “o” maiúsculo).
} 
do processo não é o maior dos problemas se comprado com demora e ineficiência, embora também seja um deles, se a parte quiser uma defesa ou um ataque vigoroso; demora e ineficiência são, sem dúvida, problemas que assolam o Judiciário brasileiro. No mesmo caminho trilhado pela Inglaterra, tem se observado no Brasil um largo esforço em chamar a atenção das partes em litígio para alternativas de solução de controvérsias que prescindem do Judiciário.

A primeira questão que se coloca ao se sugerir a introdução de um mecanismo experimentado em outra jurisdição é a seguinte: é possível conceber tal introdução quando as características de uma jurisdição e de outra são tão distintas?

No caso, entende-se que a distinção não tem a magnitude que se costuma atribuirlhe. Tanto aqui quanto na Inglaterra, os problemas que se verificam no sistema processual civil são muito similares e as dificuldades para o cumprimento que se verificaram lá provavelmente seriam as mesmas que se verificariam aqui tivesse a mesma iniciativa sido introduzida no Brasil: preocupações com custos, com demora, com discricionariedade excessiva do juiz, com a falta de parâmetros bem estabelecidos.

Escreveu PAUlo EdUARdo Alves Da Silva sobre esta semelhança entre o cenário inglês e o brasileiro, ao tratar do gerenciamento de processos:

"O primeiro objetivo deste artigo é conhecer o case management dos sistemas de common law, declaradamente concebido para um cenário similar ao brasileiro: processos judiciais demorados e complexos, limites ao acesso à justiça e sistema processual ineficiente e inefetivo."129 (destaques da transcrição)

É desnecessário trazer elementos que demonstrem que demora (imprevisibilidade da duração do processo), volume excessivo de processos e ineficiência são traços característicos do Judiciário brasileiro. Por outro lado, parece importante pontuar que a comunidade jurídica tem se empenhado para mostrar ao jurisdicionado que a sentença proferida pelo juiz não é a única alternativa existente para que conflitos de interesse sejam resolvidos.

É nesse contexto que iniciativas à semelhança dos Protocolos e da Oferta têm bastante a oferecer. Os primeiros, na medida em que visam a aproximar as partes e permitir que obtenham, uma da outra, de forma ordenanda e padronizada, documentos relevantes

\footnotetext{
${ }^{129}$ SILVA, Paulo Eduardo Alves da. Gerenciamento de processos e cultura de litigância - a experiência do “case management" inglês, cit., p. 637.
} 
para o esclarecimento da disputa, facilitando a autocomposição. A segunda, por seu turno, visa a criar incentivos para que, uma vez mais inteiradas das bases da disputa, as partes façam propostas de acordo uma à outra e que a parte que a receber tenha condições e incentivos para, se reputá-la uma oferta justa, aceitá-la.

Ainda aproximando a Inglaterra do Brasil, FLAVIO LUIZ YARSHELL escreveu:

"A avaliação das partes, tanto mais em países que praticam o sistema capitalista em sua mais intensa acepção, presume-se seja feita de forma objetiva; e essa objetividade reside, dentre outros fatores, na consideração dos elementos de prova disponíveis e nas conseqüências econômico-financeiras de se ir a juízo com base neles." 130

Entretanto, os ditos incentivos apenas se verificarão se e quando a controvérsia transformar-se em ação proposta perante o Judiciário. Assim, interessa aqui examinar os efeitos processuais do cumprimento ou descumprimento dos protocolos e de uma oferta não aceita. Em outras palavras, passarão a interessar ao juiz os efeitos processuais de condutas extra-processuais, permitindo que as partes pautem sua conduta por aquilo que acreditem será a convicção do juiz a seu respeito.

Para OWEN FISS, cujo pensamento será exposto adiante, existe um frenesi em torno da promoção do acordo, o que entende ser altamente pernicioso, argumentando que os incentivos para que os acordos sejam feitos são todos errados, como por exemplo, a certeza de que o julgamento demorará tempo demais. Essa certeza impulsiona a aceitação de um acordo ruim, apenas para abreviar o recebimento de seja lá o que se tiver acordado, ainda que pouco.

É verdade que toda a transação pode vir a ser um bom ou um mau negócio e nunca se saberá seguramente se a decisão do juiz viria num ou noutro sentido e em que medida. Entretanto, uma coisa é certa: quanto menos as partes sabem uma sobre a outra, sobre seus argumentos, sobre suas provas, maior o risco a que se sujeitam e menor a chance de um bom acordo ser realizado, posto que menos elementos terão para projetar a convicção do juiz ${ }^{131}$. Neste particular, alguém poderia objetar: “mas ninguém é capaz de prever a decisão

\footnotetext{
${ }^{130}$ YARSHELL, Flávio Luiz. Antecipação da prova sem o requisito da urgência, e direito autônomo à prova, cit., p. 78.

${ }^{131}$ No mesmo sentido escreveu YARSHELL: "Como antes sugerido, a concepção de autocomposição sem melhor conhecimento dos fatos e disponibilidade de prova correspondente parece considerar que as partes se disponham a transigir "no escuro"; o que leva a suspeitar de que, sem elementos objetivos a permitir uma avaliação de suas chances de êxito, as partes considerar a conveniência de autocomposição a partir de
} 
de um juiz". Ocorre que parte da atuação dos advogados, especialmente daqueles que militam no contencioso, diz respeito a aconselhar seu cliente sobre qual a provável leitura que o juiz fará desse ou daquele argumento, dessa ou daquela prova, sobre a tendência dos tribunais, sobre o perfil desse ou daquele juiz. O que é isso se não uma avaliação sobre a possível convicção do juiz? Esta é grande parte do trabalho do advogado e, na medida em que dispuser de mais elementos sobre a causa, é certo que sua condição (e de seus clientes) de prever a decisão do juiz melhorará.

Outra crítica de cunho cultural poderia ser oposta ao aproveitamento desses institutos no Brasil: poder-se-ia sustentar que o sistema de Protocolos parece ter maior afinidade com um sistema adversarial, em que é conferida às partes (ou aos seus advogados) a tarefa de instruir o processo, enquanto que no sistema chamado inquisitorial o juiz tem papel mais relevante. De fato, ao introduzir os Protocolos, a intenção da reforma inglesa foi transferir, tanto quanto possível, a atividade instrutória que antes cabia às partes no curso do processo para uma etapa prévia a ele (ressalte-se, contudo, que depoimentos pessoais e provas testemunhais em geral não são produzidos no curso dos Protocolos). Assim, seria possível entender que quanto mais as partes (e seus advogados) estão acostumados a prescindir do juiz para a instrução do processo, maior a facilidade, ou pelo menos mais arraigado o hábito de que depende delas, e não do juiz, trocar as informações relevantes para o deslinde da questão debatida.

Contudo, ainda que os países de tradição de civil law sejam geralmente referidos como adotantes do princípio inquisitorial, não existe sistema puro. Existem, sim, combinações, e os matizes advindos dessas combinações dependem do grau de influência de umas ou outras características. Sobre o tema bem escreveu BARBOSA MOREIRA:

"O confronto entre civil law e common law tem sido feito por diversos
prismas. No campo do processo, é critério recorrente o que se tira da
"divisão do trabalho" entre juiz e partes (rectius: entre juiz e advogados
das partes) na instrução probatória. Adverte-se aí uma diferença de
acentuação: os ordenamentos anglo-saxônicos atribuem a tarefa
principalmente aos advogados, enquanto para nós da família romano-

outros fatores que, a rigor, não deveriam ser (os mais) relevantes no momento em que se cogita de uma conciliação." (...)

"Tomando-se a realidade brasileira, aliás, é possível que, sem dispor de elementos objetivos que a antecipação da prova poderia permitir, os interessados se disponham à autocomposição fundados em descrença no próprio sistema e no entendimento de sua incapacidade de dar solução à controvérsia em tempo útil ou, pelo menos, razoável. E, se for assim, é lícito indagar se soluções dessa ordem, ainda que adotadas pelas próprias partes, seriam verdadeiramente aptas a pacificar. $\mathrm{Na}$ verdade, parece que a conciliação feita com base na crença de que o sistema não funciona é a negação dos escopos da jurisdição. E o custo de tal distorção - esse, sim - parece ser incomensurável.”, in YARSHELL, Flávio Luiz. Antecipação da prova sem o requisito da urgência, e direito autônomo à prova, cit., p. 348-349. 
germânica assume relevância maior o papel do órgão judicial. Cunharam-se até denominações, no âmbito do common law, para assinalar o contraste: ao processo do tipo dominante na família romanogermânica chama-se "inquisitorial", ao outro tipo "adversarial". ’̀ evidência, jamais existiu e com certeza jamais existirá ordenamento processual "quimicamente puro": todos combinam, em variável dosagem, elementos de ambos os tipos."

De fato, não existe sistema puro. Embora no Brasil o art. 130 do Código de Processo Civil confira ao juiz poderes instrutórios, que podem ser exercidos ex officio, as partes têm vital importância no processo de trazer ao juiz a prova e mesmo a notícia de sua existência. Assim, mesmo que se identifique o sistema brasileiro pela alcunha de inquisitorial, não se pode subestimar o papel das partes na instrução probatória. Os ônus da prova funcionam como parâmetros de conduta das partes e elas tendem a deles se desincumbir, embora o juiz sempre conserve seus poderes instrutórios, os quais são mais frequentemente vistos em questões versando sobre direitos indisponíveis ou em que haja desequilíbrio substancial entre as partes. Assim, ainda que o juiz conserve papel de destaque, a iniciativa de produzir a prova e a criação de meios para que ela seja produzida recaem, na maioria dos casos, sobre as partes, mesmo que a figura do juiz se interponha em dados momentos, principalmente naqueles em que se presta prova oral.

Ademais, mesmo em países de tradição nitidamente adversarial, como é o caso da Inglaterra, as alterações trazidas pelas CPR conferiram ao juiz mais poderes, dando a ele maior controle sobre quais provas são produzidas, ordenando provas que as partes não requisitaram, na hipótese de não estar convencido dos fatos. Eis aí o que se poderia chamar de um passo rumo ao sistema inquisitorial.

Assim, é a posição aqui defendida que um regime de Protocolos, embora de maior afinidade natural com um sistema preponderantemente adversarial, pode perfeitamente aplicar-se ao Brasil.

Essas considerações tiveram a intenção de mostrar que: temos problemas parecidos, a demandar soluções parecidas; os problemas decorrentes da introdução dos Protocolos e da Oferta são os mesmos, presume-se, que potencialmente se veriam no Brasil, donde se tem que a natureza do povo britânico não é tão distante da natureza do brasileito, pelo menos não no aspecto de que este trabalho se propôs a tratar; e, embora o brasileiro

\footnotetext{
${ }^{132}$ BARBOSA MOREIRA, José Carlos. O processo civil contemporâneo: um enfoque comparativo. Revista Forense, Rio de Janeiro, v. 370, p. 54, nov. 2003.
} 
aparentemente tenha raízes tais que demandam decisões imperativas, tem-se cada vez mais buscado mecanismos de autocomposição, seja em virtude do amadurecimento dos litigantes, seja pelos defeitos que o Judiciário apresenta. É certo que os conflitos têm peculiaridades e é importante se identificar qual conflito se encaixaria em qual forma de resolução: imperativa estatal, imperativa não estatal (como é o caso da arbitragem), consensual, etc.

Busca-se, então, uma estrutura de incentivos que favoreça o acordo. Entretanto, em vez de prescindir do Judiciário, essa estrutura em última análise dele depende. No decorrer deste trabalho, propor-se-á uma forma de estruturação da entrada desses institutos no ordenamento brasileiro, o que importará o alargamento de alguns conceitos, a assimilação de uma cultura de cooperação (incentivada economicamente) e, certamente, alterações legislativas.

A intenção deste trabalho, de aqui em diante, é buscar a estruturação do sistema de protocolos e de um equivalente à Oferta e, além disso, estruturar os efeitos processuais e não processuais desses institutos como única forma de conferir-lhes efetividade. Para que isso seja possível, o juiz deverá atentar para a conduta extra-processual das partes; eis aí o ponto de partida da mudança de paradigma. Hoje, o juiz atenta à conduta da parte dentro do processo e, fora dele, apenas às condutas que digam respeito à questão substancial posta à sua apreciação.

Antes de se passar à realidade brasileira especificamente, uma nota sobre qual tem sido a tendência mundial em matéria de procedimentos anteriores à ação pode ser elucidativa. 


\title{
2. TENDÊNCIA MUNDIAL EM PROCEDIMENTOS PRELIMINARES
}

“Novas Tendências nos Procedimentos Preliminares", que em inglês recebeu o nome de "New Trends in Pre-Action" foi um dos temas do XIII Congresso Mundial de Direito Processual, ocorrido em 2007, no Brasil. Após o Congresso, foram publicadas as discussões que nele se travaram.

A grande maioria dos relatórios de cada Estado indicou que a fase pré-processual, também chamada de preliminar (entendida como o período compreendido entre o surgimento da controvérsia no plano material e o início formal do processo - ajuizamento da ação) não tem sido objeto de extensa regulamentação, mas que uma reformulação nesse sentido tem sido buscada. Além disso, embora os ordenamentos dos países analisados não apresentem uma regra geral e detalhada sobre a atuação das partes durante a fase préprocessual, observam-se disposições esparsas a esse respeito.

Mencionou-se estar em curso na Holanda (país de tradição de civil law), uma grande reforma de sua lei processual. Nos relatórios (preliminar - 2003 - e final - 2007) de revisão da lei processual naquele país, as semelhanças com os atos que precederam a reforma inglesa são notáveis: fala-se do até então esquecimento da fase pré-processual e da necessidade de se criarem padrões de comportamento para a relação das partes durante este período. BART KRANS, da Universidade de Groningen, comentando acerca de seu país, afirma:

\begin{abstract}
"A systematic approach to an early exchange of information between the parties is the goal of a proposal in the fundamental review. Following the example of English law, pre-action protocols and offers to settle should be introduced in Dutch law."133
\end{abstract}

Vê-se, aqui, que também a doutrina holandesa entende que esses dois elementos introduzidos pelas CPR - pre-action protocols e offers to settle - são, em conjunto, de grande valia para um sistema de direito processual, especialmente um que confere importância a que as partes tentem se autocompor antes do processo e, se isso não for possível, preparem-se bem para a ação, conhecendo as alegações e provas uma da outra desde cedo.

\footnotetext{
${ }^{133}$ ANDREWS, Neil. The pre-action phase. General Report-Common Law, cit., p. 203, nota de rodapé 10.
} 
O relatório menciona países que adotaram a mediação ou outra forma de ADR como condição precedente à propositura da ação (Província de Ontário, Noruega e Suíça lembrando que neste último costumam participar desta etapa juízes de paz, obtendo índice de acordo bastante elevado). A condição visa a dissuadir autores de ajuizarem demandas fúteis, dissuadir réus de se oporem a demandas bem fundamentadas, reduzir a carga de trabalho que recai sobre os juízes e proteger as partes de uma escalada de custos desnecessária. Entretanto, o sistema de mediação/conciliação obrigatório sugere alguns pontos negativos, tais como o ADR ser prematuro, o mediador ser inadequado ou mal treinado, custos financeiros elevados. Michele LuPOI, da Universidade de Bolonha, aponta essa tendência - o mecanismo das Commissione di Conciliazione é utilizado na Itália, especialmente em questões laborais - com certo pesar, pois sugere que sua mola propulsora não é o desejo genuíno de promover a solução amigável de controvérsias, mas sim aliviar o trabalho dos juízes. ${ }^{134}$ Holanda e Alemanha são contrárias a essa tendência, argumentando não poder haver tal espécie de condição para acesso ao Judiciário.

Através do sistema de Protocolos, explica ANDREWS, a Inglaterra exerce uma pressão indireta para que as partes busquem meios alternativos de solução de conflitos por meio de sanções em relação aos custos, na hipótese de a corte entender que as partes "unreasonably rejected ADR attempts".

Sobre a atitude dos países em relação ao acordo, tem-se que o Brasil abraça ADRs em algumas causas, mas que, em regra, é um país bastante litigioso. Entretanto, afirma PAUlo HenRiQue dos SAntos LuCON (autor do relatório a respeito do Brasil) que “embora a porcentagem de acordos seja baixa, medidas devem ser adotadas para que os juízes não sejam obrigados a decidir um número ainda maior de casos." 135 Indica, inclusive, o Projeto de Lei de Mediação em apreciação no Senado, do qual adiante se tratará brevemente.

A respeito das ofertas de acordo feitas na fase pré-processual, ANDREWs narra a experiência inglesa da Part 36 Offer to Settle e aponta que tal regime existe também na Dinamarca e tem sido recomendado como parte da reforma processual que está sendo empreendida na Holanda.

Em seção a respeito dos Protocolos, aponta sua existência na Inglaterra; aponta, ainda, que o Japão possui um regime pré-ação recente, o Canadá ainda hesita em promover

\footnotetext{
${ }^{134}$ ANDREWS, Neil. The pre-action phase. General Report-Common Law, cit., p. 210, nota de rodapé 44. ${ }^{135}$ ANDREWS, Neil. The pre-action phase. General Report-Common Law, cit., p. 220, nota de rodapé 88.
} 
alteração legislativa dessa natureza e a Austrália os tem para certos casos, apresentando nesta categoria uma diminuição no volume de ações ingressadas em juízo. Sobre a grande especificidade dos Protocolos ingleses, ANDREws afirma que tem a vantagem de o Protocolo ser confeccionado para atender características peculiares a cada tipo de controvérsia, mas que, ao mesmo tempo, podem gerar uma impressão de confusão e complexidade. $^{136}$

A guisa de conclusão, ANDREWS alerta:

"However, pre-litigation regulation should not become excessively prescriptive: over scrupulous regulation might generate disproportionate costs. Pre-litigation duties should be adjusted according to these criteria: they should be appropriate; such duties must not be too burdensome in terms of effort, time and expense, especially if this will create or exacerbate inequalities between the parties; the pre-litigation regime should complement settlement and ADR apportunities, and not impede them. $" 137$

A parte final do relatório compilado por BART GROEN aponta que se visuliza uma tendência de introduzirem-se procedimentos anteriores à ação, os quais têm dois objetivos: melhor preparação para a ação (se proposta) e oferecimento de possibilidades de acordo, desde cedo e fora do Judiciário. A troca de informações e documentos parece ser um elemento chave na busca por esses objetivos, mesmo que a obrigação seja limitada (dentro da ação e, mais ainda, fora dela). Por fim, assinala que se deve ter em mente que o processo civil não é um mal a ser evitado; ter acesso a uma corte e obter um julgamento suficientemente rápido, perante um juiz imparcial, a custos razoáveis é o exercício mesmo de um dos direitos fundamentais da pessoa. Acredita que estimular a criação de regras sobre novos procedimentos anteriores à açao pode levar à abertura da mente dos litigantes e seus advogados em prol de uma cultura de cooperação e auto-composição. ${ }^{138}$

\footnotetext{
${ }^{136}$ ANDREWS, Neil. The pre-action phase. General Report-Common Law, cit., p. 237 e 240.

${ }^{137}$ ANDREWS, Neil. The pre-action phase. General Report-Common Law, cit., p. 240-241.

${ }^{138}$ GROEN, Bart. New trends in pre-action. General Report Civil Law. In: GRINOVER, Ada Pellegrini; CALMON FILHO, Petrônio (Orgs.). DIREITO PROCESSUAL COMPARADO. CONGRESSO MUNDIAL DE DIREITO PROCESSUAL, cit.
} 


\section{INICIATIVAS BRASILEIRAS PARA PROMOVER O ACORDO}

Diversas são as evidências de que no Brasil se tem buscado uma cultura de acordo. A seguir são ressaltadas apenas algumas delas.

A inauguração dos Juizados de Pequenas Causas, em 1984, foi a primeira dessas iniciativas. Quase uma década mais tarde, a edição da Lei 9.099/95, que implantou os Juizados Especiais Cíveis e Criminais, foi também fruto da percepção de que o Estado deveria oferecer às partes a oportunidade de dialogar, especialmente em se tratando de conflitos de pouca expressão econômica. Já seu artigo $2^{\circ}$ prescrevia que se deveria buscar, sempre que possível, a conciliação ou a transação.

A entrada em vigor da Lei 9.307/96 - Lei da Arbitragem - trouxe meios mais efetivos a reforçar a percepção de que o Judiciário não era a única e, muitas vezes não era nem mesmo a melhor alternativa para solucionar determinados conflitos ${ }^{139}$. Ainda, conferir à sentença arbitral a qualidade de título executivo judicial demonstra a vontade de se imprimir eficácia ao instituto.

O Código de Processo Civil tem diversos dispositivos que incentivam a conciliação. Por exemplo, o art. 125 diz que competirá ao juiz, a qualquer tempo, tentar conciliar as partes.

Existe desde 2002 o Setor de Conciliação de Segunda Instância, e desde 2004, a implementação de Setores de Conciliação em São Paulo e nas comarcas do interior do Estado, baseadas nos Provimentos do Tribunal de Justiça de São Paulo.

A elaboração do texto do Projeto de Lei de Mediação (PL 4.827/98) pela Deputada Zulaiê Cobra, aprovado no Senado Federal com o substitutivo do Senador Pedro Simon ${ }^{140}$ e ora em trâmite na Câmara dos Deputados, é outra evidência desse movimento. ${ }^{141}$

\footnotetext{
${ }^{139}$ Como se sabe, a arbitragem não surgiu com a Lei 9.307/96; a arbitragem já estava presente no Código Civil de 1916 ao tratar do compromisso arbitral no Art. 1.037 e seguintes.

${ }^{140}$ Porque longa e bastante cheia de peculiaridades e, ainda, por não ser a mediação, ou mesmo os ADRs, o objeto deste trabalho, os detalhes deste projeto não são aqui relatados. Entretanto, vale indicar algumas das suas características: o termo lavrado após o acordo obtido em razão da mediação será considerado título executivo extra-judicial (Art. $7^{\circ}$ ) e, uma vez homologado pelo juiz, terá eficácia de título executivo judicial $\left(\right.$ Art. $8^{\circ}$ ). A mediação poderá ser anterior ao processo, seu requerimento interrompe a prescrição e o processo de mediação deverá desenrolar-se por não mais de 90 dias (Art. 29). A mediação será chamada de "judicial" quando realizada por advogados com pelo menos 3 anos de efetivo exercício de atividades jurídicas capacitados, selecionados e inscritos no Registro de Mediadores, na forma da lei.

141، Por derradeiro, incumbe alertar a existência de uma revolução silenciosa em curso no país, em prol da pacificação da sociedade brasileira, onde a mediação ocupa destaque. Cada vez mais se tem notícia da
} 
Ademais, mencione-se também a Semana da Conciliação promovida pelo Conselho Nacional de Justiça em dezembro de 2006, 2007, 2008 e 2009, como parte do movimento "Conciliar é Legal"142.

\subsection{Objeções à cultura do acordo}

Agora, após demonstrar-se quão ansiosa por promover o acordo tem se mostrado a comunidade jurídica brasileira, interessante trazer o contra-ponto desse fervor, colocado em célebre texto de OWEN FISS intitulado "Contra o Acordo".

Nele, FISS coloca alguns problemas, segundo ele frequentemente vistos em casos em que são realizados acordos: (i) distribuição desigual de riquezas entre os litigantes, (ii) dificuldade de criar um consenso legítimo, (iii) necessidade de a corte continuar supervisionando as partes após o julgamento, (iv) necessidade social de interpretação legítima do direito.

Sobre o primeiro problema, FISS diz que a disparidade de recursos pode influenciar o acordo de três formas: a parte mais pobre pode não conseguir reunir e analisar informações a contento; pode precisar imediatamente dos valores em questão, dispondo-se a ceder diante da demora que um processo judicial representaria; ou pode ser levada a celebrar um acordo em razão de não ter meios para financiar um processo judicial. $\mathrm{O}$ autor entende que arranjos como "contingent fees agreement" (em que o advogado recebe pelo

implementação de iniciativas que incluem o instituto, provenientes tanto de Órgãos Públicos do Poder Judiciário, quanto do Poder Executivo, sem mencionar os já existentes impulsionados pelo setor privado, que é o responsável por torná-la uma realidade dentro de um território onde inexiste um diploma legal específico que a regule." BRAGA NETO, Adolfo. Reflexões sobre a conciliação e a mediação de conflitos. In: SALLES, Carlos Alberto de (Coord.). As grandes transformações do processo civil brasileiro: homenagem ao Professor Kazuo Watanabe. São Paulo: Quartier Latin, 2009. p. 506.

${ }^{142}$ Em texto a respeito da Semana da Conciliação de 2008, intitulado "A Sociedade merece um bom acordo", Andréa Pachá, juíza do TJ-RJ, conselheira do CNJ e presidente da Comissão de Conciliação esclarece o propósito deste movimento: "Criado em agosto de 2006, com o objetivo de alterar a cultura da litigiosidade e promover a busca de soluções para os conflitos mediante a construção de acordos, o movimento conta com a adesão de todo o Judiciário nacional. Durante uma semana, 56 Tribunais realizaram 306 mil audiências de conciliação em todo o país. Nessas audiências $44,3 \%$ dos processos foram solucionados de forma definitiva, evitando o congestionamento do sistema e impedindo frustrações para as partes envolvidas. Os valores acordados chegaram à cifra aproximada de R \$ 1 bilhão.” Ainda, sobre as matérias em que a conciliação parece um instrumento bastante adequado, diz a autora: "Nos países onde a cultura da conciliação é assimilada, o índice de acordos chega a 70\%. No Brasil, esse número ainda beira os 30\%, mas já se pode observar algum avanço. Processos de família, sistema habitacional, desapropriações, previdência, despejos, são algumas das matérias onde a conciliação tem se mostrado uma via satisfatória de solução de conflitos." Não se pode citar o número da página da qual foi extraído o trecho acima transcrito pois o texto, encontrado na internet, não apresenta número de páginas. 
êxito) e assistência jurídica, que são limitados e cuja obtenção não é sem obstáculos, não igualam as bases. Segundo ele, o juiz tem papel relevante na diminuição das diferenças de poder entre as partes, quando, por exemplo, complementa as exposições que fazem por meio de perguntas, chama suas próprias testemunhas, etc. A diminuição das desigualdades pode não ser expressiva, mas não por isso deve ser ignorada, diz ele. ${ }^{143}$

Quanto à ausência de consentimento legítimo, FISS levanta o fato de que muitas vezes quem faz o acordo não é o interessado diretamente, mas pessoas que têm interesses próprios no desfecho do litígio, como a seguradora, ou o advogado, ou o presidente da empresa, os quais podem conflitar com os interesses do autor/réu. Cita, por exemplo, o caso das class actions, em que grupos sem estrutura formal são representados, faltandolhes procedimentos para a criação de um consentimento legítimo. Os representantes do grupo, na maioria das vezes, são auto-indicados, e suas alegações não são testadas pelo juiz; são tomadas pura e simplesmente conforme feitas pelo representante.

No tocante à supervisão continuada pela corte, FISS cita o exemplo de ações de natureza concorrencial, em que o monitoramento do cumprimento do acordo é essencial. Muitas vezes, diz FISS, o acordo deriva da vontade de evitar a instrução probatória do caso (o que não é a situação quando se fala na adoção de um regime de protocolos).

Em relação ao último problema aventado, FISS entende que a jurisdição utiliza recursos públicos e emprega agentes públicos, cujo trabalho não é maximizar os interesses dos particulares, mas fazer valer as leis e a Constituição, atividade que não é desempenhada quando as partes celebram um acordo. Além disso, o acordo priva as cortes da oportunidade de "dizer o direito", de fornecer uma interpretação dos textos legais, o que entende ser prejudicial à sociedade.

E conclui: “Ser contra o acordo não é exigir que as partes sejam 'forçadas' a litigar. (...) Ser contra o acordo é apenas sugerir que quando as partes celebram um acordo a sociedade obtém menos do que parece, por um preço que não sabe que está pagando. (...) Celebrar um acordo significa aceitar menos do que o ideal". ${ }^{144}$

Após um breve apanhado dos argumentos levantados por OWEN FISS, algumas observações podem ser feitas.

\footnotetext{
${ }^{143}$ FISS, Owen. Contra o acordo. In: ___. Um novo processo civil: estudos norte-americanos sobre jurisdição, constituição e sociedade. Coordenação da tradução de Carlos Alberto de Salles; Trad. Daniel Porto Godinho da Silva, Melina de Medeiros Rós. São Paulo: Ed. Revista dos Tribunais, 2004. p. 124.

${ }^{144}$ FISS, Owen. Contra o acordo, cit., p. 140.
} 
Conforme se disse no início deste trabalho, independentemente de quão bem aparelhado esteja o Judiciário, há questões que podem perfeitamente ser bem resolvidas pelas partes e quanto a essas, deve, sim, haver um esforço para que se obtenha a autocomposição.

Quanto à desigual distribuição de recursos que é "amenizada pelo juiz", diga-se que, se as partes tiverem um guia a respeito das informações que devem fornecer uma à outra e o fizerem de forma eficiente (o que é o intuito dos protocolos), o tempo e o dispêndio para "reunir e analisar informações a contento" é minimizado. Quanto a precisar-se imediatamente dos valores em questão, dispondo-se a ceder diante da demora que um processo judicial representaria, se a parte realmente precisasse imediatamente de valores, esperar a decisão judicial não lhe seria nenhuma vantagem.

Sobre a ausência de consentimento legítimo (exceto pelo exemplo das class actions, que de fato é peculiar), a lei e arranjos particulares conferem a determinadas pessoas o poder de representação de outras, tanto para fazer acordos, como para firmar contratos que não digam respeito a controvérsias, mas sim sejam fruto do dia-a-dia das empresas. Não se pode pretender que, para firmar acordos em litígios existentes ou potenciais, essa representação não seja apropriada.

No tocante à necessidade de acompanhamento dos termos e cumprimento do acordo, é verdade que em alguns casos a figura coercitiva do juiz é bem-vinda, mas cabe aos interessados avaliar em que momentos tal acompanhamento é necessário e, assim, que casos merecem ou não ser objeto de acordo.

Sobre seu último ponto, i.e., o de que o acordo impede que a corte "diga o direito", tem-se que para questões de direito, a jurisdição pode até ser o caminho preferível, enquanto que para questões de fato, o dizer da corte não é igualmente significativo. É importante que haja pronunciamentos judiciais sobre as controvérsias, pois do contrário as partes nem mesmo saberiam em que sentido projetar o convencimento do juiz para decidirem por celebrar um acordo com esta ou aquela feição. Mas caberá às partes avaliar se a questão é "velha" e a projeção da convicção do juiz é possível ou, se não, se é melhor esperar que o Judiciário pronuncie-se.

Os argumentos de FISS são interessantes e muitas vezes os problemas por ele aventados devem ser a causa de acordos cujo custo social seja maior do que o que se faz transparecer em um primeiro momento. Acredita-se, contudo, que um mecanismo segundo 
o qual as partes tenham amplos conhecimentos sobre o caso uma da outra possibilite acordos mais justos ou, pelo menos, acordos cujos riscos possam ser mais bem avaliados.

Outra questão que se coloca quando se fala em promover a evolução da "cultura da sentença" para a "cultura da paz", expressão cunhada pelo Professor KAZUO WATANABE $^{145}$, é a de se impulsionar as iniciativas que prescindem do Judiciário como forma de enfrentar a crise por que este passa.

Mas, pergunta-se: a busca de métodos alternativos de solução de controvérsias destina-se apenas a aliviar a carga de trabalho dos juízes, em vez de melhorar o Judiciário, ou decorreria da percepção de que existem tipos de controvérsias que podem, com alguma facilidade e boa vontade (movida, obviamente, a incentivos econômicos) resolver-se sem a intervenção estatal? Ainda que a primeira possa ser a motivação de muitos dos que se empenham em promover ADRs, a motivação do presente trabalho é a segunda alternativa e tem como efeito colateral (e positivo) aliviar a carga de trabalho que pesa sobre o Judiciário, até para que os recursos de que dispõe sejam destinados às causas que de fato deles precisam. Assim, abre-se espaço nos cartórios, nas mesas e na agenda dos juízes, para ações que os demandem. Essa parece ser uma forma de promover o acesso à justiça, não de limitá-lo.

A mesma impressão é compartilhada por outros juristas.

Ao falar da mediação ${ }^{146}$, ANTÔNIO RoDRIGUES DE FREITAS JR. disse:

“(...) realço desde já que não penso o processo de mediação (...) como terapêutica devotada ao enfrentamento da presente crise do Judiciário; sabidamente grave e preocupante no Brasil como em muitos outros países."

Reconhecendo que a mediação possa trazer efeitos benéficos na atuação do Judiciário, continua:

"Isso não autoriza, nem sequer justifica o vezo, de certa desidiosa e indefensável política do Judiciário, de preconizar a mediação como um instrumento destinado à redução do problema da oferta pela constrição da demanda. E assim sustento por ao menos quatro principais motivos: 1. Óbvias restrições éticas; 2. Discutível impacto; 3. Imprescindibilidade

\footnotetext{
${ }^{145}$ WATANABE, Kazuo, Cultura da sentença e cultura da pacificação. In: YARSHELL, Flávio Luiz; MORAES, Maurício Zanóide de. Estudos em homenagem à professora Ada Pellegini Grinover. 1. ed. São Paulo: DPJ Ed., 2005.

${ }^{146} \mathrm{O}$ presente trabalho não trata da mediação, mas a ela é importante fazer referência em determinados momentos, na medida em que ela constitui um dos meios de promoção do acordo entre as partes e incentivos ao acordo é, propriamente, o objeto deste estudo.
} 
de Estado e de Judiciário fortes e ágeis, como condição necessária à própria alternativa da mediação; e 4. Mas não menos importante, porque se algum benefício trouxesse à agilidade do Judiciário (induvidosamente grave fator de injustiça), nenhum ganho traria à promoção da justiça, vista na acepção de acesso à fruição do bem da vida e de pacificação das relações intersubjetivas." ${ }^{147}$

Entretanto, não há como negar que aliviar o Judiciário é algo que está por trás de uma série de reformas que se vem fazendo no Brasil, haja vista a sistemática de recursos repetitivos, de repercussão geral, de improcedência de ações iguais antes mesmo da citação do réu. É certo que várias dessas mudanças também têm o condão de conferir uniformidade às decisões judiciais, mas o desafogamento do Judiciário, inclusive para poder julgar o que lhe resta com mais acuidade, é um objetivo que se tem perseguido. Em outros países, a intenção não é diferente: em 1996, ao implantar-se a Lei de Mediação na Argentina (na qual a tentativa de mediação, antes de que se instaure a ação, é obrigatória), objetivou-se "descongestionar la carga que hoy tiene la Justicia Nacional". ${ }^{148} \mathrm{O}$ mesmo objetivo consta da "Exposição de Motivos do Projeto de Lei Consensual, conforme substitutivo apresentado pelo senador Pedro Simon (PL 94/03), onde se escreveu sobre a transformação da cultura de litígio em cultura de pacificação através da mediação: "único caminho a ser perseguido para uma verdadeira reforma da política judiciária em nosso país, sem a qual - apesar de todos os esforços de simplificação do processo - não se chegará jamais a desafogar os tribunais."

BARBOSA MOREIRA ${ }^{149}$ aponta que ADRs não são solução pra tudo, que a assistência judiciária é indisponível em ADR e que grande carga dos processos da atualidade versa sobre direitos indisponíveis. Além disso, diz que, frequentemente, mudanças legislativas não resolvem o problema.

De fato, o mestre tem razão em todos os seus pontos. Entretanto, isso não afasta os benefícios da ADR ou dos protocolos. Existe, com efeito, uma parte relevante dos processos que versam sobre direitos indisponíveis; entretanto, existe parte substancial que

\footnotetext{
${ }^{147}$ FREITAS JR. Antônio Rodrigues de. Conflitos de justiça e limites da mediação para a difusão da cultura da paz. In: SALLES, Carlos Alberto de (Coord.). As grandes transformações do processo civil brasileiro: homenagem ao Professor Kazuo Watanabe, cit., p. 510.

${ }^{148}$ DIAS, José Carlos de Mello. A mediação vista como forma de pacificação de conflitos. In: SALLES, Carlos Alberto de (Coord.). As grandes transformações do processo civil brasileiro: homenagem ao Professor Kazuo Watanabe, cit., p. 570.

${ }^{149}$ BARBOSA MOREIRA, José Carlos. O problema da duração dos processos: premissas para uma discussão séria. In: SERRANO MIGALLON, Fernando. Estúdios jurídicos em homenaje a Cipriano Gómez Lara. 1. ed. México: Porrua, 2007. p. 73.
} 
versa sobre direitos disponíveis e sobre essa parte a autocomposição poderia ser tentada. É certo, também, que nem sempre é possível obter a autocomposição, seja porque as partes tem rixa tamanha que a aproximação entre elas é impensável, seja porque a questão é de tal forma complexa que demanda a intervenção de alguém mais abalizado, onde entraria, por exemplo, a arbitragem; seja porque as partes desejam uma solução imperativa, etc. É certo, contudo, que existe uma gama considerável de questões e de sujeitos que se inclinariam a aproximarem-se e a tentarem, por si sós, uma solução para a controvérsia que se coloca entre eles. A necessidade de comunicação entre as partes é comumente subestimada.

Em relação à inexistência de assistência judiciária quando se está fora do âmbito do processo - a letra da Lei n. 1.060/1950, que disciplina a assistência judiciária, usa, em seu art. $1^{\circ}$, a locução "que necessitarem recorrer à Justiça penal, civil, militar ou do trabalho", donde não ser possível obter assistência judiciária fora do Judiciário -, é elemento que precisa ser considerado com cuidado. Diferentemente do que ocorre na ação judicial, onde a atuação do advogado é mandatória (exceto para as causas de até 20 salários mínimos em curso perante os Juizados Especiais Cíveis, para as quais a assistência é facultativa, a menos que o adversário esteja representado por advogado), os métodos alternativos de resolução de controvérsias podem ser levados adiante pela própria parte, embora se entenda que o patrocínio de advogado possa ser muitas vezes relevante e, assim, recomendável.

Por fim, quanto ao argumento de que mudanças legislativas não resolvem o problema, não se pode considerar a afirmação de forma absoluta. Muitas mudanças tornam-se letra morta, algumas não têm o alcance que se desejaria, outras têm, sim, o mérito de promover transformações, principalmente quando estabelecem consequiências para o descumprimento de um padrão de conduta imposto, monitora-se a conduta e as conseqüências são de fato feitas sentir. Esta é a única forma de a mudança se operar, quando a mudança dependa de lei.

JosÉ IGNÁCIO BotelHo DE MESQUiTA também teceu críticas à conciliação e à transação. Segundo ele, “o juiz passa a agir como amigo de ambas [as partes], em lugar de atuar como órgão da jurisdição. Configura administração pública de interesses privados, que qualifica a função como sendo de jurisdição voluntária, administriva ou graciosa. $\mathrm{O}$ 
Estado se abstém de definir a norma aplicável a atuá-la no caso concreto, subtraindo-se ao dever de prestar a jurisdição"150.

E continua:

\begin{abstract}
"Essa forma de extinção do processo pode, em certos casos, ter suas vantagens. Preferi-la, porém, emprestando-lhe valor maior do que à solução do conflito mediante sentença, pode ter para as partes, e a meu ver tem, um custo institucional muito alto, porque transfere para elas a responsabilidade pela solução do litígio." (...) "A expectativa da parte que se julga lesada pela outra é a de que, recorrendo ao juiz, o Estado lhe dará razão, confirmando sua confiança no império do direito e, reforçando na parte contrária a consciência da responsabilidade pelo cumprimento das próprias obrigações. Essa expectativa se frustra ao ver a parte que o juiz, sem lhe negar razão, insta a que ela abra mão de parte do seu direito em favor daquele que nenhum direito tem. A preferência estatal pela conciliação constitui um fator de enfraquecimento do direito, enquanto método para a solução dos conflitos intersubjetivos, porque abala a confiança no império da lei. Torna desconfiados os homens simples e mais confiados os aventureiros."
\end{abstract}

"A certeza de que os processos demoram um tempo enorme e de que, por isso mesmo, os juizes, conciliadores, mediadores e árbitros tudo farão para que se encerrem por autocomposição do litígio, aliada à incerteza sobre se o juiz decidirá segundo a lei e não pela ideologia de sua preferência, constitui um poderoso estímulo ao descumprimento das obrigações e, portanto, à criação de litígios que, não fora isso, maiores seriam as probabilidades de adesão espontânea ao império da lei." ${ }^{152}$

BOTELHO DE MESQUiTA parece dirigir suas críticas eminentemente às inúmeras tentativas de promoção da conciliação pelo juiz, que se subtrai à solução do litígio. Um sistema de protocolos, contudo, não deseja ou necessita do juiz e dá-se antes do recurso a ele. Cabe às partes e apenas a elas a tentativa de autocomposição.

Dessa forma, entende-se que os méritos dos protocolos não estão em forçar o acordo, mas sim em dar elementos às partes para avaliarem a oferta e a aceitação dela, de modo que a decisão seja informada. Assim sendo, as críticas de BOTELHO DE MESQUITA não se dirigiriam a um sistema como o aqui proposto.

\footnotetext{
${ }^{150}$ BOTELHO DE MESQUITA, José Ignácio. As novas tendências do direito processual: uma contribuição para seu reexame. Revista Forense, Rio de Janeiro, v. 98, n. 361, p. 62, maio/jun. 2002.

${ }^{151}$ BOTELHO DE MESQUITA, José Ignácio. As novas tendências do direito processual: uma contribuição para seu reexame, cit., p. 62.

${ }^{152}$ BOTELHO DE MESQUITA, José Ignácio. As novas tendências do direito processual: uma contribuição para seu reexame, cit., p. 66.
} 


\section{NATUREZA DO PROTOCOLO}

Qual exatamente a natureza do protocolo? Condição da ação, pressuposto de constituição e desenvolvimento válido do processo, dever ou ônus?

Subscritores da teoria de LiEBMAN, que distingue entre condições da ação, pressupostos processuais e mérito, BOTELHO DE MESQUITA et al. descrevem fenômeno que se tem verificado na doutrina brasileira a respeito do "esmaecimento da separação entre condições da ação e mérito da causa" ${ }^{\text {153 }}$, pondo em crise sua autonomia frente ao direito material e minando a teoria de LIEBMAN. Tal esmaecimento poderia até mesmo conduzir alguém a sustentar que se nem mesmo as condições da ação atuais se sustentam, posto que prefere-se o julgamento do mérito, o que se dizer da criação de mais uma condição da ação?

Com o objetivo de trazer um pouco de luz ao "buraco negro", como dizem, Botelho DE MESQuita et all. empreenderam esforço bem sucedido no sentido de "isolar conceitualmente, do mérito da causa, as condições da ação" ${ }^{\text {,154 }}$, devolvendo-lhes a importância que lhes é peculiar e a clareza que lhes é necessária para que desempenhem o papel a elas atribuído $^{155}$. Dessa clareza, tem-se a retomada da ordenação em termos de modo de extinção do processo e de revestimento da decisão que o extingue pela coisa julgada.

As condições da ação são, pois, exigências para que a parte tenha o direito de ação, o direito de vir ao Poder Judiciário e de obter uma sentença de mérito, não constituindo obstáculos ao acesso ao Poder Judiciário. Entretanto, poderiam vir a sê-lo no caso de haver excessos na sua fixação. Hoje, por exemplo, tem legitimidade para postular em juízo aquele que se diz titular do direito material ofendido (exceto as hipóteses legais de legitimação extraordinária); nada mais natural e essencial à organização da vida das pessoas, pois do contrário instalar-se-ia o caos.

À primeira vista, um sistema de protocolos poderia ser tomado como uma condição da ação, i.e., algo que deve ser cumprido para que, somente então, a parte possa dizer-se

\footnotetext{
${ }^{153}$ BOTELHO DE MESQUITA, José Ignácio et al. O colapso das condições da ação? Um breve ensaio sobre os efeitos da carência de ação. Revista do Advogado, São Paulo, v. 26, n. 88, p. 110, nov. 2006.

${ }^{154}$ BOTELHO DE MESQUITA, José Ignácio et al. O colapso das condições da ação? Um breve ensaio sobre os efeitos da carência de ação, cit., p. 118.

${ }^{155}$ Segundo os autores, as condições da ação (legitimidade ad causam, possibilidade jurídica do pedido e interesse de agir, conforme divisão adotada pelo CPC) dizem respeito ao pedido isoladamente considerado, e não à relação existente entre pedido e causa de pedir, sendo a esta relação o mérito da causa.
} 
titular do direito de ação. Contudo, um instituto não se relaciona com o outro. Com efeito, as dimensões parecem tão distantes que até a comparação (para posterior rejeição) fica prejudicada. A ação que existia antes do protocolo continua a existir do mesmo modo depois de ter o protocolo sido rejeitado.

O mesmo se dá com os pressupostos processuais de constituição e desenvolvimento válido do processo.

Com efeito, a ação será julgada procedente ou improcedente, o processo pode ser tido por válido ou inválido, eficaz ou ineficaz, sem que isso seja influenciado pelo cumprimento ou não dos protocolos. Seu não cumprimento apenas sujeitará as partes a consequiências desfavoráveis.

Há inúmeros requisitos para que uma ação seja proposta e para que o processo possa se desenvolver eficaz e validamente, de que são exemplos as condições da ação e os pressupostos processuais de constituição e desenvolvimento válido do processo, quanto aos quais não se ousa dizer que são óbices ao acesso à justiça. Diz-se, sim, que são filtros ou técnicas importantes para seu manejo ${ }^{156}$.

Também o cumprimento de protocolos não representaria obstáculo ao acesso ao Poder Judiciário, mas sim um procedimento prévio que teria como razão subjacente possibilitar que as partes se aproximassem e cooperassem, sem a necessidade de intervenção do Estado.

Algo que poderia ser tido como semelhante aos protocolos surgiu no ramo do direito do trabalho, a propósito da criação do requisito de que as partes da relação trabalhista sejam previamente submetidas a uma tentativa de conciliação antes de que se instaure a ação judicial, conforme artigo $625-\mathrm{D}$, introduzido na $\mathrm{CLT}^{157}$. Cogitou-se, então, conforme afirmou Octavio Bueno Magano, que os procedimentos prévios de

\footnotetext{
${ }^{156}$ No mesmo sentido, SALLES, Carlos Alberto de. Mecanismos alternativos de solução de controvérsias e acesso à justiça: a inafastabilidade da tutela jurisdicional recolocada. In: FUX, Luiz; NERY JR., Nelson; WAMBIER, Teresa Arruda Alvim (Coord.). Processo e Constituição: estudos em homenagem ao professor José Carlos Barbosa Moreira. São Paulo: Ed. Revista dos Tribunais, 2006. p. 782.

${ }^{157}$ Art. 625 - D - Qualquer demanda de natureza trabalhista será submetida à Comissão de Conciliação Prévia se, na localidade da prestação de serviços, houver sido instituída a Comissão no âmbito da empresa ou do sindicato da categoria.

(...)

$\S 2^{\circ}$ - Não prosperando a conciliação, será fornecida ao empregado e ao empregador declaração da tentativa conciliatória frustrada com a descrição de seu objeto, firmada pelos membros da Comissão, que deverá ser juntada à eventual reclamação trabalhista.

$\$ 3^{\circ}$ - Em caso de motivo relevante que impossibilite a observância do procedimento previsto no caput deste artigo, será a circunstância declarada na petição inicial da ação intentada perante a Justiça do Trabalho.
} 
conciliação figurariam "como condição para o exercício da ação judicial","158, implicando verdadeiro óbice para o acesso ao Poder Judiciário, donde sua inconstitucionalidade.

A idéia de classificar a passagem pela comissão prévia de conciliação como uma condição da ação ou pressuposto processual foi rechaçada pelo Tribunal Regional do Trabalho da $2^{\mathrm{a}}$ Região ao editar a Súmula n. 2: "Comissão de conciliação prévia. Extinção de processo (RA n. 08/2002-
DJE 12.11.2002, 19.11.2002, 10.12.2002 e 13.12.2002). O
comparecimento perante a Comissão de Conciliação Prévia é uma
faculdade assegurada ao obreiro, objetivando a obtenção de um título
executivo extrajudicial, conforme previsto pelo artigo 625-E, parágrafo
único, da CLT, mas não constitui condição da ação, nem tampouco
pressuposto processual na reclamatória trabalhista, diante do comando
emergente do artigo $5^{\circ}$, XXXV, da Constituição Federal."159 (destaques
da transcrição)

Também contrário à idéia de condição da ação ou pressuposto processual manifestou-se IVES GANDRA DA SILVA MARTINS, para quem não há que se falar em óbice ao acesso ao Judiciário, na medida em que a comissão de conciliação é apenas uma instância prévia conciliatória ${ }^{160}$.

Recentemente, o Tribunal Superior do Trabalho exarou acórdão onde decidiu não ser obrigatória a passagem pelas Comissões de Conciliação Prévia. O fundamento do acórdão, ainda que velado, parece ser a inconstitucionalidade de entender-se diferentemente, dado que feriria a garantia de acesso ao Judiciário ${ }^{161}$.

Vê-se, pois, que a idéia de condicionar o ingresso no Judiciário à passagem por uma instância prévia de conciliação foi afinal recusada. Frise-se, aqui, que jamais essa seria a sistemática a ser implantada caso seja, no Brasil, adotado um sistema de protocolos. Seja dever ou seja ônus da parte cumpri-lo, não cumpri-lo jamais poderia implicar a impossibilidade de ingressar em juízo; a sanção ou a conseqüência desfavorável que sofreria deverá ser outra.

BEDAQUE, ao discorrer sobre técnicas adotadas na fase preliminar ao processo (a que se poderia chamar de instância prévia ou pré-processual), faz uma observação:

\footnotetext{
${ }^{158}$ MAGANO, Octavio Bueno. Legislação e autocomposição. Revista do Tribunal Regional do Trabalho da Oitava Região, Belém, n. 70, p. 154, jan./jun./2003.

${ }^{159}$ TARTUCE, Fernanda. Mediação nos conflitos civis. São Paulo: Método, 2008. p. 144, nota 52.

${ }^{160}$ MARTINS FILHO, Ives Gandra. A justiça do trabalho do ano 2000: as Leis ns. 9.756/1998, 9.957 e 9.958/2000, a Emenda Constitucional n. 24/1999 e a reforma do Judiciário. Revista LTr, São Paulo, v. 64, n. 2, p. 164, fev. 2000.

${ }^{161}$ E-ED-RR 349/2004-241-02-00.4, SDI-1, TST, julgado em julho de 2009.
} 
"o sistema constitucional brasileiro impede a adoção, pelo legislador ordinário, de qualquer medida extrajudicial prévia, de natureza obrigatória. A garantia de acesso à justiça é ampla e irrestrita (CF, art. $5^{\circ}$, inciso XXXV). Existe uma única exceção, aceita porque prevista na própria constituição. Trata-se dos conflitos sobre disciplina e competições desportivas, para os quais existe tribunal administrativo, cuja decisão antecede obrigatoriamente a via judicial (CF, art. 217, par. $\left.1^{\circ}\right) . " 162$

Algumas ponderações sobre as palavras de BEDAQUE são, contudo, de rigor, pois colocadas fora de contexto levam o leitor a conclusões equivocadas.

Primeiramente, não se pode falar, em termos absolutos, em proibição da obrigatoriedade de "qualquer medida extrajudicial prévia" por ferir a garantia constitucional de inafastabilidade do Poder Judiciário, de acesso à Justiça. Tem-se exemplo de medidas extrajudiciais prévias e obrigatórias na notificação do promitente comprador para que purgue a mora antes que se possa propor a ação de adjudicação compulsória do imóvel $^{163}$, e quanto à sua constituicionalidade não há dúvidas.

O contexto em que BEDAQUE proferiu essas palavras era peculiar. Tratava-se de determinado painel do Congresso Internacional de Direito Processual, comentado à exaustão em Capítulo precedente, onde se falava da possibilidade de se instituir procedimento preliminar, pré-processual, para o que disse, ao final, que o Brasil estaria preparado, que não afrontaria nossas instituições. Recusava-se, contudo, a aceitar que tal procedimento fosse obrigatório, no sentido de impedir a parte que não o cumprisse de socorrer-se imediatamente do Judiciário, o que é perfeitamente adequado ao que se propõe neste trabalho.

Já eliminada a possibilidade de inserir-se os protocolos na mesma categoria das condições da ação ou dos pressupostos processuais, passa-se ao exame de outras possibilidades.

\footnotetext{
${ }^{162}$ BEDAQUE, José Roberto dos Santos. Novas tendências em matéria de fase preliminar, cit., p. 258.

${ }^{163}$ Maiores detalhes na nota supra.
} 


\title{
4.1. Dever e ônus
}

Sobre as situações jurídicas das partes no processo, explica CÂNDIDO RANGEL DINAMARCO:

\begin{abstract}
"Dizem-se passivas as situações jurídicas processuais que impelem o sujeito a um ato (deveres e ônus) ou lhe impõem a aceitação de um ato alheio. Os deveres das partes são situações jurídicas desfavoráveis ao titular, porque lhe limitam a liberdade de atuar ou omitir-se segundo sua própria vontade; a conduta devida é do interesse do adversário ou da Justiça (dever de lealdade etc.) Os ônus situam-se em posição intermédiaria, porque se cumprem no interesse do titular mas sob a ameaça de que, se não forem cumpridos, ele se prejudica (ônus da prova etc.)"164 165
\end{abstract}

São mais freqüentes na marcha processual os ônus do que os deveres, acarretando mais situações vantajosas ou desvantajosas (como o julgamento de procedência ou de improcedência de uma ação) do que ilícitos processuais. Assim é o ônus de propor a ação, de contestar, de provar. Os ônus não são impostos para o bem do outro sujeito, senão do próprio sujeito a quem se dirigem. Seu descumprimento não causa malefícios ou frustra expectativas de outrem.

Já o descumprimento do dever contraria o direito e "é sempre passível de ser sancionado de alguma forma, para que o beneficiário venha afinal a obter o resultado que o cumprimento voluntário e espontâneo teria produzido". ${ }^{166}$ Os deveres existentes ao longo do processo podem ser classificados amplamente como dever de lealdade, do qual decorrem diretamente os deveres de veracidade, de cooperação, etc. São, pois, institutos para a defesa do interesse público no correto e eficiente exercício da jurisdição (o correto exercício da jurisdição é interesse geral do Estado), incorrendo em ilícito aquele que os descumpre.

Para se definir a natureza do protocolo, cabe responder a seguinte questão: a quem pertence o interesse de que o protocolo seja cumprido?

\footnotetext{
${ }^{164}$ É verdade que há hipóteses, especialmente em se tratando de direitos indisponíveis, em que o juiz não se pode contentar com a simples não produção da prova, entendendo, por exemplo, que houve confissão ficta. Entretanto, matéria de direitos indisponíveis não interessa a este trabalho pois sobre elas não versarão os protocolos.

${ }^{165}$ DINAMARCO, Cândido Rangel. Instituições de direito processual civil. São Paulo: Malheiros Ed., 2001. v. 2 , p. 201.

${ }^{166}$ DINAMARCO, Cândido Rangel. Instituições de direito processual civil, cit., p. 204.
} 
O interesse de que seja cumprido o protocolo é das partes que o cumprem: do autor, dando início, do réu, respondendo. Existe, assim, uma transferência do ônus, do autor para o réu e vice-versa ao longo de toda a fase de cumprimento do protocolo: no momento em que um cumpre sua parte, transfere ao outro, imediatamente, o ônus de cumprir a sua.

Entende-se, assim, que cumprir o protocolo seja ônus.

Mas se poderia falar em um ônus que é essencialmente processual antes do ingresso no processo? O ônus é processual porque se for cumprido produzirá efeitos no futuro processo. Contudo, não acarretará efeitos processuais se for descumprido, apenas sujeitando a parte a uma sanção econômica, não processual (a parte não perderá quaisquer de seus direitos processuais).

\subsection{Deveres éticos presentes na fase de cumprimento dos protocolos}

A opção por se entender o cumprimento do protocolo como o desincumbir-se de um ônus não significa que, dentro dele, não possam estar inscritos deveres. Ajuizar a ação e contestá-la são ônus, mas uma vez no processo, as partes têm deveres processuais, deveres importantes para que a jurisdição seja prestada de forma correta e eficiente.

Se os atos das partes antes do processo passarão a ser objeto da apreciação do juiz (na hipótese de a ação ser ajuizada), isso quer dizer que a conduta pré-processo passará a importar (para as partes e para o juiz) e a ser disciplinada (caso as partes nela decidam embarcar) e é importante que assim o seja se uma das pretensas vantagens do protocolo está em que ele gere conseqüências para o processo.

A expansão dos deveres processuais para fora do processo, para fase anterior a ele, demanda também alteração legislativa. Assim, a lei que criar os protocolos deverá prever que os deveres do art. 14, CPC aplicam-se aos protocolos.

O CPC traz diversos deveres, alguns dos quais relevantes para este estudo.

$\mathrm{O}$ art. 14, CPC prevê como deveres das partes e de seus procuradores: (I) expor os fatos em juízo conforme a verdade; (II) proceder com lealdade e boa-fé; (III) não formular pretensões, nem alegar defesa, cientes de que são destituídas de fundamento; (IV) não produzir provas nem praticar atos inúteis ou desnecessários à declaração ou defesa do direito (omite-se, aqui, o inciso V). Mais adiante, o art. 17, CPC trata das correspondentes 
violações aos deveres do art. 14, reputando o infrator litigante de má-fé. A este, o art. 18, CPC comina pena de multa de até $1 \%$ do valor da causa, além de indenização da parte contrária pelos prejuízos que sofreu, mais honorários advocatícios e despesas que efetuou, a qual não deve ser superior a $20 \%$ do valor da causa ou liquidada por arbitramento (art. 18 , par. $\left.2^{\circ}, \mathrm{CPC}\right)$.

Em seguida, no Capítulo intitulado "Das Provas”, o art. 339, CPC traz a seguinte disposição: "Ninguém se exime do dever de colaborar com o Poder Judiciário para o descobrimento da verdade". Além desses dispositivos, existem também aqueles relacionados à exibição de documento ou coisa, seja no curso do processo (arts. 355, CPC e seguintes), seja cautelarmente (art. 844, CPC). Ora, a exibição de documento ou coisa nada mais é que um mecanismo posto à disposição das partes para se fazer prova e potencialmente chegar-se à verdade.

Dizem os ingleses que o processo civil é o mecanismo para descobrir-se a verdade (do que não discorda o ordenamento brasileiro) e é para isso que se servem do processo de disclosure, mais especificamente, de full and frank diclosure, cuja premissa básica é revelar à parte contrária tudo que é relevante para a disputa, inclusive os documentos e informações que sejam prejudiciais às alegações da parte que os revela. Não interessa aqui debater as razões filosóficas e históricas para que o nosso disclosure não tenha alcançado este estágio evolutivo ou mesmo se tal estágio evolutivo é melhor ou pior que o nosso. Entretanto, ainda que o dever não seja "full and frank", ele existe e disso não se pode duvidar.

Assim, além de partidário, portanto, do dever de veracidade, o CPC brasileiro também endossa e promove os deveres de lealdade, de boa-fé processual e de cooperação com o Judiciário para a descoberta da verdade. Se adotado o sistema de protocolos, todos esses deveres devem ser entendidos como vigentes na etapa de cumprimento de tais protocolos, de modo que quem violá-los deverá ser tido como litigante de má-fé.

A litigância de má-fé não é objeto deste estudo, mas algumas palavras sobre o assunto são necessárias. 


\subsubsection{A litigância de má-fé}

Parecem ser de duas ordens as conseqüências que a parte poderá sofrer durante a fase de cumprimento dos protocolos:

A primeira delas será a consequiência desfavorável (uma multa, da qual se tratará no item 6.2.1, da Parte II) e que, será, essencialmente, o incentivo da parte para iniciar e dar continuidade ao cumprimento do protocolo. Cooperação é a pedra de toque do protocolo. Recusar-se a cooperar significa pouco apreço ao ato mesmo de ir ao Judiciário e aos recursos empregados por este, os quais poderiam ser destinados a causas cuja resolução pelo juiz fosse de fato necessária ou para causas cuja autocomposição houvesse sido genuinamente tentada. Recusar a cooperação deve gerar a conseqüência desfavorável de que se falou acima, variando dentro de uma escala que vai desde a recusa integral à parcial.

A segunda refere-se às penas por litigância de má-fé, caso seu comportamento se inscreva em algum dos incisos do art. 17, CPC (os quais deverão ser aplicáveis aos protocolos, com as devidas adequações). Por fim, entende-se que esse comportamento também é de duas ordens: (i) dentro do protocolo e (ii) no processo, cotejado com o que se obteve na fase de cumprimento dos protocolos.

Para que as consequiências do descumprimento dos deveres do art. 17, CPC também sejam encontradas nos protocolos, será necessário que a lei que o instituir preveja a aplicação, aos protocolos, do art. 17 e 18, CPC, no que couber. Deverá, ainda, haver previsão na lei de que configura litigância de má-fé a propositura de ação ou dedução de defesa ignorando o quanto descoberto (e tido por incontroverso) no protocolo.

A chance de conhecerem melhor a versão uma da outra e de obterem elementos probatórios relevantes, através de um padrão de conduta estipulado (objetivado) pelo protocolo, possibilitando às partes uma melhor avaliação do caso e das chances de êxito, potencializará deveres éticos hoje inscritos no Código de Processo Civil brasileiro. É sabido que não se deve ingressar com ações manifestamente infundadas ou resistir a pretensões manifestamente fundadas. Entretanto, o fato de a parte ter consciência (objetivamente considerada) disso antes do processo deve gerar-lhe uma sanção maior do 
que aquela que sofreria se não tivesse tido elementos que lhe permitissem chegar a essa conclusão $^{167}$.

Para aferir-se a correção ou não da conduta das partes, deve-se divisar com maior clareza os comportamentos potencialmente alternativos de cada uma delas, ou seja, se poderiam, ou não, ter agido de outra forma. O padrão de conduta dado pelo protocolo tornará mais objetiva essa análise. Sabe-se que a parte teve conhecimento de certas informações e fatos (pois o que se trocou na fase dos protocolos será posto diante do juiz). Se o protocolo aconselhava-a a trocar essa ou aquela informação relevante, não o fazia de forma pueril, mas sim para que efetivamente se debruçasse sobre as informações obtidas e as considerasse, valorando-as e agindo de acordo com sua convicção a respeito delas. Permitir um comportamento inconseqüente da parte que, mesmo de posse de informação que lhe dissuade de ingressar em juízo decide fazê-lo, é desrespeitar o intuito do protocolo, desrespeitar a parte que se empenhou em fornecer-lhe informações e desrespeitar o Estado que lhe destinou recursos. É por esse conjunto de motivos que tal atitude da parte não pode passar sem a devida repreensão.

Em interessante estudo sobre a litigância de má-fé, JEAN CARLOS DiAs analisa como a letra do CPC e a jurisprudência estimulam-na. Para ele, o jurisdicionado funciona mediante estímulos econômicos, cujos fatores são (a) o valor da multa, (b) o momento em que deva ser paga, e (c) qual é a recorrência da condenação do jurisdicionado, pelos tribunais, na pena da litigância de má-fé. Tomados esses dados, a parte os põe na balança e avalia o que lhe é mais economicamente atrativo. Considerando os dois primeiros fatores apontados, conclui o autor que "o sistema legal, portanto, como demonstrado, é absolutamente ineficiente e estimula, invariavelmente, a litigância de má-fé"168, posto que

\footnotetext{
${ }^{167}$ Empregando raciocínio semelhante, mas com o objetivo de defender a existência de uma ação de obtenção de prova sem o requisito da urgência, YARSHELL escreve: “(...) parece útil considerar que a insistência no julgamento estatal, mesmo após a obtenção - ou possibilidade de obtenção - de elementos de prova preliminares, pode efetivamente levar a parte a conseqüências mais gravosas. Se assim não ocorrer, corre-se o risco de não haver maior sentido em se empregar tempo e energia na produção preliminar da prova (ainda que não se possa estabelecer um vínculo necessário entre ela e o futuro julgamento). Por outras palavras, a insistência no processo (declaratório) diante da prova produzida de forma antecipada, há que levar ressalvadas as peculiaridades de cada caso - a consequiências que compensem o dispêndio de recursos empregados, pelo Estado ou pelo adversário, na produção antecipada da prova.”, in YARSHELL, Flávio Luiz. Antecipação da prova sem o requisito da urgência, e direito autônomo à prova, cit., p. 80. Mais adiante, afirma: "Embora a má-fé (que não se presume) dependa, obviamente, da consideração de cada caso concreto, ela pode estar associada à propositura de demanda em desacordo com prova de alguma forma produzida antes do processo e por algum meio acessível ao demandante", p. 132. Em outro trecho, afirma que parece haver, ainda calcado no aspecto ético, um "dever da parte de considerar os elementos de prova pré-constituídos e de orientar sua conduta em função desses indicadores.", p. 199.

${ }^{168}$ DIAS, Jean Carlos. Como a legislação processual civil e a jurisprudência brasileira estimulam a litigância de má-fé. Revista Dialética de Direito Processual, São Paulo, n. 75, p. 58, jun. 2009.
} 
a multa é de valor muito baixo e pagável tão-somente ao fim do processo. Quanto ao terceiro fator, analisa acórdãos proferidos pelo STJ em 2008, concluindo que de 10 casos, o STJ manteve a condenação em 7, donde conclui que a "taxa de recorrência" é razoavelmente alta. Entretanto, parece que chegarem ao STJ apenas 10 casos de litigância de má-fé em 2008 seja indicativo de pouca aplicação do instituto da litigância de má-fé.

Disso, tem-se que a litigância de má-fé, tal como hoje configurada e aplicada, é instituto que pouco estimula as partes ao cumprimento de seus deveres éticos. Assim, é importante considerar-se a majoração da multa e a mais constante e uniforme aplicação do instituto como fatores importantes não só para o propósito deste estudo, mas para o processo como um todo.

\subsection{Necessidade de parâmetros para o juiz}

Alguém poderá objetar que essa dinâmica (multa recém-criada, a correr dentro de uma escala, e litigância de má-fé) aumenta excessivamente os poderes discricionários do juiz, o que certamente não é desejável. É por esse motivo que parâmetros devem ser objetivamente definidos. Os protocolos objetivam (no sentido de tornarem objetiva) a decisão do juiz (e das partes ao cumpri-lo), diminuindo-se a margem para discricionariedade.

Entretanto, na hipótese de as partes cumprirem os protocolos e não chegarem a um denominador comum, é importante que os atos empreendidos, isto é, as provas que as produziram, possam ser aproveitados no processo, sob pena de duplicação de esforços, gastos e tempo. Sobre esse aproveitamento, falar-se-á no item 6.1.1 da Parte II.

Também pelo motivo exposto no primeiro parágrafo deste item 4.3, a introdução no Brasil de um Protocolo geral, na linha do que seja hoje a Diretriz Prática do Reino Unido, parece ser adequada como forma de fazer com que a cultura de cooperação se inicie, sendo possível que o real benefício de um sistema de protocolos, no Brasil, apenas ocorra quando protocolos específicos forem criados, o que certamente levará tempo. Protocolos específicos, com roteiros de conduta pré-determinados, propiciam ao juiz parâmetros mais precisos para aferir se a conduta das partes foi ou não conforme ao protocolo atinente à sua espécie de controvérsia. 


\section{PROTOCOLOS: IMPLICAÇÕES DA SUA ADOÇÃO, PANORAMA E ESTRUTURA}

\subsection{Implicações}

Adotar um sistema de protocolos significa assumir duas possibilidades: que as partes irão ou não cooperar. Na medida em que o cumprimento do protocolo é composto de uma série de condutas, existe uma escala de cooperação, a qual vai desde a cooperação completa da parte até a total ausência de cooperação.

Não cooperar pode tomar diversas formas: não oferecer determinada informação ou determinado documento, recusar-se a nomear perito comum, protelar injustificadamente o cumprimento do protocolo, dentre outros. Frise-se que, neste momento, não se está tratando das infrações aos deveres de lealdade e veracidade, por exemplo, pois muito mais do que não cooperação, se estaria diante de autêntico ilícito processual, apenável nos termos dos dispositivos que tratam da litigância de má-fé, conforme anteriormente exposto.

Em regra, a cooperação fará o autor e o réu evitarem a incidência de multa ao final do processo, a qual poderia se somar a ou ser subtraída da condenação. Além disso, cooperar, fornecendo informações e produzindo provas, terá implicações no âmago do processo, caso esse venha a ser instaurado, aproveitando-se provas e informações colhidas durante o protocolo.

\subsection{Direitos disponíveis}

Antes de se adentrar à estrutura do protocolo propriamente dita, algumas palavras sobre os direitos e questões que lhe tocarão são necessárias.

De acordo com o art. 841 do Código Civil de 2002, "só quanto a direitos patrimoniais de caráter privado se permite a transação". Na medida em que a intenção do protocolo é possibilitar a aproximação e, em última análise, o acordo, nada mais razoável do que determinar que os protocolos recairão apenas sobre direitos patrimoniais de caráter privado, ou seja, direitos disponíveis. Some-se a este o argumento de que os direitos 
disponíveis não exigem a presidência do juiz, o monitoramento do Estado. Posto que o protocolo se desenrola sem a presença do juiz, direitos que dela necessitam estão fora de seus âmbito de atuação.

\subsection{Protocolo genérico e específicos}

Os protocolos específicos, como já se viu, destinam-se a aproximar as partes, entre si, de uma controvérsia sobre questões de fato ou de direito. Mas não quaisquer questões, e sim questões recorrentes e que apresentem certa homogeneidade, em que se possa ter, de antemão, idéia suficiente sobre quais as informações e provas que tendem a ser relevantes para seu deslinde. É o caso, por exemplo, da grande maioria das questões que lotam os Juizados Especiais Cíveis, isto é, colisões de veículos, assuntos relacionados ao direito do consumidor, principalmente a serviços de utilidade pública como fornecimento de luz, gás, água, telefone ${ }^{169}$. Essas seriam, certamente, áreas em que protocolos específicos favoreceriam a resolução da controvérsia sem o auxílio do juiz.

Apenas abrindo um pequeno parênteses: poder-se-ia objetar que as partes necessitariam da ajuda de um terceiro para chegarem a um acordo. A resposta a essa objeção seria a seguinte: os protocolos visam a maximizar o conhecimento das partes em relação à controvérsia. Cumprido o protocolo, são livres tanto para fazer um acordo, como para buscar um terceiro que as auxilie, seja ele o juiz ou não.

A tarefa de criar protocolos específicos, como se viu ocorrer na Inglaterra, depende da montagem de grupos de trabalho com profissionais de áreas específicas, cada qual fornecendo elementos da prática para criar um protocolo razoável e que atenda às necessidades verificadas. Este, aliás, é o motivo pelo qual não se busca neste trabalho trazer protocolos prontos, e nem mesmo um esboço deles. Essa é atividade que, se e quando encampada pela comunidade jurídica, deve ser conduzida por profissionais que

\footnotetext{
${ }^{169}$ De acordo com pesquisa empreendida pelo Centro Brasileiro de Estudos e Pesquisas Judiciais - CEBEPEJ em 2006, em parceria com a Secretaria de Reforma do Judiciário do Ministério da Justiça, que radiografou as ações ajuizadas em 2002 perante JECs escolhidos por todo o Brasil, "A principal reclamação levada aos juizados é relativa à relação de consumo. Enquadram-se neste tipo de matéria 37,2\% dos processos analisados. Em seguida, mas com um percentual correspondendo à metade dessas reclamações, aparece acidente de trânsito - 17,5\%. Ações de cobrança respondem por 14,8\% das reclamações. A execução de título extrajudicial representa 9,8\%." In CENTRO BRASILEIRO DE ESTUDOS E PESQUISAS JUDICIAIS - CEBEPEJ, Juizados Especiais Cíveis: estudo. Brasília, 2006. p. 26. Disponível em: $<$ www.cebepej.org.br>.
} 
militam nas áreas do direito a que o protocolo dirá respeito. Muito provavelmente, a OAB seria uma boa candidata a organizar grupos de trabalho com esse fim.

Quanto à recorrência das ações, sabe-se que as estatísticas de que se dispõe em relação ao perfil das ações que entram no Judiciário são parcas. A Resolução n. 15/2008, do Conselho Nacional de Justiça, determinou maiores iniciativas nessa área e, desde então, o Poder Judiciário dos Estados e os Tribunais Federais vêm se movimentando para adotar um sistema com critérios únicos, que permita um levantamento de dados uniforme e consistente. Esse trabalho começou a ser implantado em 2008, mas os resultados ainda não apareceram. Será, sem dúvida, um instrumento importante na avaliação do volume de causas recorrentes e, assim, no direcionamento dos esforços para a confecção de protocolos específicos.

Nos mesmos moldes do que foi feito na Inglaterra, sugerir-se-á aqui a introdução de um protocolo genérico, a se aplicar a todas as controvérsias e, subsidiariamente, àquelas para as quais venham a ser criados protocolos específicos. Ressalte-se, contudo, o entendimento de que os protocolos específicos têm mais a contribuir para a solução da controvérsia de maneira eficiente e produtiva, posto que apresentarão às partes um roteiro de conduta mais preciso, o quanto possível, minimizando as chamadas "fishing expeditions" e maximizando os resultados que poderão ser extraídos de seu cumprimento.

\subsection{Positivação do protocolo}

Qual deverá ser a fonte pela qual os protocolos adentrarão o Direito? Poder-se-ia caracterizar a instituição dos protocolos como matéria de direito processual? Se a resposta for positiva, integrarão as normas que regem o protocolo a categoria das normas processuais e, portanto, deve ele ser positivado mediante lei federal ordinária..

A resposta à pergunta acima deve ser positiva, pois na medida em que as consequiências do cumprimento dos protocolos surtem efeitos no processo, o regramento do protocolo deve também ser entendido como lei processual. 


\subsection{Estrutura}

A seguir, colocam-se as linhas mestras que o protocolo genérico deverá seguir. É lógico que uma alteração dessa magnitude impõe debates com a sociedade, consultas públicas, etc. $\mathrm{O}$ que se segue é apenas uma sugestão do que parece ser o procedimento adequado, lembrando-se, contudo, posicionamento já enunciado em itens precedentes no sentido de que protocolos específicos têm mais a oferecer à solução eficiente de controvérsias do que um protocolo genérico.

Ademais, no tocante ao protocolo genérico, entende-se que não há de ser demasiadamente prescritivo, sob pena de transformar-se em um processo fora do processo.

\section{Carta}

Tão logo uma pessoa física ou jurídica tenha a intenção de contra outra promover uma ação, deverá notificá-la dessa intenção, enviando-lhe uma carta. Nesta carta, o autor (embora seja um potencial autor, aqui se utilizará apenas a expressão 'autor' para designálo) exporá os fatos que embasam o direito que entende ter contra seu interlocutor, tão precisamente quanto possível, oferecendo os elementos probatórios que fundamentam tais alegações e solicitando de seu potencial adversário (que aqui se denominará 'réu') uma tomada de posição a respeito do quanto exposto na carta e demonstrado documentalmente. O autor terá, ainda, o direito de solicitar do réu documentos que se encontrem em seu poder e que sejam importantes para o correto entendimento das questões de fato.

A carta deverá ser enviada pelo correio, por currier, via cartório, enfim, da forma como preferir o autor, desde que seja possível solicitar o aviso de recebimento. Nos casos em que o autor não obtiver meios de encontrar a parte contrária, o protocolo perde significado. Como uma notificação por algo semelhante ao que se encontra na hipótese de citação por edital não é razoável, especialmente porque a intenção do protocolo é aproximar as partes (o que não ocorreria caso se admitisse a notificação por edital), não se haverá de impor qualquer multa ao autor ou ao réu neste caso.

Quanto ao prazo para resposta, entende-se que um paralelo com o prazo para contestar (15 dias) seria pertinente. Entretanto, tendo em vista que os réus têm, em regra, 
ciência do processo muito antes de seu prazo para contestar começar a correr, um prazo de 30 dias contados da data de recebimento da correspondência parece ser suficiente.

É importante que haja prazo estabelecido para a resposta, pois deixar a cargo do autor estipulá-lo ou do réu dizer de quanto tempo necessita, ou optar por expressão como "tempo razoável", demasiadamente aberta, são soluções que tendem a pecar pela imprecisão e pela dificuldade de se avaliar o comportamento das partes, isto é, dificultam o trabalho do juiz ao identificar, objetivamente, se a parte cumpriu ou não o protocolo e podem gerar procrastinação pela parte eventualmente mal-intencionada.

Abre-se um parênteses: a procura por um prazo mais exíguo pretende rebater crítica (que se antevê) no sentido de que o processo já é longo demais, de modo que a adoção dos protocolos apenas faria com que o tempo necessário para que uma parte visse sua pretensão atendida fosse prolongado. Entretanto, há que se visualizar a situação numa perspectiva temporal, i.e., dada a demora da prestação jurisdicional hoje em dia, dedicar algum tempo para observar protocolos é um mal pequeno comparado às vantagens que dali podem advir. Por fim, uma observação é de rigor: fala-se que o processo é longo, ocorre que, salvo melhor juízo, nem o processo, nem os prazos processuais são longos; o que é longo é o tempo que o processo fica parado no Judiciário.

\section{Resposta}

Com a resposta, o réu deve oferecer sua versão dos fatos e todos os documentos que corroboram suas alegações, nos moldes do que faria ao se desemcumbir do ônus de contestar no curso de um processo judicial, podendo, ainda, solicitar documentos de seu adversário, respeitado o disposto abaixo.

\section{Solicitação e apresentação de documentos}

A respeito dos documentos que a parte poderia lhe ter solicitado, as mesmas regras que vigoram para a exibição de documento no atual Código de Processo Civil deverão ser observadas, tudo isso, obviamente, mediante a devida positivação. O protocolo há, pois, que espelhar tais regras, observando-se prazos. ${ }^{170}$

\footnotetext{
${ }^{170}$ No processo inglês, as partes têm obrigações extensas de disclosure, ou seja, de dar notícia da existência e exibir uma à outra tudo que pode ser relevante para a solução da disputa, inclusive aquilo que possa afetar
} 


\section{Prova pericial}

No caso de se concluir pela necessidade da prova pericial, a parte interessada na produção da prova deverá oferecer à parte contrária uma lista com 3 profissionais com expertise na área técnica em questão, vinculados a instituição de renome ou escolhidos dentre os peritos que normalmente atuam em juízo, disponibilizados conforme lista oferecida pelo Poder Judiciário ${ }^{171}$. Ao enviar os nomes dos peritos sugeridos, a parte interessada deverá anexar o currículo de cada um deles, acadêmico e profissional, o que será fornecido à parte pelo perito.

O adversário terá, então, a oportunidade de escolher um dos peritos sugeridos, ao que a parte que os sugeriu não poderá se opor. No caso de opor-se a todos os nomes, deverá bem justificar tal recusa. Se impossível o acordo entre as partes quanto à escolha de um perito comum, a prova pericial não se deverá realizar no âmbito do protocolo.

A intenção desse mecanismo é possibilitar que as partes tenham um perito cujo laudo possa futuramente vir a ser aproveitado, na medida em que sua escolha terá contado com aquiescência de ambas as partes. Além disso, tem-se como dispendiosa e muitas vezes desnecessária a indicação de assistentes técnicos. Com o presente mecanismo, a intenção é permitir que o laudo pericial seja aproveitado em juízo e com isso evitar a repetição da prova pericial e minimizar o volume de pareceres de assistentes técnicos.

\footnotetext{
os interesses de quem exibe e auxiliar as alegações do adversário. Em vários casos essa obrigação é trazida para a etapa de cumprimento dos protocolos, sempre a depender do tipo de ação e do protocolo correspondente que há de ser seguido, posto que há protocolos específicos e, consequentemente, os documentos e informações a serem noticiados e exibidos variam de acordo com eles.

Assim, caso as partes não revelem uma à outra, enquanto cumprem os protocolos, todos os documentos relevantes para o caso, inclusive aqueles que lhes são desfavoráveis, o risco de que a eles se chegue no curso da ação e as partes sofram sanções pelo descumprimento do protocolo é um poderoso incentivo para que o cumpram.

A discussão sobre ser vantajoso ou não que no curso do processo haja tal obrigação de diclosure ("full diclosure", como se costuma dizer), não cabe nesse trabalho. O que se pretende mostrar, contudo, é que o nível de disclosure que se dá no protocolo depende do nível de disclosure que se dá no curso da ação.

${ }^{171}$ Hoje, profissionais podem cadastrar-se como peritos de determinada vara, mediante a apresentação de documentação solicitada, que é analisada pelo Poder Judiciário. Embora exista, em tese, a possibilidade do cadastramento ser rejeitado, a prática dita que o cadastramento de todos é admitido. Embora não haja uma rotação obrigatória entre peritos a serem nomeados pelo juiz da vara, tende-se a fazer um rodízio, o qual não é obrigatório, pois o juiz tem liberdade para nomear como perito do caso o profissional que seja de sua confiança. Para que a proposta aqui apresentada vingue, o Poder Judiciário deverá disponibilizar aos jurisdicionados lista contendo o nome de todos os profissionais cadastrados, com suas respectivas áreas de expertise e currículos, para que as partes possam escolher 3 dentre eles. Para que a confiança do jurisdicionado nesta lista seja potencializada, será importante que o processo de cadastramento do perito passe por crivo acurado e, mais, que peritos cujo trabalho não seja condizente com parâmetros normais de profissionalismo e qualidade, sejam descadastrados pelo Poder Judiciário.
} 
Quanto a quem arcará com os honorários periciais, deve ser a parte que o solicitou, podendo adiante e a depender do resultado da prova, incluir o quanto dispendera como parte do acordo, no caso de se alcançar um.

As objeções aos nomes de peritos sugeridos pelo adversário deverão ser bem fundamentadas, sob pena de, entendendo-as fracas e não razoáveis, a parte que solicitou a prova propor a ação, alegando descumprimento do procolo pelo seu adversário, pois este recusara-se, sem bom motivo, a escolher um perito comum.

\section{Propositura da ação}

A recusa da parte em cumprir o protocolo deverá importar o direito da parte contrária de ingressar em juízo imediatamente. Terá o mesmo direito quando a parte contrária não o cumprir dentro do prazo estabelecido. Poderá, contudo, relevar o retardamento e esperar o cumprimento (o que não é possível fazer em juízo), a seu exclusivo critério. Entretanto, a partir do momento que uma parte relevar a demora no cumprimento do protocolo pela outra, o que deverá ser formalizado por escrito, não poderá alegar descumprimento do protocolo pela parte que ocasionou o retardamento.

Frise-se, contudo, que o direito da parte de ingressar em juízo jamais deve ser ameaçado. Como dito acima, o protocolo é ônus e, dele não se desincumbindo a parte, sujeitar-se-á a consequiências patrimoniais desfavoráveis no processo, mas nunca verá tolhido seu direito de ação em vista do descumprimento de um protocolo.

\section{Prescrição e decadência}

Também poderá a parte ingressar em juízo sem cumprir o protocolo quando o tempo para cumpri-lo importar o risco da ocorrência de prescrição ou decadência. Entretanto, deve cumpri-lo tanto quanto possível e, uma vez ajuizada a ação, deve dar notícia ao juiz da suspensão do cumprimento do protocolo, podendo este se manifestar determinando que o processo seja suspenso para que as partes finalizem o procedimento estipulado pelo protocolo. 


\section{PROTOCOLOS: EFEITOS PROCESSUAIS}

\subsection{Efeitos da cooperação}

\subsubsection{Aproveitamento das provas produzidas}

$\mathrm{Na}$ Inglaterra, uma das preocupações relacionadas aos protocolos diz respeito à duplicação de custos. De fato, caso não se chegue a um acordo, a replicação de custos e do tempo gasto verificar-se-á em alguma medida. Contudo, essa conseqüência é minimizada à medida em que se encontram formas de se aproveitar, na ação, os atos praticados e os resultados obtidos no protocolo. Um dos resultados obtidos são as provas nele produzidas. Assim, analisa-se, a seguir, a possibilidade de transporte de tais provas para a ação.

Produzir prova testemunhal e depoimento pessoal das partes no curso do protocolo parece pouco compatível com o nosso sistema. A falta de uma autoridade que presida a prova testemunhal parece prejudicar a tentativa de trazê-la ao protocolo. Obviamente, as partes poderão dizer e dirão, por escrito, uma à outra suas versões dos fatos, mas reduzir isso a termo e transferir o documento correspondente para o processo (caso seja instaurado), como se depoimento pessoal fosse, parece afrontar em demasia nosso ordenamento, baseado que é na produção da prova perante o juiz (especialmente a prova oral), embora essa seja tendência verificada em diversos países ${ }^{172}$.

Quanto aos documentos produzidos, entende-se não haver dúvidas sobre a possibilidade de seu transporte para a ação judicial, posto que a todo o momento pessoas pré-constituem provas, separadas ou conjuntamente, e essas provas pré-constituídas são invariavelmente levadas ao juiz.

Contudo, pode dar-se a hipótese de que para determinados casos, os protocolos deveram prever a produção de prova pericial, ccaso em que a prova deverá ser produzida por perito escolhido de comum acordo pelas partes, nos termos do quanto sugerido no item 5.5 da Parte II. Assim sendo, entende-se que esta prova deverá, sim, ser transportada para a ação, se e quando obtida.

\footnotetext{
${ }^{172}$ Nesse sentido, Inglaterra e Estados Unidos, por exemplo, fazem uso da colheita do testemunhos que, reduzida a termo, é apresentada ao juiz.
} 
Neste caso, entende-se que não se trataria de prova emprestada, mas sim de prova pré-constituída, produzida antes da propositura da ação e que, como tal, deve ser simplesmente juntada aos autos, sem necessidade de falar-se em empréstimo da prova.

O papel de relevo da nomeação conjunta de perito está em abreviar a fase de instrução probatória em juízo - se a ela se chegar - o que se alcança aproveitando, no processo, o laudo produzido na fase de cumprimento do protocolo. É certo que, embora haja a presunção, por ambas as partes, de confiabilidade do profissional escolhido, esta prova, como qualquer outra trazida para os autos, deverá ser objeto de juízo de admissibilidade no processo pelo juiz e de contraditório entre as partes ${ }^{173}$. Pode, ainda, chegar-se à hipótese de o juiz entender que o laudo produzido durante o cumprimento do protocolo é insuficiente ou teratológico (das premissas não decorre a conclusão), caso em que poderá determinar produção de nova prova. O fato é que a escolha conjunta do perito e a produção da prova pericial fora do processo têm, em regra, o condão de abreviar o processo, de poupar custos e de possibilitar que as partes tenham controle sobre o profissional que escolhem, o que lhes pode ser um conforto.

O aproveitamento das provas produzidas durante os protocolos é essencial para que se evite duplicação de esforços, seja em tempo, sejaem recursos financeiros.

\subsection{Efeitos da não-cooperação}

\subsubsection{Multa}

A não cooperação (ou a cooperação) tem gradações: pode ir da cooperação total até a não-cooperação total e a sua conseqüência deve sofrer a mesma gradação. Quem irá aferir o comportamento das partes e medir-lhes as conseqüências será o juiz, potencializando os poderes discricionários que detém. Diante desse cenário, o importante é

\footnotetext{
${ }^{173}$ Já dizia Moacyr Amaral Santos que a prova "é sujeita à avaliação e vale pelo poder de convencimento que carrega. Tanto poderá, por si só, convencer, como poderá cooperar no convencimento, quando mais não seja, pelo seu simples valor argumental, como ainda poderá ser considerada inteiramente ineficiente, tudo dependendo das condições objetivas e subjetivas que apresenta, das partes nela interessadas, do caráter do fato probando, da natureza do processo, enfim, das circunstâncias que influem na avaliação e estimação das provas", in SANTOS, Moacyr Amaral. Prova judiciária no cível e comercial. São Paulo: Max Limonad, 1952. v. 1, p. 309.
} 
o estabelecimento de padrões de conduta precisos para as partes, para que a margem de discricionariedade do juiz seja mitigada.

A gradação das conseqüências será aferida de acordo com a multa a ser imposta à parte não-cooperadora, que variará de 10 a $20 \%$ sobre o valor da condenação, tomando como inspiração o art. 20, pars. $3^{\circ}$ e $4^{\circ}, \mathrm{CPC}$, inclusive os critérios por ele ali adotados, no que for aplicável. O necessário é que o valor seja suficiente para causar incentivo econômico ao cumprimento dos protocolos e, além disso, que a multa de fato seja aplicada.

A multa será aplicada na sentença e independerá do resultado da demanda.

São exemplos de não cumprimento do protocolo: nem mesmo iniciá-lo, não respondê-lo, respondê-lo sem as informações e documentos necessários a embasar a versão dos fatos sustentada, retardar respostas, retardar o oferecimento de informações e documentos, não concordar com perito comum sem justificativa razoável.

Sobre a recusa de oferecer documentos ou informações solicitados, se a justificativa da parte enquadrar-se nas hipóteses de escusas do CPC não deverá ela ser apenada; caso contrário, deverá sofrer conseqüências. Isso servirá de incentivo para que a parte não oculte, simplesmemte, certo documento; se não apresentar documento, deverá tal comportamento ter sido fruto de decisão consciente, não de mero estrategema. Assim, caso a parte entenda que a exibição não seria devida em juízo (e portanto não é devida na fase dos protocolos), deve estar preparada para sustentar que seu entendimento encaixa-se nas hipóteses de escusas justificáveis enumeradas pelo CPC (conforme item 5.5 da Parte II Solicitação e apresentação de documentos). Esse mecanismo tende, assim, a incentivar maior correção na atitude da parte.

Se a controvérsia chegar ao Judiciário e a escusa for, então, apresentada ao juiz, poderá este entender que de fato os argumentos da parte que se escusara procedem. Caso entenda que não procedem, mandará exibir a coisa ou documento. Caber a esta mesma parte, no presente exemplo, alguma conseqüência desfavorável, é matéria bastante delicada, pois de duas uma: ou a parte acreditava que seus argumentos para não exibir o quanto solicitado eram válidos e deveriam proceder em juízo (atitude que não deve ser repreendida), ou seus argumentos visavam apenas à pura e simples recusa, sem que estivesse embasada em qualquer lei ou princípio (atitude que deve ser repreendida). Neste caso, entende-se que a parte deverá estar sujeita à multa aqui enunciada. 


\subsubsection{Exibição, em juízo, de documentos omitidos na fase dos protocolos}

Diferente, contudo, é o seguinte caso: a parte instada a apresentar documento ou coisa não o faz, dizendo que não o detém ou mesmo nada dizendo (simplesmente abstendo-se de apresentá-lo); entretanto, uma vez iniciada a ação, apresenta o documento ou coisa anteriormente solicitado (ou, ainda, apresenta documento que não havia sido expressamente solicitado, mas que era relevante para dar sustentação às suas alegações). Esse comportamento faz pouco do protocolo, da parte que se empenhou em cumpri-lo e do Judiciário, a cujo recurso poderia ter sido evitado. Neste caso, qual deveria ser a conseqüência apropriada? Ter o documento como não apresentado, salvo se a parte que o apresentar demonstrar que dele teve conhecimento apenas após a instauração da ação?

Seria essa medida dura demais? Para refletir-se a respeito, uma paralelo com a mecânica desenvolvida nos arts. 396 e 397 do CPC pode ser interessante. Tais artigos prescrevem que a inicial e a contestação devem vir acompanhadas dos documentos destinados a provar-lhes as alegações e que documentos podem ser juntados posteriormente desde que novos.

A questão de como lidar com documentos apresentados tardiamente é controversa na jurisprudência, havendo decisões que entendem devam ser apresentados juntamente com a inicial (ou com a contestação) apenas os documentos tidos como pressupostos da causa ou da defesa. "Os demais podem ser apresenados em outras fases, ou até mesmo na via recursal, desde que ouvida a parte contrária e inexistente o espírito de ocultação premeditada e o propósito de surpreender o juízo." ${ }^{174}$ Assim, não se há que confundir ‘documento essencial à propositura da ação' com ‘ônus da prova do fato constitutivo do direito', que pode ser desempenhado ao longo da fase instrutória.

Outros, contudo, entendem que "não se destinando os documentos a fazer prova contrária e deles dispondo a parte desde antes da propositura da demanda, não é admissível que só os junte com as razões de apelação. Em tais razões, deles não se deve tomar conhecimento." 175

\footnotetext{
${ }^{174}$ NEGRÃO, Theotônio; GOUVÊA, José Roberto F. Código de Processo Civil e legislação processual em vigor. São Paulo: Saraiva, 2008, nota 1a ao Art. 397, p. 511, conforme RSTJ 13/359.

${ }^{175}$ NEGRÃO, Theotônio; GOUVÊA, José Roberto F. Código de Processo Civil e legislação processual em vigor, cit., nota 1a ao Art. 397, p. 512, conforme JTA 122/29.
} 
Esses são alguns exemplos, apenas, para que se reflita sobre qual deva ser a conseqüência adversa a ser experimentada pela parte que ocultou documento na fase dos protocolos e, assim, negou à parte contrária a possibilidade de melhor conhecer a controvérsia e avaliar, antes do ingresso em juízo, suas chances de êxito.

Sob pena de cometerem-se injutiças, poder-se-ia sustentar que a consequiência mais adequada ao caso da parte que ocultou documento durante a fase de protocolos quando expressamente instada a apresentá-lo ou quando tal documento embasasse suas alegações, é ter em mente a caracterização de relevância do documento para o caso. Se relevante, deveria ter sido apresentado anteriormente, de modo que o documento deveria ser tido por não apresentado e, assim, não seria considerado pelo juiz ao formar sua convicção.

Entretanto, essa conseqüência parece dura demais, podendo chegar ao extremo de que todos os documentos não juntados na fase de protocolos não poderiam ser futuramente aceitos em juízo. Isso, sem dúvida, seria medida demasiadamente drástica e indesejável.

Assim, entende-se que a imposição de multa é a conseqüência mais adequada.

Se a parte mentiu ao dizer que não dispunha ou não conhecia determinado documento, além da multa por descumprimento do protocolo, a apresentação posterior deste mesmo documento em juízo denotará violação ao dever de veracidade, sujeitando-a a pena por litigância de má-fé, a menos que comprove que só mais tarde obteve o referido documento, tratando-se, assim, de documento novo.

Se, contudo, não houve violação do dever de veracidade, mas apenas apresentação tardia (no processo), a cooperação, inerente ao protocolo, haverá sido desrespeitada e a parte se sujeitará à multa. Neste caso, não se tratará de litigância de má-fé, mas sim da multa própria do descumprimento do protocolo, enunciada no item 6.2.1 da Parte II.

\subsection{Presença do advogado}

Na Inglaterra, a parte pode prescindir do patrocínio do advogado, seja em juízo, seja fora dele, como, por exemplo, na fase de obediência ao protocolo. A que se deve esse posicionamento? Seria ao maior grau de instrução da população? Seria à noção de liberdade e independência, arraigada e presente na cultura do povo? Não se pretende oferecer resposta a essas perguntas, mas tão-somente constatar o fenômeno. 
No Brasil, contudo, o panorama é diferente: o advogado é considerado essencial à administração da Justiça e a parte não pode dele prescindir durante o processo judicial. Mas poderia dele prescindir durante a fase de obediência dos protocolos? E o que aconteceria àquele que se apresenta em juízo sozinho, frente a um oponente representado por advogado? Estender-se-ia ao caso a solução oferecida pela Lei n. 9099/95, segundo a qual quando uma das partes for representada, ou for pessoa jurídica, a outra também deverá ser representada por advogado?

No caso de a parte não se sentir à vontade para cumprir o protocolo por si só poderá, obviamente, contratar advogado para representá-la. Mas o que ocorrerá quando a parte não tiver meios para contratar um advogado? Seria possivel valer-se de um banco de advogados dativos? Tal como posta hoje, a resposta dada pela letra da lei que disciplina a assistência judiciária - Lei n. 1.060/1950 - seria "não", posto que usa a locução: "dos que necessitarem do processo". Na medida em que o protocolo não se desenvolve perante autoridade judiciária e que não se tem a quem requerer o deferimento do benefício da assistência judiciária, restariam os cidadãos desamparados?

É verdade que a assistência judiciária não é extensível à arbitragem ou a outras formas de resolução de controvérsias, o que sob certas circunstâncias pode ser danoso para as partes. No caso dos protocolos, poderá também ver-se prejudicada a parte não assistida por advogado, inclusive porque de sua ignorância poderá resultar o descumprimento do próprio protocolo. Dessa forma, entende-se recomendável a ampliação dos casos em que o Estado poderá providenciar a representação da parte por advogado, incluindo, então, a hipótese dos protocolos, sem prejuízo de que a esse respeito disponha a própria lei que os discipline.

Mas a lei pressupõe que o juiz conceda o benefício da assistência gratuita. No caso de representação na fase de protocolos, onde não há juiz, não haveria a quem requerer a concessão do benefício. A solução mais prática será autorizar-se a parte a requerer o benefício diretamente à autoridade responsável pela concessão da assistência de advogado. 


\section{OFERTA POTENCIALIZADA DE ACORDO}

\subsection{Notas introdutórias e breve retomada da sistemática da Part 36 Offer}

A oferta feita nos termos da Part 36 traz consigo conseqüências patrimoniais que têm como parâmetro, invariavelmente, os custos incorridos no processo. Como já se disse nos itens 3.1 e 3.3 da Parte I deste trabalho, onde a sistemática da Oferta foi amplamente tratada, a regra no direito inglês é aquela segundo a qual "costs follow the event", ou seja, o vencido paga os custos do vencedor, sendo certo que os custos do processo (costs), na Inglaterra, envolvem tanto taxas recolhidas aos cofres do Poder Judiciário como os valores contratados entre as partes e seus respectivos advogados. Afora isso, tem-se, ainda, que se reputa vencedora a parte que, na sentença, recebe tudo ou parte do que de início pleiteara, mesmo se a porção que receber seja ínfima em relação ao que requerera.

Dado que os custos são um fator bastante sensível para as partes, a sua fixação é uma forma de criar estímulos e desestímulos de modo a direcionar a conduta das partes.

$\mathrm{Na}$ medida em que os custos são incorridos do início ao fim do processo, a depender sua intensidade do maior ou menor volume de trabalho a recair sobre os patronos das partes, trabalhar com a variável costs significa poder criar um marco no tempo e atribuir até dado momento os custos do processo a uma das partes e, a partir de então, à outra. Como se vê, o momento de realização da oferta tem impacto direto no tamanho da conta a ser paga.

De acordo com a CPR Part 36, feita a oferta, começa a correr o Período Relevante, dentro do qual o destinatário da oferta poderá aceitá-la (sem necessidade de permissão do juiz); dentro desse mesmo Período Relevante, caso o ofertante queira alterar ou retirar a oferta, necessitará da permissão do juiz. Expirado o Período Relevante, o ofertante não mais precisará da permissão do juiz para alterar ou retirar a oferta, enquanto que o seu destinatário deverá obter a permissão do juiz para aceitá-la.

Supondo-se que 'A' aceite a oferta de 'B' dentro do Período Relevante, B será responsável pelo pagamento dos custos incorridos por ' $A$ ' até o momento em que este houver aceito a oferta. Supondo-se, contudo, que 'A' aceite a oferta de 'B' fora do Período Relevante, 'B' pagará os custos de 'A' até a data de expiração do Período Relevante e, de 
tal data até a data da aceitação da oferta, 'A' pagará os custos do ofertante 'B'. De acordo com esse mecanismo, a parte que se entende em condições de fazer uma oferta tem incentivos para fazê-la o quanto antes, na medida em que, se a oferta for aceita, estancará os custos sendo incorridos pelo adversário com seus advogados, diminuindo-se a conta final a ser reembolsada à parte.

A rejeição da oferta também se faz sentir em termos de alocação de custos: tendo ' $\mathrm{R}$ ' (réu) feito oferta de acordo a 'A' (autor) por uma quantia ' $\mathrm{x}$ ' e, ao final do processo (com o advento da sentença), recebendo 'A' quantia menor ou igual a ' $\mathrm{x}$ ', 'A' deverá arcar com os custos incorridos por ' $\mathrm{R}$ ' a partir do término do Período Relevante (conforme definido no item 3.3 da Parte I). Contudo, se a oferta for feita por 'A', que disser aceitar receber ' $\mathrm{x}$ ' para pôr fim à controvérsia, recebendo ao final do processo valor maior ou igual a ' $x$ ', será ' $R$ ' condenado a pagar a condenação, somando-se a ela os custos incorridos por ' $A$ ' a partir do término do Período Relevante, bem como juros a uma taxa mais elevada.

Como se teve a oportunidade de enunciar ao longo deste trabalho, os custos na Inglaterra são freqüente alvo de pesquisas e de revisões por parte dos órgãos públicos do Reino Unido, sempre com o fim de reduzi-los ou de melhor distribuí-los, com a firme convicção de que em boa parte dos casos os custos do processo impedem as partes de pleitearem seus direitos em juízo. Além disso, o fato de que uma das partes seja condenada, pelo juiz, a reembolsar seu adversário por todo o montante que este tenha despendido com seu advogado propicia discussões longas e paralelas sobre se o valor despendido era razoável, se os honorários do advogado contratado eram justificáveis em vista do mérito da causa e dos valores em discussão. É a chamada 'satellite litigation'.

Assim, embora o conceito de manter a parte vencedora indene (inclusive, e com razão, quanto ao que foi obrigada a gastar com advogado) seja interessante e louvável ${ }^{176}$,

\footnotetext{
${ }^{176}$ No Brasil, prevê o art. 20, CPC, que "a sentença condenará o vencido a pagar ao vencedor as despesas que antecipou e os honorários advocatícios", donde não deveria haver dúvidas que os honorários caberiam ao vencedor, não ao seu patrono, como forma de indeniza-lo do que havia gasto para fazer valer seus direitos. O antigo Estatuto da Ordem dos Advogados - Lei $n^{\circ} 4.215$, de 27 de abril de 1963 - então previa, em seu art. 99, que "se o advogado fizer juntar aos autos, até antes de cumprir-se o mandato de levantamento ou precatório, o seu contrato de honorários, o juiz determinará lhe sejam estes pagos diretamente, por dedução da quantia a ser recebida pelo constituinte, salvo se este provar que já os pagou". Com isso, a intenção do artigo era propiciar ao advogado a possibilidade de garantir seu crédito, não de receber em dobro (do seu constituinte e da parte contraria). Entretanto, o artigo bastou para que as divergências doutrinarias e jurisprudenciais sobre a matéria ganhassem expressão, até que fossem sepultadas pelo o advento do atual Estatuto da Advocacia - Lei n. 8.906/94, que assentou serem os honorários fixados pelo juiz, em qualquer circunstância, devidos ao advogado, não ao vencedor. Essa pequena digressão serve apenas para frisar que o princípio de indenizar o vencedor pelo que gastou com a
} 
os litígios paralelos que gera não parecem justificar se cogite sobre a aplicação de sistema semelhante no Brasil. Dessa forma, inexistente aqui um sistema que permita o estabelecimento de conseqüências patrimoniais que guardem perfeita relação com o momento em que a oferta é feita, outra sistemática, i.e., outro parâmetro para a atribuição de conseqüências, há de ser pensado.

Neste Capítulo, chamar-se-á de OPAc (Oferta Potencializada de Acordo) a oferta a ser desenvolvida no direito brasileiro à semelhança da Part 36 Offer.

\subsection{Natureza, disponibilidade de direitos e positivação}

Não cabe aqui a discussão sobre a natureza da OPAc, pois ela nada mais é do que uma proposta de transação, e portanto uma proposta de negócio jurídico. Exatamente por esse motivo, desnecessário frisar que apenas direitos disponíveis poderão ser objeto de OPAc.

Sobre sua positivação, na medida em que se tratará de atribuir à sua recusa ou aceitação consequiências patrimoniais a serem apuradas dentro do processo, é natural e necessário que essa dinâmica seja disciplinada em lei federal ordinária, tal como as demais normas processuais.

\subsection{Momento da realização da OPAc}

À semelhança do caso inglês, entende-se que a OPAc possa ser feita a qualquer momento, seja no curso do processo ou antes dele e, neste caso, seja no curso do cumprimento de um protocolo ou não. Como se frisou logo na introdução deste trabalho, os dois institutos não são indissociáveis ou interdependentes; são, sim, complementares e tendem a potencializar-se mutuamente.

Na medida em que não se adota no Brasil o sistema inglês de alocação de custos, os incentivos econômicos para que a parte faça proposta de acordo o quanto antes

ação, seja com despesas variadas, seja com honorários advocatícios, não é desconhecido pelo direito brasileiro. Ocorre que, aqui, o juiz fixava (e ainda fixa) os honorários tomando por base o valor da condenação, enquanto que na Inglaterra o princípio vigora de forma mais plena e atrelada à realidade, desejando-se devolver à parte tudo o quanto gastou. 
(estancando, assim, os custos do adversário com que eventualmente terá de arcar) ficam prejudicados. Aceita a OPAc antes, no início, no meio ou em momento próximo ao fim do processo, pouca diferença fará.

\subsection{Adequação da OPAc a determinadas causas}

Conforme ressaltado no item 3.4.4 da Parte I deste trabalho, embora a Parte 36 contemple Ofertas realizadas em ações com qualquer objeto, o fato é que, apesar de vasta pesquisa realizada, os exemplos doutrinários e os julgados encontrados naquele país tratam de ações cuja obrigação é de pagar quantia (money claims).

Para se aferir se o julgamento foi mais vantajoso em uma money claim, basta comparar a oferta, atualizada, com o valor da condenação. Para se aferir a mesma vantagem em uma non-money claim, a tarefa, parece, é inglória e altamente sujeita a gerar novas controvérsias. Isso porque, ainda que se possa sub-dividir o pedido e avaliar se para este ou aquele sub-pedido a decisão judicial fora mais ou menos vantajosa que a Oferta, não se teria parâmetros objetivos pra conferir pesos aos pedidos. Por isso, entende-se desaconselhável permitir que a OPAc seja feita para pôr fim a controvérsias que não tratem exclusivamente de obrigação de pagar quantia.

\subsection{Efeitos da aceitação}

Aceita a OPAc, restará realizado o acordo.

Na hipótese de a OPAc ser aceita no curso do processo, as partes poderão submeter o acordo ao juiz para homologação por sentença, tornando-se esta título executivo judicial, nos termos do art. 475-N, CPC. Haverá, contudo, a hipótese de a OPAc ser proposta e aceita antes mesmo que exista ação. Nesse caso, para que se venha a obter título executivo judicial, o art. 475-N, V, CPC estabelece que o acordo deverá ser homologado judicialmente ${ }^{177}$.

\footnotetext{
${ }^{177}$ Conforme Nelson Nery e Rosa Maria de Andrade Nery, em comentário ao art., a homologação desse acordo se dá "por meio de simples apresentação ao juízo do instrumento do acordo", em NERY JUNIOR, Nelson; NERY, Rosa Maria de Andrade. Código de Processo Civil comentado e legislação extravagante. São Paulo: Ed. Revista dos Tribunais, 2008.v. 18, p. 752.
} 
Entretanto, é possível que se conformem as partes com um instrumento de transação que valerá como título executivo extrajudicial, se referendado pelos advogados dos transatores, nos termos do art. 585, II, CPC.

Cumpre não perder de vista que, atribuindo ao acordo celebrado entre as partes a natureza de transação, a ela se aplicará a regra do art. 849, CC, por força do qual a transação só se anula por dolo, coação ou erro essencial quanto à pessoa ou coisa controversa.

\subsection{Efeitos da não-aceitação}

Para que as partes não se sintam indevidamente pressionadas a fazer ou a aceitar uma OPAc, é importante que os incentivos econômicos que carrega consigo sejam suficientes para incentivar, mas não sejam drásticos a ponto de serem reputados cruéis e injustos.

Repita-se, mais uma vez, a idéia subjacente ao sistema inglês: se o réu faz uma oferta ao autor, este não a aceita, e mais tarde obtém julgamento de procedência que condena o réu a pagar quantia igual ou inferior à oferta, deverá o autor ser penalizado por não ter aceito a oferta (sendo esta pena o pagamento de parte dos custos do réu). $\mathrm{Na}$ medida em que era uma oferta razoável, não se justificava continuar litigando e consumindo tempo e recursos de todos envolvidos no processo. Se, por outro lado, a oferta for feita pelo autor - ao dizer que aceita pôr fim ao processo mediante o recebimento de quantia inferior ao quanto requerido na inicial -, o réu não aceitar pagar o montante sugerido e, ao final do processo for condenado a pagar exatamente o valor ou mais do que aquilo que teria pago tivesse aceito a oferta do autor, deverá o réu ser penalizado por ter despendido recursos de seu adversário e do Estado em um processo que poderia ter sido encerrado antes (sendo esta pena o pagamento de parte dos custos do autor, mais juros a uma taxa mais elevada do que a praticada pelo Banco Central inglês).

Embora não se possa falar aqui em realocação de custos, pelos motivos já mencionados, entende-se que o método mais adequado seja o estabelecimento de uma multa. Sua quantificação, contudo, é tema delicado. Assim, sugere-se uma multa entre 10 e $50 \%$ sobre a diferença apurada entre a OPAc - devidamente atualizada pela tabela do Tribunal de Justiça ou por outro índice que se entenda adequado - e a condenação no 
processo (nela não incluídas despesas do processo e honorários advocatícios - tratar-se-á apenas do 'principal' da condenação).

Calcular a multa sobre a diferença favorece a posição daqueles que tomaram o cuidado de fazer uma OPAc séria, pensada, que guarde relação com a realidade, com as provas e informações trocadas pelas partes. Assim, a chance de que tal OPAc se aproxime do valor da condenação é maior, portanto menor será a diferença apurada que servirá de base de cálculo para a multa.

Defende-se a existência de uma multa mínima de 10\% (sobre a diferença enunciada no parágrafo anterior) para que as partes tenham consciência de que haverá, sem dúvida, alguma multa, de modo que efetivamente incluam-na na sua avaliação de riscos e vantagens ao cogitarem fazer, aceitar ou rejeitar uma OPAc. O CPC está repleto de multas que raramente são usadas, sendo a multa pela litigância de má-fé um exemplo. Garantindose um mínimo de $10 \%$, saber-se-á que toda vez que uma OPAc for feita e rejeitada, haverá uma multa de, no mínimo, $10 \%$ a recair sobre autor ou réu, a depender do desfecho da ação. Isso parece fornecer incentivo para que as partes considerem a OPAc com maior seriedade.

Sobre o máximo da multa, entende-se que deva ser um percentual relevante, a ponto de representar penalidade que não passe despercebida e, dessa forma, que paute a conduta das partes.

A variação percentual da multa conforme a escala acima sugerida deverá levar em consideração fatores semelhantes àqueles enumerados pelas CPR, as quais se passa a seguir.

\subsection{Mecanismo de aplicação da multa}

Uma vez comparando-se o valor da condenação ao valor atualizado da OPAc, verificar-se-á qual será a parte a sofrer as consequiências pecuniárias aqui sugeridas.

Se a OPAc recusada era tão ou mais vantajosa ao autor do que a condenação a que fez jus ao final do processo, deveria tê-la aceitado. Não a tendo aceitado, sujeitar-se-á a uma multa. Se, por outro lado, a OPAc recusada mostrou-se inferior ao valor da 
condenação, aquele que a recebera agiu bem ao não aceitá-la e, assim, ficará o ofertante sujeito à multa.

Como, entretanto, será feita a aplicação da multa? Quais fatores e que regras deverão balizar a atividade do juiz?

Quanto aos fatores, acredita-se que os seguintes cumpririam a função de dirigir a atividade do juiz na aplicação da multa:

(a) os termos financeiros da OPAc (aí considerados forma de pagamento e encargos financeiros);

(b) a informação disponível às partes ao tempo da realização da OPAc; e

(c) a conduta das partes em relação a dar ou a recusar-se a dar informações com fins a proporcionar que a proposta ou a aceitação da OPAc fosse bem avaliada.

$\mathrm{O}$ item (b) acima, por exemplo, visa a garantir que a parte que rejeita OPAc formulada muito cedo no processo (ou antes dele, mas no início dos protocolos) não seja apenada da mesma forma que seria uma outra parte que houvesse rejeitado OPAc realizada em momento onde o processo (ou o protocolo) estivesse já mais maduro. Isso porque o receptor da OPAc realizada quando a troca de informações entre as partes era ainda muito incipiente não tinha, exatamente por essa razão, condições de avaliá-la e, por isso é possível que tenha decidido rejeitá-la. Diferente é a situação daquele que, dispondo de informações que poderia leva-lo a concluir que a OPAc era razoável, rejeita-a.

Entende-se que a utilização dos critérios acima enumerados possa ser sumarizada da forma exemplificada abaixo:

\begin{tabular}{|l|l|l|}
\hline & Cenário 1 & Cenário 2 \\
\hline \hline Valor da Sentença & $\$ 100$ & $\$ 100$ \\
\hline \hline Proposta (Atualizada) & $\$ 70$ & $\$ 130$ \\
\hline Diferença & $\$ 30$ & $\$ 30$ \\
\hline Feita pelo Autor & $\begin{array}{l}\text { Penaliza Réu } \\
\text { Avalia qualidade da recusa }\end{array}$ & $\begin{array}{l}\text { Penaliza Autor } \\
\text { Avalia qualidade da oferta }\end{array}$ \\
\hline Feita pelo Réu & $\begin{array}{l}\text { Penaliza Réu } \\
\text { Avalia qualidade da oferta }\end{array}$ & $\begin{array}{l}\text { Penaliza Autor } \\
\text { Avalia qualidade da recusa }\end{array}$ \\
\hline
\end{tabular}




\section{Explica-se:}

Em primeiro lugar, deve-se identificar quem sofrerá as conseqüências patrimoniais adversas aqui sugeridas, através da comparação da OPAc atualizada com o valor do principal da condenação.

Feito isso, deve o juiz ter clareza dos extremos em termos de cada um dos critérios sugeridos para que então possa trabalhar com os percentuais intermediários. Como se observa, não se escapará da discricionariedade do juiz, posto que é inviável prescrever todas as gradações entre as combinações dos fatores acima. Entretanto, na medida em que o juiz tenha parâmetros claros para definir a multa, ameniza-se os efeitos potencialmente nocivos da discricionariedade do juiz.

Supondo que ficará sujeita à multa a parte que fez a oferta, deverá o juiz observar a 'qualidade da oferta'; se, pelo contrário, a parte sujeita à multa for aquela que rejeitou a OPAc, o juiz deverá observar a 'qualidade da recusa'. Explica-se: sob o ângulo da oferta, se esta houver sido 'totalmente ruim', a pena imposta deverá ser de $50 \%$. Se 'totalmente boa', a pena será de 10\%, o mesmo exercício repetindo-se sob o ângulo da recusa.

A OPAc será tida por 'totalmente ruim' quando, analisados os fatores antes enumerados, a conclusão apontar para sua rejeição. Assim, (a) propunha-se o pagamento do valor ofertado em parcelas a perder de vista, sem qualquer compensação financeira; (b) o receptor da OPAc não dispunha de informações para avaliá-la; e (c) o ofertante recusarase a fornecer informações e documentos que possibilitassem ao ofertado tal avaliação. Caso fosse esse o resultado da análise, a pena imposta deveria ser de 50\% sobre a diferença acima enunciada.

O extremo oposto seria o seguinte: (a) a oferta propusera pagamento à vista; (b) a parte que a recebera dispunha de informações e documentos que lhe permitissem avaliar com clareza a OPAc; e (c) o ofertante revelara, ou dispusera-se a revelar, ao ofertado tantas informações e documentos quantos fossem necessários para que a avaliação fosse adequada. Neste caso, a pena imposta deveria ser de apenas $10 \%$.

Trabalhar o caminho entre 10 e $50 \%$ será função do juiz, observando-se que previsibilidade e rigor são elementos indispensáveis a que uma sistemática como a que ora se propõe surta efeitos positivos. 


\subsection{Outras observações}

A mecânica aqui proposta, ainda que incipiente, tem por finalidade indicar as condições gerais do que se imagina seria adequado ao Brasil. Como se vê, o procedimento aqui proposto é bastante mais simples do que aquele em vigor na Inglaterra. Tal complexidade, dentre outras coisas, deve-se ao fato de que o sistema da Oferta inglesa é baseado nos custos do processo, o que demanda ritual mais detalhado para se determinar a realocação destes.

Entretanto, entende-se que, a semelhança do que ocorre na Inglaterra, deva-se indicar na OPAc seu período de validade, dentro do qual o ofertante não poderá retira-la ou alterar seus termos em seu próprio benefício. Expirado esse período, a OPAc poderá ser a qualquer tempo retirada ou alterada pelo ofertante, mediante notificação do adversário. Caso nao o faça, a OPAC permanecerá válida e aberta a aceitação pelo adversário.

Na hipótese de que, como fruto da produção de provas, tenham surgido novos documentos a justificar a revisão dos termos da OPAc ou da própria realização da OPAc, seus termos originais prevalecerão até que ela seja retirada ou modificada, com a devida notificação do adversário.

Diferentemente do processo inglês, em nenhum momento deverá ser solicitada autorização do juiz, seja para modificar a OPAc, seja para aceita-la fora do período de validade.

Ademais, da mesma forma como ocorre na Inglaterra, entende-se que a existência da OPAc não poderá ser comunicada por qualquer das partes ao juiz do processo, no caso de existir ação em curso. A parte que por ação ou negligência fizer chegar ao juiz a notícia da existência da OPAc perderá os benefícios dela, caso fizesse jus a tais benefícios, o que só seria aferível quando prolatada a sentença.

Por fim, quanto ao destinatário da multa, acredita-se que ela deva ser paga ao adversário, não ao advogado ou aos cofres públicos, pois embora nao se possa dizer que tenha caráter indenizatório (na medida em que se falar em indenização importaria atividade probatória para quantificar o dano sofrido, o que não é o caso), enxerga-se na multa espécie de compensação pelo tempo e dinheiro que despendera em um processo que poderia ter sido evitado. 


\section{CONCLUSÕES}

Desde a implantação dos Juizados de Pequenas Causas, em 1984, tem-se notado no Brasil esforços para a promoção de acordos entre partes de processos judiciais.

Assim, a tomada de conhecimento dos pre-action protocols ("Protocolos") espécie de procedimento que se desenrola antes do processo judicial, incentivando o diálogo e a troca de informações e produção de prova entre as partes - e da Part 36 Offer ("Oferta") - uma oferta de acordo cuja rejeição ou aceitação traria consigo conseqüências patrimoniais às partes envolvidas na controvérsia -, dois institutos do direito inglês que vieram no bojo da reforma do direito processual do Reino Unido que culminou com a entrada em vigor das Civil Procedure Rules em 1999, e cujo objetivo precípuo é a promoção do acordo, fez surgir a seguinte indagação: seria conveniente e, mais do que isso, seria possível trazer ao direito brasileiro mecanismos semelhantes?

Antes de responder-se a esses questionamentos, conveio explorar tais institutos conforme aplicados pelas cortes inglesas e percebidos pela comunidade jurídica daquele país, especialmente por meio de pesquisas encomendadas pelo próprio governo. Desse exercício extraíram-se conclusões no sentido de que eram ambos percebidos de maneira positiva, contribuindo significativamente para a celebração de acordos entre as partes. Contudo, não eram sem defeitos.

Dentre os riscos identificados no instituto dos Protocolos citaram-se a demora no seu cumprimento, os gastos para cumpri-lo, que poderiam ter que ser repetidos no processo, as fishing expeditions. Por fim, ressaltou-se que as cortes deveriam aplicar as conseqüências desfavoráveis atinentes ao descumprimento de modo mais efetivo e uniforme. Sobre a Oferta, identificaram as pesquisas inglesas que a previsibilidade das conseqüências da aceitação ou rejeição da Oferta era elemento essencial para que o instituto produzisse os efeitos desejados e, ainda, que havia casos em que os incentivos eram opressores e 'forçavam' o acordo.

Compreendidos funcionamento e resultados obtidos na Inglaterra, passou-se, então, à análise de como tais institutos poderiam ser implantados no Brasil. Inicialmente, sob o aspecto cultural, que poderia ser levantado para repelir a introdução desses mecanismos no direito brasileiro; observou-se que as características que determinaram o aparecimento dos institutos além-mar repetem-se aqui: a grande necessidade vista na Inglaterra dizia respeito 
a promover o acesso à justiça, baixando os custos do processo, diminuindo demoras injustificadas e facilitando acordos entre as partes, por meio de um maior contato entre elas desde logo. Problemas e necessidades muito semelhantes são sentidos no Brasil, da mesma forma como as críticas feitas na Inglaterra poderiam perfeitamente ter sido pronunciadas no Brasil, fossem os institutos parte de nosso ordenamento jurídico.

Superada a questão cultural, observou-se tendência mundial no sentido de se adotar procedimentos preliminares ao processo, conforme relatado no XIII Congresso Mundial de Direito Processual, ocorrido em 2007, no Brasil e, em seguida, as críticas dirigidas por alguns autores ao frenesi que se instaurou em torno da promoção de acordos pelo Poder Judiciário e da motivação a ela subjacente.

Frequentemente se exalta a promoção de acordos sob o argumento de que a prestação jurisdicional é demasiadamente demorada, de modo que a transação seria preferível à jurisdição. Entretanto, a busca de métodos alternativos de solução de controvérsias (e aqui se trata dos comumente usados, como arbitragem, conciliação e mediação) destina-se apenas a aliviar a carga de trabalho dos juízes, em vez de melhorar o Judiciário, ou decorreria da percepção de que existem tipos de controvérsias que podem, com alguma facilidade e boa vontade (movida, obviamente, a incentivos econômicos) resolver-se sem a intervenção estatal? A motivação do presente trabalho foi a segunda alternativa, a qual tem como efeito colateral (e positivo) aliviar a carga de trabalho que pesa sobre o Judiciário, até para que os recursos de que dispõe sejam destinados às causas que de fato deles precisam. Com isso, abre-se espaço nos cartórios, nas mesas e na agenda dos juízes, para ações que os demandem, de forma a promover o acesso à justiça, não de limitá-lo.

Os holofotes, portanto, devem ser postos sobre a comunicação entre as partes, a cooperação e a troca de informações e provas que lhes possibilitem uma avaliação de chances de êxito calcada na realidade e, portanto, mais justa.

Investigou-se, assim, a natureza dos protocolos, chegando-se à conclusão de que seriam um ônus, cujo descumprimento acarretaria consequiências desfavoráveis ao final do processo. Como exemplos de não cumprimento do protocolo identificou-se: nem mesmo iniciá-lo, não respondê-lo, respondê-lo sem as informações e documentos necessários a embasar a versão dos fatos sustentada, retardar respostas, retardar o oferecimento de informações e documentos, não concordar com perito comum sem justificativa razoável. Observou-se, também, que os deveres éticos inerentes ao processo aplicar-se-iam também 
aos protocolos, incorrendo na multa por litigância de má-fé aquele que violasse tais deveres no decorrer do protocolo.

Portanto, seriam de duas ordens as consequiências que a parte poderia sofrer durante a fase de cumprimento dos protocolos: (a) multa própria, a constituir o incentivo essencial para que a parte inicie e dê continuidade ao cumprimento do protocolo; e (b) penas por litigância de má-fé, caso seu comportamento se inscreva em algum dos incisos do art. 17, CPC (os quais deverão ser aplicáveis aos protocolos, com as devidas adequações). Por fim, entende-se que esse comportamento também seria de duas ordens: (i) dentro do protocolo e (ii) no processo, cotejado com o que se obteve na fase de cumprimento dos protocolos.

Preferiram-se, ainda, protocolos específicos ao genérico, na medida em que aqueles, confeccionados para tratar de controvérsias com feições específicas, poderiam fornecer um roteiro mais detalhado para a conduta das partes, identificando com maior precisão as informações e documentos a serem trocados, o que maximizaria a obtenção de acordos e minimizaria o risco de que as partes enveredassem pelas chamadas fishing expeditions.

A despeito da predileção por protocolos específicos, entendeu-se como importante a criação de um protocolo genérico, ainda que bastante simples, como forma de incentivar a cultura de cooperação para o alcance de decisões bem informadas.

Observaram-se, por fim, os efeitos do protocolo a serem sentidos no processo (i) seja a respeito do aproveitamento das provas e informações nele trocadas, o que faria com que a causa chegasse ao juiz mais amadurecida e, assim, fossem potencialmente poupados tempo e dinheiro, (ii) seja a imposição de multa, quando da prolação da sentença, sobre a parte que não se comportasse conforme prescrevia o protocolo.

No último Capítulo, retomaram-se elementos básicos da Part 36 Offer e passou-se a pensar sobre como um mecanismo à sua semelhança poderia ser implementado no Brasil, a qual chamou-se de Oferta Potencializada de Acordo - OPAc. Esse exercício permitiu notar que os parâmetros para o descumprimento não poderiam ser os custos do processo, jogando-se com sua realocação entre as partes. E isso não seria possível, essencialmente, porque o sistema de custos em vigor no Brasil é bastante diferente do inglês, conforme explicado em maior detalhe em diversos momentos do trabalho.

Sendo assim, a alternativa aventada para que as partes tivessem incentivos econômicos para fazer e aceitar uma OPAc residiria em uma multa a ser aplicada à parte 
que, na sentença, não obtivesse benefício maior do que teria obtido houvesse aceitado (ou feito) a OPAc. Para que não representasse pena excessiva, a multa seria calculada sobre a diferença apurada entre a sentença e a OPAc, conforme escala e critérios detalhados no Capítulo 7.

Enfim, o que se procurou demonstrar foi a possibilidade e conveniência de implantar-se no Brasil, com determinados ajustes, duas experiências que se mostraram significativas na promoção de acordos informados na Inglaterra. 


\section{REFERÊNCIAS BIBLIOGRÁFICAS}

ABDO, Helena Najjar. O abuso do processo. São Paulo: Ed. Revista dos Tribunais, 2007 (Coleção Estudos de Direito de Processo Enrico Tullio Liebman, v. 60).

ACCESS to Justice: Final Report (1996), By The Right Honourable the Lord Woolf, Master of the Rolls. July 1996. Disponível em: <www.dca.gov.uk/civil/final/index.htm>.

ACCESS to Justice: Interim Report (1995), Lord Woolf. Disponível em: $<$ www.dca.gov.uk/civil/interim/index.htm>.

ACCESS to Justice. By The right honourable the Lord Woolf. Disponível em: $<$ http://www.dca.gov.uk/civil/interim/contents.htm>.

AGUIAR, João Carlos Pestana de. Reintrodução ao estudo da prova. Revista da EMERJ, Rio de Janeiro, v. 2, n. 8, p. 69-84, 1999.

Reintrodução ao estudo da prova (segunda parte). Revista da EMERJ, Rio de Janeiro, v. 3, n. 9, p. 120-135. 2000.

ALVES, Francisco Glauber Pessoa. Apontamentos sobre a nova feição do princípio dispositivo, os juizados especiais e matéria probatória (perícia). Cadernos Jurídicos, Escola Paulista da Magistratura, São Paulo, v. 2, n. 3, p. 87-100, jan./fev. 2001.

ALVIM, José Manoel de Arruda. Manual de direito processual civil. 6. ed. São Paulo: Ed. Revista dos Tribunais, 1997. v. 1 e 2.

. Sobre as multas instituídas nos arts. 14 e 18 do Código de Processo Civil. In: YARSHELL, Flávio Luiz; MORAES, Maurício Zanóide de. Estudos em homenagem à professora Ada Pellegini Grinover. 1. ed. São Paulo: DPJ Ed., 2005.

ALVIM, Teresa Arruda. Reflexões sobre o ônus da prova. Revista de Processo, Sao Paulo, v. 19, n. 76, p. 141-145, out./dez. 1994.

ANDREWS, Neil. English civil procedure: fundamentals of the new civil justice system. Oxford: Oxford University Press, 2003.

. The modern civil process: judicial and alternative forms of dispute resolution. Tubingen: Mohr Siebeck, 2008. 
ANDREWS, Neil. The pre-action phase. General Report - Common Law. In: GRINOVER, Ada Pellegrini; CALMON FILHO, Petrônio (Orgs.). DIREITO PROCESSUAL COMPARADO. CONGRESSO MUNDIAL DE DIREITO PROCESSUAL, 13. Rio de Janeiro: Forense, 2007.

ANDRIGHI, Fátima Nancy. Arbitragem nas relações de consumo: uma proposta concreta. Revista de Arbitragem e Mediação, São Paulo, v. 3, n. 9, p. 13-21, abr./jun. 2006.

. Mediação: um instrumento judicial para a paz social. Revista do Advogado, São Paulo, v. 26, n. 87, p. 134-137, set. 2006.

ARAGÃO, Egas Dirceu Moniz de. Direito a prova. Revista de Processo, São Paulo, v. 10, n. 39 , p. $98-118$, jul./set. 1985.

Regras de prova no Código Civil. Revista Forense, Rio de Janeiro, v. 100, n. 376, p. 45-57, nov./dez. 2004.

ARENHART, Sérgio Cruz. Ônus da prova e sua modificação no processo civil brasileiro. Revista Jurídica, Porto Alegre, v. 54, n. 343, p. 25-60, maio. 2006.

ASSIS, Araken de. Cumprimento da sentença. Rio de Janeiro: Forense, 2006.

AZEVEDO, Luis Carlos. Causas de reduzido valor econômico e seu tratamento no direito luso-brasileiro: o juiz das vintenas, o altomace, o juiz de paz. Revista da Faculdade de Direito da Universidade de São Paulo, São Paulo, v. 83, p. 129-34, jan./dez. 1988.

BARBOSA MOREIRA, José Carlos. Alguns problemas atuais da prova civil. Revista de Direito do Tribunal de Justiça do Estado do Rio de Janeiro, Rio de Janeiro, n. 4, p. 19-28, 1989.

. A importação de modelos jurídicos. In: Temas de direito processual: $8^{\mathrm{a}}$ série. São Paulo: Saraiva, 2004.

. O neoprivatismo no processo civil. Revista Síntese de Direito Civil e Processual Civil, Porto Alegre, v. 6, n. 34, p. 5-16, mar./abr. 2005.

O problema da duração dos processos: premissas para uma discussão séria. In: SERRANO MIGALLON, Fernando. Estúdios jurídicos em homenaje a Cipriano Gómez Lara. 1. ed. México: Porrua, 2007.

O processo civil brasileiro entre dois mundos. Revista Forense, Rio de Janeiro, v. 98, n. 359, p. 123-130, jan./fev. 2002. 
BARBOSA MOREIRA, José Carlos. O processo civil contemporâneo: um enfoque comparativo. Revista Forense, Rio de Janeiro, v. 370, p. 53-65, nov. 2003.

Provas atípicas. Revista de Processo, São Paulo, v. 19, n. 76, p. 114-126, out./dez. 1994.

A revolução processual inglesa. Revista de Processo, São Paulo, v. 29, n. 118, p. 75-88, nov./dez. 2004.

A subserviência cultural. In: Temas de direito processual: $7^{\mathrm{a}}$ série. São Paulo: Saraiva, 2004.

. Uma novidade: o Código de Processo Civil inglês. Revista de Processo, São Paulo, v. 25, n. 99, p. 74-83, jul./set. 2000.

(Coord.). Abuso de direitos processuais. Rio de Janeiro: Forense, 2000.

BARBOSA, Águida Arruda; MALHEIROS, Antonio Carlos; GROENINGA, Giselle; ROSO, Jayme Vita; DIAS, José Carlos de Mello; PRADO, Lídia Reis de Almeida; GUILHERME, Luiz Fernando do Vale de Almeida; MORAES, Nel. Mediação e outros meios de pacificação de conflitos. Projeto de lei 4.827/98 de autoria da deputada Zulaê Cobra, bem como as versões de consenso apresentadas pelo instituto brasileiro de direito processual e instituto brasileiro de direito de família, foram objeto de análise pelo instituto dos advogados de São Paulo, por meio da instauração do processo 350/2004. Revista do Instituto dos Advogados de São Paulo, São Paulo, v. 8, n. 16, p. 339-365, jul./dez. 2005.

BEDAQUE, José Roberto dos Santos. Novas tendências em matéria de fase preliminar. Relatório Síntese. In: GRINOVER, Ada Pellegrini; CALMON FILHO, Petrônio (Orgs.). DIREITO PROCESSUAL COMPARADO. CONGRESSO MUNDIAL DE DIREITO PROCESSUAL, 13. Rio de Janeiro: Forense, 2007.

BENTHAM, Jeremias. Tratado de las pruebas judiciales. Buenos Aires, Valleta, 2002.

BERLONI, Ugo. Affidavit come modalità alternativa di assunzione della prova testimoniale - l'esperienza nordamericana. Rivista Trimestrale di Diritto e Procedura Civile, Milano, v. 61, n. 4, p. 1267-1289, dic. 2007.

BERNSTEIN, Lisa. Understanding the limits of court-connected ADR: a critique of federal courts-annexed arbitration programs. Pennsylvania Law Review, Philadelphia, PA, v. 141, n. 2169, 1993. 
BESSO, Chiara. La prova prima del processo. Turim: G. Giappichelli, 2004.

BOTELHO DE MESQUITA, José Ignácio. Coisa julgada. Rio de Janeiro: Forense, 2004.

. As novas tendências do direito processual: uma contribuição para seu reexame. Revista Forense, Rio de Janeiro, v. 98, n. 361, p. 47-72, maio/jun. 2002.

- Teses, estudos e pareceres de processo civil. São Paulo: Ed. Revista dos Tribunais, 2005-2007. v. 1 e 3.

et al. O colapso das condições da ação? Um breve ensaio sobre os efeitos da carência de ação. Revista do Advogado, São Paulo, v. 26, n. 88, p. 109-127, nov. 2006.

BRAGA NETO, Adolfo. Reflexões sobre a conciliação e a mediação de conflitos. In: SALLES, Carlos Alberto de (Coord.). As grandes transformações do processo civil brasileiro: homenagem ao Professor Kazuo Watanabe. São Paulo: Quartier Latin, 2009.

BRANNAN, Julie et al. Blackstone's guide to the civil procedure rules. London: Blackstone, 1999.

BRAZIL, Wayne D. The adversary character of civil discovery: a critique and proposals for change. Vanderbilt Law Review, Nashville, TN, v. 31, 1978.

BUCHAN, Andrew; KENNEDY, Jenny; WOOLF, Eliot. Personal injury practice. 5. ed. rev. London: Tottel Publishing, 2008.

CAENEGEM, R.C. van. History of European civil procedure. New York: Oceana, 1973.

CAHALI, Yussef Said. Honorários advocatícios. São Paulo: Ed. Revista dos Tribunais, 1997.

CÂMARA, Alexandre de Freitas. Conciliação a mediação no processo civil brasileiro estado da questão. Revista Dialética de Direito Processual, São Paulo, n. 22, p. 9-10, jan. 2005 .

Das relações entre a arbitragem e o poder judiciário. Revista CBAR, São Paulo, n. 6, p. 18-28, 2005.

CAMBI, Eduardo. Direito constitucional à prova no processo civil. São Paulo: Ed. Revista dos Tribunais, 2001.

O direito à prova no processo civil. Revista da Faculdade de Direito Universidade Federal do Paraná, Curitiba, v. 32, n. 34, p. 143-159. 2000. 
CAMBI, Eduardo. A prova civil: admissibilidade e relevância. São Paulo: Ed. Revista dos Tribunais, 2006.

CAPPELLETTI, Mauro. Os métodos alternativos de solução de conflitos no quadro do movimento universal de acesso à justiça. Revista de Processo, São Paulo, v. 19, n. 74, p. 82-97, abr./jun. 1994.

Political methods and political aspects of civil procedure reforms and trends in western and eastern Europe. Michigan Law Review, Ann Arbor, v. 69, n. 5, Apr. 1971.

Proceso, ideologias, sociedad. Buenos Aires: Ediciones Jurídicas EuropaAmérica, [s.d.].

CARMONA, Carlos Alberto. Arbitragem e processo. 2. ed. São Paulo: Atlas, 2004. . A arbitragem no processo civil brasileiro. São Paulo: Malheiros Ed., 1993.

CARNELUTTI, Francesco. La prueba civil. Buenos Aires: Ediciones Arayua, 1955.

CENTRO BRASILEIRO DE ESTUDOS E PESQUISAS JUDICIAIS - CEBEPEJ, Juizados Especiais Cíveis: estudo. Brasília, 2006. Disponível em: <www.cebepej.org.br>.

CHASE, Oscar G. A “excepcionalidade” americana e o direito processual comparado. Revista de Processo, São Paulo, v. 28, n. 110, p. 115-140, abr.jun. 2003.

. Legal processes and national culture. Cardozo Journal of International and Comparative Law, New York, v. 5, n. 1, 1997.

CHIARLONI, Sergio. Per la chiarezza di idee in tema di analisi comparata della prova per testimoni. Rivista di Diritto Processuale, Padova, v. 49, n. 2, p. 382-394, apr./giug. 1994.

CHIOVENDA, Giuseppe. Instituições de direito processual civil. Trad. de J, Guimarães Menegale. São Paulo: Saraiva, 1965. v. 1, 2 e 3.

CINTRA, Antonio Carlos de Araújo; GRNOVER, Ada Pellegrini; DINAMARCO, Cândido Rangel. Teoria geral do processo. 20. ed. São Paulo: Malheiros Ed., 2004.

CIVIL Procedure Rules and Pre-Action Protocols. Disponível em: $<$ http://www.justice.gov.uk/civil/procrules_fin/>.

CLERMONT, Kevin M; SHERWIN, Emily. A comparative view of standards of proof. The American Journal of Comparative Law, Berkeley, v. 50, n. 2, p. 243-275, 2002. 
COUTURE, Eduardo J. Fundamentos del derecho procesal civil. Buenos Aires: De Palma, 1987.

CRANSTON, Ross. Complex litigation: the Commercial Court. Civil Justice Quarterly, v. 190, 2007.

CRESCI SOBRINHO, Elicio de. Dever de veracidade das partes no novo Código de Processo Civil. São Paulo: Vellenich, 1975.

. Fundamentos histórico-retóricos da teoria geral da prova. Revista de Processo, São Paulo, v. 16, n. 63, p. 42-53, jul./set. 1991.

CRUZ, José Raimundo Gomes da. Exibição de documento ou outra coisa. Revista de Processo, São Paulo, v. 30, n. 124, p. 67-75, jun. 2005.

DALL'AGNOL JUNIOR, Antonio Janyr. Distribuição dinâmica dos ônus probatórios. Revista dos Tribunais, São Paulo, v. 90, n. 788, p. 92-107, jun. 2001.

DAMASKA, Mirjan R. The faces of justice and state authority. Yale University Press, 1986.

DAVID, René. O direito inglês. 2. ed. São Paulo: Martins Fontes, 2006.

Os grandes sistemas de direito contemporâneo. São Paulo: Martins Fontes, 2002.

DAVIES, Geoffrey. The reality of civil justice reform: why we must abandon the essential elements o four system. Journal of Judicial Administration, v. 12, n. 155, 2003.

DIAS, Jean Carlos. Como a legislação processual civil e a jurisprudência brasileira estimulam a litigância de má-fé. Revista Dialética de Direito Processual, São Paulo, n. 75, p. 55-60, jun. 2009.

DIAS, José Carlos de Mello. A mediação vista como forma de pacificação de conflitos. In: SALLES, Carlos Alberto de (Coord.). As grandes transformações do processo civil brasileiro: homenagem ao Professor Kazuo Watanabe. São Paulo: Quartier Latin, 2009.

DINAMARCO, Cândido Rangel. Instituições de direito processual civil. São Paulo: Malheiros Ed., 2002.

_. Instituições de direito processual civil. São Paulo: Malheiros Ed., 2001. v. 2. ; GRINOVER, Ada Pellegrini; CINTRA, Antonio Carlos de Araújo. Teoria geral do processo. 15. ed. São Paulo: Malheiros Ed., 1999. 
EMERGING Findings. An early evaluation of the civil justice reforms, March 2001. Disponível em: <http://www.dca.gov.uk/civil/emerge/emerge.htm>.

ENGELMANN, Arthur. A history of continental civil procedure. London: J. Murray, 1928.

FISS, Owen. Contra o acordo. In: Um novo processo civil: estudos norteamericanos sobre jurisdição, constituição e sociedade. Coordenação da tradução de Carlos Alberto de Salles; Trad. Daniel Porto Godinho da Silva, Melina de Medeiros Rós. São Paulo: Ed. Revista dos Tribunais, 2004. p. 121-145.

FOSKETT, David. Settlement under the civil procedure rules. London: Sweet and Maxwell, 1999.

FRANKEL, Marvin E. The search for truth continued: more disclosure, less privilege. University of Colorado Law Review, Boulder, CO, v. 51, 1982-1983.

FRANQUEVILLE, Charles de, Le système judiciaire de la Grande Bretagne. Paris, Rothschild, 1893. 2 v.

FREITAS JR. Antônio Rodrigues de. Conflitos de justiça e limites da mediação para a difusão da cultura da paz. In: SALLES, Carlos Alberto de (Coord.). As grandes transformações do processo civil brasileiro: homenagem ao Professor Kazuo Watanabe. São Paulo: Quartier Latin, 2009.

FREY, Martin A. Alternative dispute resolution in the twenty-first century: does ADR offer second class justice? Tulsa Law Journal, Buffalo, New York, v. 36, n. 727, 2001.

FULLER, Lon. The forms and limits of adjudication. Harvard Law Review, Cambridge. v. 92, n. 353, 1979.

FURTHER Findings. A continuing evaluation of the civil justice reforms, March 2001. Disponível em: <http://www.dca.gov.uk/civil/reform/ffreform.htm>.

FUX, Luiz et al. (Coords.). Processo e Constituição: estudos em homenagem ao professor José Carlos Barbosa Moreira. São Paulo: Ed. Revista dos Tribunais, 2006.

GALANTER, Marc. A justiça não se encontra apenas nas decisões dos tribunais. In: HESPANHA, Antonio M. (Coord.). Justiça e litigiosidade: história e perspectiva. Lisboa: Fundação Calouste Gulbenkian, 1993.

Why the "haves" come out ahead: speculations on the limits of legal change. Law and Society Review, Denver, v. 9, n. 95, 1974. 
GAMBOA BALBÍN, César Leônidas. Las virtudes e los vícios de la conciliación extrajudicial: dualidad discursiva de la justicia moderna. Lima: Justicia Viva, 2005. Disponível em: <www.justiciaviva.org.pe/concurso_giusti/gamboa.pdf>.

GARAPON, Antoine; PAPADOPOULOS, Ioanis. Introduction to comparative legal culture: the civil law and the common law on evidence and judgment. Cornell Law School Working Papers, Paper, n. 15, 2004.

GERLIS, Stephen M; LOUGHLIN, Paula. Civil procedure. London: Cavendish, 2004.

GILLES, Peter. Civil justice systems and civil procedures in conversion. Main problems and fundamental reform movements in Europe: a comparative view. Revista de Processo, São Paulo, v. 34, n. 173, jul. 2009.

GLASSON, Ernest Désiré. Histoire du droit et des institutions politiques, civiles et judiciaires de l'Angleterre, comparés au droit et aux institutions de la France, depuis leur origine jusqu'à nos jours. Paris: G. Pedone-Lauriel, 1883.

La preuve en justice de l'Antiquité à nos jours. Rennes: Presses Universitaires de Rennes, 2003.

GLOSSARY.

Disponível

em:

$<$ http://www.justice.gov.uk/civil/procrules_fin/menus/glossary.htm>.

GLOVER, Jeremy. Paying the price of failing to comply with the pre Action Protocol. (Stent Foundations Ltd) (Peter Dann Ltd) (Case overview), Mondaq Business Briefing, Mai/07. Disponível em: <http://www.accessmylibrary.com/coms2/summary_028630836320_ITM>.

- A pragmatic approach to the pre Action Protocol. (Orange Personal Communications Services Ltd v Hoare Lea) (Case overview). Mondaq Business Briefing, Feb./08. Disponível em: <http://www.accessmylibrary.com/coms2/summary_028633935624_ITM>.

GOLANN, Dwight. Making alternative dispute resolution mandatory: the constitutional issues. Oregon Law Review, Eugene, OR, v. 68, n. 487, 1989.

GOLDING, Martin P. On the adversary system and justice. In: BRONAUGH, R. Philosophical law: authority, equality, adjudication, privacy. Westpoint, Conn.: Greenwood Press, 1978. 
GOTTWALD, Peter. Simplified civil procedure in West Germany. American Journal of Criminal Law, Austin, TX, v. 31, n. 687, 1983.

GRECO, Leonardo. A prova no processo civil: do código de 1973 ao novo código civil. Revista Forense, Rio de Janeiro, v. 100, n. 374, p. 183-199, jul./ago. 2004.

GRINOVER, Ada Pellegrini. A marcha do processo. Rio de Janeiro: Forense Universitária, 2000.

GROEN, Bart. New trends in pre-action. General Report Civil Law. In: GRINOVER, Ada Pellegrini; CALMON FILHO, Petrônio (Orgs.). DIREITO PROCESSUAL COMPARADO. CONGRESSO MUNDIAL DE DIREITO PROCESSUAL, 13. Rio de Janeiro: Forense, 2007.

HARRISON, Richard; WILLIAMSON, Ashleigh. Sanctioning non-compliance? Mondaq Business Briefing, Ago/2003. Disponível em:<http://www.accessmylibrary.com/coms2/summary_0286-24078460_ITM>.

HAZARD JR., Geoffrey C.; TARUFFO, Michele. Transnational rules of civil procedure rules and commentary. Cornell International Law Journal, Ithaca, NY, v. 30, n. 4931997. JACKSON, John D. Playing the culture card in resisting cross-jurisdictional transplants: a comment on "legal processes and national culture", Cardozo Journal of International and Comparative Law, New York, v. 5, n. 51, 1997.

JACKSON, Lord Justice Rupert. Review of civil litigation costs: preliminary report. May 2009. Disponível em: <http://www.judiciary.gov.uk/about_judiciary/costreview/index.htm>.

JACOB, Joseph M. Civil litigation: practice and procedure in a shifting culture. Hertfordshire: EMIS Professional Publishing, 2001.

JAVIER RAZNOVICH, Leonardo; Radiografía del proceso civil argentino. Buenos Aires: Ciudad Argentina, 1998.

JOLOWICZ, J. A. Adversarial and Inquisitorial Models of Civil Procedure (2003) 52 ICLQ 281. Trad. por José Carlos Barbosa Moreira. Revista Forense, Rio de Janeiro, v. 100, n. 372, p. 135-147, mar./abr. 2004.

Civil litigation: what's it for? Cambridge Law Journal, v. 508, 2008. 
JOLOWICZ, J. A. On civil procedure (Cambridge Studies in International and Comparative Law). Cambridge: Cambridge University Press, 2000. . A reforma do processo civil inglês: uma derrogação ao Adversary System. Revista de Processo, São Paulo, v. 19, n. 75, p. 64-75, jul./set. 1994.

. The woolf report and the adversary system. Civil Justice Quarterly, v. 15, n. 198, 1996.

KHAN, Malcolm; ROBSON, Michelle. Clinical negligence. 2. ed. Routledge Cavendish, 2001.

KINGSBURY, Esra. Civil procedure rules: part 36 and pre-action offers. The National Law Journal, v. 152, n. 714, May 2002.

LANGBEIN, John H. German advantage in civil procedure. University of Chicago Law Review, v. 52, n. 823, 1985.

LE GALL, Erwan. Le devoir de collaboration des parties à la manifestation de la vérité dans les litiges privés: remarques sur l'adage nemo tenetur edere contra se. Thesis (Doctoral) - Université de Paris, 1967.

LEGUM, Barton. Discovery in aid of foreign proceedings provided by United States Courts. Revue de Droit des Affaires Internationales, Paris, n. 7, p. 747-753, 1998.

LEITE, Jose Luis Marasco C. Verdade, prova e sociedade. Revista da Faculdade de Direito da Universidade Federal de Pelotas, v. 39, n. 15, p. 233-243, maio 1995.

LEMES, Selma M. Ferreira. O cenário atual da arbitragem no Brasil. Revista de Arbitragem e Mediação, São Paulo, v. 1, n. 3, p. 129-137, set./dez. 2004.

LIEBMAN, Enrico Tullio. Manual de direito processual civil. Rio de Janeiro: Forense, 2004.

LOPES, João Batista. Iniciativas probatórias do juiz e os arts. 130 e 133 do CPC. Revista dos Tribunais, São Paulo, v. 84, n. 716, p. 41-47, jun. 1995.

. O direito a prova no processo civil. Revista Jurídica, Campinas, v. 15, n. 2, p. 6670, 1999.

O juiz e a litigância de má-fé. Revista dos Tribunais, São Paulo, v. 86, n. 740, p. 128-133, jun. 1997. 
LOPES, João Batista. A prova no direito processual civil. 3. ed. São Paulo: Ed. Revista dos Tribunais, 2007.

LORENCINI, Marco Antônio Garcia Lopes. Prestação jurisdicional pelo estado e meios alternativos de solução de controvérsias: convivência e formas de pacificação social. Uma sugestão de integração. 2006. Tese (Doutorado) - Faculdade de Direito, Universidade de São Paulo, São Paulo, 2006.

MAGANO, Octavio Bueno. Legislação e autocomposição. Revista do Tribunal Regional do Trabalho da Oitava Região, Belém, n. 70, jan./jun./2003.

MALUF, Carlos Alberto Dabus. Exibição de documento ou coisa. Revista Forense, Rio de Janeiro, v. 302, n. 84, p. 261-267, jun. 1988.

MARCHEIS, Chiara Besso. Litigant's duty to disclose. Apresentação oferecida na Italian Academy na Universidade de Columbia, fev. 2008.

MARINONI, Luiz Guilherme. Estudos de direito processual civil: homenagem ao professor Egas Dirceu Moniz Aragão. São Paulo: Ed. Revista dos Tribunais, 2005.

_ (Coord.). Estudos de direito processual. São Paulo: Ed. Revista dos Tribunais, 2005.

MARTINS, Sergio Pinto. Cabimento da arbitragem para solucionar conflitos trabalhistas. Revista do Advogado, São Paulo, v. 26, n. 86, p. 76-82, jul. 2006.

MARTINS FILHO, Ives Gandra. A justiça do trabalho do ano 2000: as Leis ns. 9.756/1998, 9.957 e 9.958/2000, a Emenda Constitucional n. 24/1999 e a reforma do Judiciário. Revista LTr, São Paulo, v. 64, n. 2, p. 161-171, fev. 2000.

MATTHEWS, Paul; MALEK, Hodge M. Disclosure. 2. ed. London: Sweet \& Maxwell, 2001.

MATTOS NETO, Antonio José de. Direitos patrimoniais disponíveis e indisponíveis à luz da lei da arbitragem. Revista de Processo, São Paulo, v. 30, n. 122, p. 151-166, abr. 2005. McQUATER, John. The future of Part 36: Part 3. Journal of Personal Injury Law, 2009. MENKEL-MEADOW, Carrie. Ethics in alternative dispute resolution: new issues, no answers from the adversary conception of lawyers' responsibilities. Texas Law Review, v. 38, n. 407, 1997. 
MENKEL-MEADOW, Carrie. Pursuing settlement in an adversary culture: a tale of innovation co-opted or the law of ADR. Florida State University Law Review, v. 19, n. 1, 1999.

MILLAR, Robert Wyness. The mechanism of fact-discovery: a study in comparative civil procedure. Illinois Law Review, v. 32, n. 260, 1937-1938.

MILLER, Arthur R. The adversary system: dinosaur or phoenix. Minnesota Law Review, v. 69, n. 1, 1984.

MORE Civil Justice? The impact of the woolf reforms on pre-action behaviour. Institute of Advanced Legal Studies; University of Westminster, Apr. 2002.

MOREIRA, F. I. de Carvalho. Constituição política do império do Brasil seguida do acto addicional, lei da sua interpretação, e a lei conselho estado. Rio de Janeiro: Eduardo \& Henrique Laemmert, 1855.

NEGRÃO, Theotônio; GOUVÊA, José Roberto F. Código de Processo Civil e legislação processual em vigor. São Paulo: Saraiva, 2008.

NERY JUNIOR, Nelson; NERY, Rosa Maria de Andrade. Código de Processo Civil comentado e legislação extravagante. São Paulo: Ed. Revista dos Tribunais, 2008.

NEVES, Daniel Amorim Assunção. Ações probatórias autônomas. 2006. Tese (Doutorado), - Faculdade de Direito, Universidade de São Paulo, São Paulo, 2006. . Ações probatórias autônomas. São Paulo: Saraiva, 2008.

Algumas considerações sobre as limitações procedimentais à busca da verdade no processo civil brasileiro. Revista Dialética de Direito Processual Civil, São Paulo, Dialética, n. 30, 2005.

NEWMAN, Paul. How much will it cost me? Construction Newsletter, 2005.

OLIVEIRA, Celso Marcelo de. Arbitragem na relação de consumo: solução para desafogar o nosso Poder Judiciário. IOB-Repertório de Jurisprudência: civil, processual, penal e comercial. São Paulo, n. 14, p. 438-435, jul. 2005.

PACHÁ, Andréa. A Sociedade merece um bom acordo. Disponível em: $<$ http://www.cnj.jus.br/index.php?option=com_content\&view=article\&id=7274:asociedade-merece-um-bom-acordo\&catid=74:artigos \&Itemid=129>. 
PADILLA, Luiz R. Nunes. Litigância de má-fé no CPC reformado. Revista de Processo, São Paulo, v. 20, n. 78, p. 101-117, abr./jun. 1995.

PART 36 of the civil procedure rules: offers to settle and payments into court. Response to consultation paper (CP(R) 02/06). Department for Constitutional Affairs, Ago. 2006. Disponível em: <http://www.dca.gov.uk/consult/civilproc36/response0206.pdf>.

PART 36 of the civil procedure tules: offers to settle and payments into court". Consultation paper (CP 02/06). Department for Constitutional Affairs, Jan. 2006. Disponível em: <http://www.dca.gov.uk/consult/civilproc36/civilprocrules_part36.pdf>.

PARTINGTON, Martin. ADR: recent developments, future challenges. Civil Justice Quarterly, v. 99, 2004.

PAYMENTS into Court in Satisfaction of Claims. Lord Chancellor Department. Aug. 2001.

PENTEADO, Jaques de Camargo. Produção de provas. Revista dos Tribunais, São Paulo, v. 77, n. 627, p. 383-388, jan. 1988.

PERFIL das maiores demandas judiciais no TJERJ, Poder Judiciário - Tribunal de Justiça do Estado do Rio de Janeiro, jul. 2004. Disponível em: <www.tjrj.jus.br>.

PEYSNER, John; SEVIRATNE, Mary. The management of civil cases: the courts and the post-Woolf landscape. DCA Research Series n. 9, Nov. 2005. Disponível em: $<$ http://www.dca.gov.uk/research/2005/9_2005_full.pdf>.

; __ The management of civil cases: a snapshot. Civil Justice Quarterly, v.

312, 2006. Disponível em: <http://www.dca.gov.uk/research/2005/9_2005_full.pdf>.

PINTO, Ana Cecília Roland Guedes. O conflito familiar na justiça: mediação e o exercício dos papéis. Revista do Advogado, São Paulo, v. 62, p. 64-71, mar. 2001.

PINTO, Nelson Luiz. Exame de livros e documentos comerciais: requerimento de produção antecipada de prova: medida inadequada: hipótese de exibição de documento: inteligência dos arts. 844, III do CPC, 17,18,19 e 290 do Código Comercial. Revista de Processo, São Paulo, v. 16, n. 62, p. 260-262, 1991. 
PITT, Gioconda Fianco. Dever de veracidade no processo civil brasileiro e sua relação com o instituto da discovery do processo norte-americano da common Law. In: KNIJNIK, Danilo (Coord). Prova judiciária: estudos sobre o novo direito probatório. Porto Alegre: Livr. do Advogado, 2007.

PORTELLA, Joaquim Pires Machado. Constituição política do império do Brazil confrontada com outras constituições e annotada. Rio de Janeiro: Typographia Nacional, 1876.

POSNER, Richard. Economic analysis of law. $5^{\text {th }}$ ed. 1998.

RESNIK, Judith. Competing and complementary rule systems: civil procedure and ADR: procedure as contract. Notre Dame Law Review, Notre Dame, v. 80, n. 593, 2005.

Many doors? Closing doors? Alternative dispute resolution and adjudication. Ohio State Journal on Dispute Resolution, v. 10, n. 212, 1995.

REYNOLDS, Michael P. The expert witness in construction disputes. WileyBlackwell, 2001 .

RIBEIRO, Darci Guimarães. Tendências modernas da prova. Revista Jurídica, Porto Alegre, v. 43, n. 218, p. 5-22, dez. 1995.

RICHARDS, Greg. Damned if you do, damned if you don't. Cons. Law, v. 17, n. 13, 2006. ROBERTS, Simon. Settlement as civil justice. Modern Law Review, v. 63, n. 739, 2000.

SAAD, Marta; MALAN, Diogo. Origens históricas dos sistemas acusatório e inquisitivo. Revista dos Tribunais, São Paulo, v. 94, n. 842, p. 413-436, dez. 2005.

SALLES, Carlos Alberto de. Mecanismos alternativos de solução de controvérsias e acesso à justiça: a inafastabilidade da tutela jurisdicional recolocada. In: FUX, Luiz; NERY JR., Nelson; WAMBIER, Teresa Arruda Alvim (Coord.). Processo e Constituição: estudos em homenagem ao professor José Carlos Barbosa Moreira. São Paulo: Ed. Revista dos Tribunais, 2006.

SANTOS, Ernane Fidelis dos. Aspectos da exibição preparatória de coisa e documento. Revista de Processo, São Paulo, v. 13, n. 52, p. 71-77, out./dez. 1988.

Sistema probatório do processo civil brasileiro. Revista Forense, Rio de Janeiro, v. 355, n. 97, p. 51-59 maio./jun. 2001. 
SANTOS, Lia Justiniano dos. A introdução da mediação no Judiciário paulista através do setor de conciliação do Tribunal de Justiça de São Paulo. Revista do Advogado, São Paulo, v. 26 , n. 87 , p. $138-144$, set. 2006.

SANTOS, Moacyr Amaral. Primeiras linhas de direito processual civil. 26. ed. rev. e atual. por Maria Beatriz Amaral Santos Köhnen. São Paulo: Saraiva, 2004. v. 1.

. Primeiras linhas de direito processual civil. 25. ed. rev. e atual. por Maria Beatriz Amaral Santos Köhnen. São Paulo: Saraiva, 2009. v. 2.

. Prova judiciária no cível e comercial. São Paulo: Max Limonad, 1952. v. 1 e 4.

SCHLOSSER, Alan. Trial Court Procedures in Continental Europe. In: PLATTO, Charles (Ed.). Trial and Court Procedures Worldwide, 1991. p. 77-101.

SCOTT. Pre-action disclosure: legislation and protocols. Civil Justice Quarterly, v. 20, n. 213, 2001.

SERRANO, Rafael H. Gamboa. Régimen probatorio segun el decreto de descongestion judicial (analisis del dec. 2651 de 1991). Universitas: ciencias juridicas y socioeconomicas, Bogotá, n. 83, p. 187-148, nov. 1992.

SILVA, Paulo Eduardo Alves da. Gerenciamento de processos e cultura de litigância - a experiência do "case management" inglês. In: SALLES, Carlos Alberto de (Coord.). As grandes transformações do processo civil brasileiro: homenagem ao Professor Kazuo Watanabe. São Paulo: Quartier Latin, 2009.

SILVA FILHO, Antonio Carlos Monteiro da. Processo civil: um anticristo na arbitragem. Revista do Advogado, São Paulo, v.25, n. 84, p. 7-16, dez. 2005.

SLAPPER, Gary; KELLY, David. The english legal system. 9. ed. Routledge-Cavendish, 2008.

SOUSA, Joaquim Rodrigues de. Análise e comentário da Constituição Política do Império do Brasil. Maranhão: B de Mattos, 1870.

TALAMINI, Eduardo. A (in)disponibilidade do interesse público: conseqüências processuais (composições em juízo, prerrogativas processuais, arbitragem e ação monitória). Revista de Processo, São Paulo, v. 30, n. 128, p. 59-77, out. 2005.

Prova emprestada no processo civil e penal. Revista de Processo, São Paulo, v. 23, n. 91, p. 92-114, jul./set. 1998. 
TARTUCE, Fernanda. Mediação nos conflitos civis. São Paulo: Método, 2008.

TARUFFO, Michele. Note per una riforma del diritto delle prove. Rivista di Diritto Processuale, Padova, v. 41, n. 23, p. 247-292, abr./set. 1986.

Observações sobre os modelos processuais de civil law e de common law. Trad. de José Carlos Barbosa Moreira. Revista de Processo, São Paulo, v. 110, n. 141, abr./jun. 2003.

TAVARES, Ana Lucia de Lyra. Paralelismo na construção do direito romano classico e do direito ingles. Revista Brasileira de Direito Comparado, Rio de Janeiro, n. 16, p. 66-89, 1999.

THEODORO JUNIOR, Humberto. Aspectos relevantes da prova no processo civil. Revista Jurídica, Porto Alegre, v. 42, n. 195, p. 5-27, jan. 1994.

. Boa-fé e processo - princípios éticos na repressão à litigância de má-fé - papel do juiz. Revista Jurídica, Porto Alegre, n. 368, jun. 2008.

Prova: princípio da verdade real; poderes do juiz; ônus da prova e sua eventual inversão; provas ilícitas; prova e coisa julgada nas ações relativas à paternidade (DNA). Revista de Direito Privado, São Paulo, v. 5, n. 17, p. 9-28, jan./mar. 2004.

THOMAS, Martin. Pre-Action Protocols (rules and structure), Mondaq Business Briefing, Ago/02. Disponível em: <http://www.accessmylibrary.com/coms2/summary_028625771306_ITM>.

TROCKER, N; VARANO, Vicenzo (Eds.). The reforms of civil procedure in comparative perspective. Torino: Giappichelli, 2005.

TRYING Woolf. Law Society Gazette, abr. 2000.

VARANO, Vincenzo. The modern civil process. Judicial and alternative forms of dispute resolution in England. Civil Justice Quarterly, v. 152, 2009. Publication review Neil Andrews.

WAISBERG, Ivo. Anteprojeto de lei de mediação no processo civil. Projeto e motivação. Figura do mediador. Mediação prévia e incidental. Revista de Arbitragem e Mediação, São Paulo, v. 1, n. 2, p. 254-259, maio/ago. 2004. 
WAMBIER, Luiz Rodrigues; WAMBIER, Teresa Arruda Alvim; MEDINA, José Miguel Garcia. Breves comentários à nova sistemática processual civil, II: Leis 11.187/2005, 11.232/2005, 11.276/2006 e 11.280/2006, São Paulo: Ed. Revista dos Tribunais, 2006.

WATANABE, Kazuo, Cultura da sentença e cultura da pacificação. In: YARSHELL, Flávio Luiz; MORAES, Maurício Zanóide de. Estudos em homenagem à professora Ada Pellegini Grinover. 1. ed. São Paulo: DPJ Ed., 2005.

WESTON, Maureen A. Checks on participant conduct in compulsory ADR: Reconciling the tension in the need for good-faith participation, autonomy and confidentiality. Indiana Law Journal, v. 76, n. 591, 2001.

WOOLF, The Additional Responsibilities of the Judiciary in the new millennium. In: Markeninis (Ed.). The clifford chance millennium lectures: the coming together of the common law and the civil law. Oxford: Hart Publishing, 2000.

YARSHELL, Flávio Luiz. Antecipação da prova sem o requisito da urgência, e direito autônomo à prova. São Paulo: Malheiros Ed., 2009.

- Breves considerações acerca da exibição do documento ou coisa no direito positivo brasileiro. In: MARINONI, Luiz Guilherme (Coord.). Estudos de direito processual civil: homenagem ao Professor Egas Dirceu Moniz de Aragão. São Paulo : Ed. Revista dos Tribunais, 2006.

ZUCKERMAN, Adrian A. S. Zuckerman on civil procedure. London: Sweet \& Maxwell, 2007.

Zuckerman on civil procedure: principles of practice. 2. ed. London: Sweet \& Maxwell, 2006.

; CRANSTON, Ross. Reform of civil procedure: essays on access to justice. Oxford : Clarendon Press, 1995.

(Ed.). Civil justice in crisis: comparative perspectives of civil procedure. Consultant editors, Sergio Chiarloni, Peter Gottwald. Oxford: Oxford University Press, 1999. 


\section{CAsos}

AL Barnes Ltd v Time Talk (UK) Ltd [2003] EWCA Civ 402.

Alfred McAlpine Capital Projects Ltd v SIAC Construction (UK) Ltd [2005] EWHC 3139 (TCC).

Ali-Reza-Delta Transport v United Arab Shipping Co [2003] 3 All ER 1297, [2004] 1 WLR 168.

Amber v Stacey [2001] 2 All ER 88, [2001] 1 WLR 1225.

Black v Sumitomo Corporation [2003] 3 All ER 643, [2002] 1 WLR 1562.

Burchard v Bullard [2005] EWCA Civ 358.

Calderbank v Calderbank [1975] 3 All ER 333, [1975] 3 WLR 586.

Capital Bank plc v Stickland [2005] 2 All ER 544, [2005] 1 WLR 3914.

Carver v BAA plc [2008] EWCA Civ 412.

Charles Church Developments Ltd v Stent Foundations Ltd [2007] EWHC 855 (TCC).

Crouch v King's Healthcare NHS Trust [2005] 1 All ER 207, [2005] 1 WLR 2015.

Cundall Johnson and Partners LLP v Whipps Cross University Hospital NHS Trust [2007] EWHC 2178 (TCC).

Cutts v Head [1984] Ch 290.

Daniels v The Commissioner of Police for the Metropolis [2005] EWCA Civ 1312.

Dunnett v Railtrack Plc [2002] 2 All ER 850, [2002] 1 WLR 2434.

Dyson v Leeds City Council [2000] CP Rep 42.

English v Emery Richmond \& Strick Ltd [2002] 3 All ER 385 at [110]-[116].

Flynn v Scougal [2004] 3 All ER 609, [2004] 1 WLR 3069.

Ford v GKR Construction Ltd [2000] 1 All ER 802, [2000] 1 WLR 1397.

Fox, Justice in the twenty-first century (2000) ch 10.

Garratt v Saxby [2004] 1 WLR 2152.

Halsey v Milton Keynes General NHS Trust [2004] 4 All ER 920, [2004] 1 WLR 3002. 
Hickman v Blake-Lapthorn [2006] EWHC 12.

Johnsey Estates (1990) Ltd v Secretary of State for the Environment [2001] EWCA Civ 535 at [32].

McGlinn v Waltham Contractors Ltd [2005] EWHC 1419 (TCC).

McLoughlin v Jones [2006] EWCA Civ 1167.

Mitchell v James [2003] 2 All ER 1064, [2004] 1 WLR 158.

Neave v Neave [2003] EWCA Civ 325 at [10].

Orange Personal Communications Services Ltd v Hoare Lea (a firm) [2008] EWHC 223 (TCC).

Reed Executive plc v Reed Business Information Ltd [2004] 4 All ER 942, [2004] 1 WLR 3026.

Reid Minty (a firm) v Taylor [2002] 2 All ER 150, [2002] 1 WLR 2800.

Sowerby v Charlton [2006] 1 WLR 568.

Stoke on Trent City Council v Walley [2006] 4 All ER 1230, [2007] 1 WLR 352. 
ANEXO

Pre-Action Protocol for Personal Injury Claims 


\section{Pre-Action Protocol for Personal Injury Claims}

\section{Contents}

1 Introduction

2 Notes of guidance

3 The protocol

4 Rehabilitation

5 Resolution of issues

A Letter of claim

B Pre-action personal injury protocol standard disclosure lists

C Letter of instruction to medical expert

D THE 2007 REHABILITATION CODE

\section{Introduction}

1.1 Lord Woolf in his final Access to Justice Report of July 1996 recommended the development of pre-action protocols:

To build on and increase the benefits of early but well informed settlement which genuinely satisfy both parties to dispute.

1.2 The aims of pre-action protocols are:

- more pre-action contact between the parties

- better and earlier exchange of information

- better pre-action investigation by both sides

- to put the parties in a position where they may be able to settle cases fairly and early without litigation

- to enable proceedings to run to the court's timetable and efficiently, if litigation does become necessary

- to promote the provision of medical or rehabilitation treatment (not just in high value cases) to address the needs of the claimant

1.3 The concept of protocols is relevant to a range of initiatives for good litigation and prelitigation practice, especially:

- predictability in the time needed for steps pre-proceedings

- standardisation of relevant information, including documents to be disclosed. 
1.4 The Courts will be able to treat the standards set in protocols as the normal reasonable approach to pre-action conduct. If proceedings are issued, it will be for the court to decide whether non-compliance with a protocol should merit adverse consequences. Guidance on the court's likely approach will be given from time to time in practice directions.

1.5 If the court has to consider the question of compliance after proceedings have begun, it will not be concerned with minor infringements, e.g. failure by a short period to provide relevant information. One minor breach will not exempt the 'innocent' party from following the protocol. The court will look at the effect of non-compliance on the other party when deciding whether to impose sanctions.

\section{Notes of guidance}

2.1 The protocol has been kept deliberately simple to promote ease of use and general acceptability. The notes of guidance which follows relate particularly to issues which arose during the piloting of the protocol.

\section{Scope of the Protocol}

2.2 This protocol is intended to apply to all claims which include a claim for personal injury (except those claims covered by the Clinical Disputes and Disease and Illness Protocols) and to the entirety of those claims: not only to the personal injury element of a claim which also includes, for instance, property damage.

2.3 This protocol is primarily designed for those road traffic, tripping and slipping and accident at work cases which include an element of personal injury with a value of less than the fast track limit and which are likely to be allocated to that track. This is because time will be of the essence, after proceedings are issued, especially for the defendant, if a case is to be ready for trial within 30 weeks of allocation. Also, proportionality of work and costs to the value of what is in dispute is particularly important in lower value claims. For some claims within the value 'scope' of the fast track some flexibility in the timescale of the protocol may be necessary, see also paragraph 3.8 .

2.4 However, the 'cards on the table' approach advocated by the protocol is equally appropriate to higher value claims. The spirit, if not the letter of the protocol, should still be followed for multi-track type claims. In accordance with the sense of the civil justice reforms, the court will expect to see the spirit of reasonable pre-action behaviour applied in all cases, regardless of the existence of a specific protocol. In particular with regard to personal injury cases with a value of more than the fast track limit, to avoid the necessity of proceedings parties are expected to comply with the protocol as far as possible e.g. in respect of letters before action, exchanging information and documents and agreeing experts.

2.5 The timetable and the arrangements for disclosing documents and obtaining expert evidence may need to be varied to suit the circumstances of the case. Where one or both parties consider the detail of the protocol is not appropriate to the case, and proceedings are 
subsequently issued, the court will expect an explanation as to why the protocol has not been followed, or has been varied.

\section{Early Notification}

2.6 The claimant's legal representative may wish to notify the defendant and/or his insurer as soon as they know a claim is likely to be made, but before they are able to send a detailed letter of claim, particularly for instance, when the defendant has no or limited knowledge of the incident giving rise to the claim or where the claimant is incurring significant expenditure as a result of the accident which he hopes the defendant might pay for, in whole or in part. If the claimant's representative chooses to do this, it will not start the timetable for responding.

\section{The Letter of Claim}

2.7 The specimen letter of claim at Annex A will usually be sent to the individual defendant. In practice, he/she may have no personal financial interest in the financial outcome of the claim/ dispute because he/she is insured. Court imposed sanctions for non-compliance with the protocol may be ineffective against an insured. This is why the protocol emphasises the importance of passing the letter of claim to the insurer and the possibility that the insurance cover might be affected. If an insurer receives the letter of claim only after some delay by the insured, it would not be unreasonable for the insurer to ask the claimant for additional time to respond.

2.8 In road traffic cases, the letter of claim should always contain the name and address of the hospital where the claimant was treated and, where available, the claimant's hospital reference number.

2.9 The priority at letter of claim stage is for the claimant to provide sufficient information for the defendant to assess liability. Sufficient information should also be provided to enable the defendant to estimate the likely size of the claim.

2.10 Once the claimant has sent the letter of claim no further investigation on liability should normally be carried out until a response is received from the defendant indicating whether liability is disputed.

\section{Reasons for Early Issue}

2.11 The protocol recommends that a defendant be given three months to investigate and respond to a claim before proceedings are issued. This may not always be possible, particularly where a claimant only consults a solicitor close to the end of any relevant limitation period. In these circumstances, the claimant's solicitor should give as much notice of the intention to issue proceedings as is practicable and the parties should consider whether the court might be invited to extend time for service of the claimant's supporting documents and for service of any defence, or alternatively, to stay the proceedings while the recommended steps in the protocol are followed. 


\section{Status of Letters of Claim and Response}

2.12 Letters of claim and response are not intended to have the same status as a statement of case in proceedings. Matters may come to light as a result of investigation after the letter of claim has been sent, or after the defendant has responded, particularly if disclosure of documents takes place outside the recommended three-month period. These circumstances could mean that the 'pleaded' case of one or both parties is presented slightly differently than in the letter of claim and response. It would not be consistent with the spirit of the protocol for a party to 'take a point' on this in the proceedings, provided that there was no obvious intention by the party who changed their position to mislead the other party.

\section{Disclosure of Documents}

2.13 The aim of the early disclosure of documents by the defendant is not to encourage 'fishing expeditions' by the claimant, but to promote an early exchange of relevant information to help in clarifying or resolving issues in dispute. The claimant's solicitor can assist by identifying in the letter of claim or in a subsequent letter the particular categories of documents which they consider are relevant.

\section{Experts}

2.14 The protocol encourages joint selection of, and access to, experts. The report produced is not a joint report for the purposes of CPR Part 35. Most frequently this will apply to the medical expert, but on occasions also to liability experts, e.g. engineers. The protocol promotes the practice of the claimant obtaining a medical report, disclosing it to the defendant who then asks questions and/or agrees it and does not obtain his own report. The Protocol provides for nomination of the expert by the claimant in personal injury claims because of the early stage of the proceedings and the particular nature of such claims. If proceedings have to be issued, a medical report must be attached to these proceedings. However, if necessary after proceedings have commenced and with the permission of the court, the parties may obtain further expert reports. It would be for the court to decide whether the costs of more than one expert's report should be recoverable.

2.15 Some solicitors choose to obtain medical reports through medical agencies, rather than directly from a specific doctor or hospital. The defendant's prior consent to the action should be sought and, if the defendant so requests, the agency should be asked to provide in advance the names of the doctor(s) whom they are considering instructing.

\section{Alternative Dispute Resolution}

2.16 The parties should consider whether some form of alternative dispute resolution procedure would be more suitable than litigation, and if so, endeavour to agree which form to adopt. Both the Claimant and Defendant may be required by the Court to provide evidence that alternative means of resolving their dispute were considered. The Courts take the view that litigation should be a last resort, and that claims should not be issued prematurely when a settlement is still actively being explored. Parties are warned that if the protocol is not followed (including this paragraph) then the Court must have regard to such conduct when determining costs. 
2.17 It is not practicable in this protocol to address in detail how the parties might decide which method to adopt to resolve their particular dispute. However, summarised below are some of the options for resolving disputes without litigation:

- Discussion and negotiation.

- Early neutral evaluation by an independent third party (for example, a lawyer experienced in the field of personal injury or an individual experienced in the subject matter of the claim).

- Mediation - a form of facilitated negotiation assisted by an independent neutral party.

2.18 The Legal Services Commission has published a booklet on 'Alternatives to Court', CLS Direct Information Leaflet 23 (www.clsdirect.org.uk/legalhelp/leaflet23.jsp), which lists a number of organisations that provide alternative dispute resolution services.

2.19 It is expressly recognised that no party can or should be forced to mediate or enter into any form of $A D R$.

\section{Stocktake}

2.20 Where a claim is not resolved when the protocol has been followed, the parties might wish to carry out a 'stocktake' of the issues in dispute, and the evidence that the court is likely to need to decide those issues, before proceedings are started. Where the defendant is insured and the pre-action steps have been conducted by the insurer, the insurer would normally be expected to nominate solicitors to act in the proceedings and the claimant's solicitor is recommended to invite the insurer to nominate solicitors to act in the proceedings and do so 7-14 days before the intended issue date.

\section{The protocol}

\section{Letter of claim}

3.1 The claimant shall send to the proposed defendant two copies of a letter of claim, immediately sufficient information is available to substantiate a realistic claim and before issues of quantum are addressed in detail. One copy of the letter is for the defendant, the second for passing on to his insurers.

3.2 The letter shall contain a clear summary of the facts on which the claim is based together with an indication of the nature of any injuries suffered and of any financial loss incurred. In cases of road traffic accidents, the letter should provide the name and address of the hospital where treatment has been obtained and the claimant's hospital reference number. Where the case is funded by a conditional fee agreement (or collective conditional fee agreement), notification should be given of the existence of the agreement and where appropriate, that there is a success fee and/or insurance premium, although not the level of the success fee or premium. 
3.3 Solicitors are recommended to use a standard format for such a letter - an example is at Annex A: this can be amended to suit the particular case.

3.4 The letter should ask for details of the insurer and that a copy should be sent by the proposed defendant to the insurer where appropriate. If the insurer is known, a copy shall be sent directly to the insurer. Details of the claimant's National Insurance number and date of birth should be supplied to the defendant's insurer once the defendant has responded to the letter of claim and confirmed the identity of the insurer. This information should not be supplied in the letter of claim.

3.5 Sufficient information should be given in order to enable the defendant's insurer/solicitor to commence investigations and at least put a broad valuation on the 'risk'.

3.6 The defendant should reply within 21 calendar days of the date of posting of the letter identifying the insurer (if any) and, if necessary, identifying specifically any significant omissions from the letter of claim. If there has been no reply by the defendant or insurer within 21 days, the claimant will be entitled to issue proceedings.

3.7 The defendant ('s insurers) will have a maximum of three months from the date of acknowledgment of the claim to investigate. No later than the end of that period the defendant (insurer) shall reply, stating whether liability is denied and, if so, giving reasons for their denial of liability including any alternative version of events relied upon.

3.8 Where the accident occurred outside England and Wales and/or where the defendant is outside the jurisdiction, the time periods of 21 days and three months should normally be extended up to 42 days and six months.

3.9 Where the claimant's investigation indicates that the value of the claim has increased to more than the value of the fast track limit since the letter of claim, the claimant should notify the defendant as soon as possible.

\section{Documents}

3.10 If the defendant denies liability, he should enclose with the letter of reply, documents in his possession which are material to the issues between the parties, and which would be likely to be ordered to be disclosed by the court, either on an application for pre-action disclosure, or on disclosure during proceedings.

3.11 Attached at Annex B are specimen, but non-exhaustive, lists of documents likely to be material in different types of claim. Where the claimant's investigation of the case is well advanced, the letter of claim could indicate which classes of documents are considered relevant for early disclosure. Alternatively these could be identified at a later stage.

3.12 Where the defendant admits primary liability, but alleges contributory negligence by the claimant, the defendant should give reasons supporting those allegations and disclose those documents from Annex B which are relevant to the issues in dispute. The claimant should respond to the allegations of contributory negligence before proceedings are issued. 
3.13 No charge will be made for providing copy documents under the Protocol.

\section{Special damages}

3.14 The claimant will send to the defendant as soon as practicable a Schedule of Special Damages with supporting documents, particularly where the defendant has admitted liability.

\section{Experts}

3.15 Before any party instructs an expert he should give the other party a list of the name (s) of one or more experts in the relevant speciality whom he considers are suitable to instruct.

3.16 Where a medical expert is to be instructed the claimant's solicitor will organise access to relevant medical records - see specimen letter of instruction at Annex C.

3.17 Within 14 days the other party may indicate an objection to one or more of the named experts. The first party should then instruct a mutually acceptable expert (which is not the same as a joint expert). It must be emphasised that if the Claimant nominates an expert in the original letter of claim, the defendant has 14 days to object to one or more of the named experts after expiration of the period of 21 days within which he has to reply to the letter of claim, as set out in paragraph 3.6.

3.18 If the second party objects to all the listed experts, the parties may then instruct experts of their own choice. It would be for the court to decide subsequently, if proceedings are issued, whether either party had acted unreasonably.

3.19 If the second party does not object to an expert nominated, he shall not be entitled to rely on his own expert evidence within that particular speciality unless:

(a) the first party agrees,

(b) the court so directs, or

(c) the first party's expert report has been amended and the first party is not prepared to disclose the original report.

3.20 Either party may send to an agreed expert written questions on the report, relevant to the issues, via the first party's solicitors. The expert should send answers to the questions separately and directly to each party.

3.21 The cost of a report from an agreed expert will usually be paid by the instructing first party: the costs of the expert replying to questions will usually be borne by the party which asks the questions.

\section{Rehabilitation}

4.1 The claimant or the defendant or both shall consider as early as possible whether the claimant has reasonable needs that could be met by rehabilitation treatment or other measures. 
4.2 The parties shall consider, in such cases, how those needs might be addressed. The Rehabilitation Code (which is attached at Annex D) may be helpful in considering how to identify the claimant's needs and how to address the cost of providing for those needs.

4.3 The time limit set out in paragraph 3.7 of this Protocol shall not be shortened, except by consent to allow these issues to be addressed.

4.4 The provision of any report obtained for the purposes of assessment of provision of a party's rehabilitation needs shall not be used in any litigation arising out of the accident, the subject of the claim, save by consent and shall in any event be exempt from the provisions of paragraphs 3.15 to 3.21 inclusive of this protocol.

\section{Resolution of issues}

5.1 Where the defendant admits liability in whole or in part, before proceedings are issued, any medical reports obtained under this protocol on which a party relies should be disclosed to the other party. The claimant should delay issuing proceedings for 21 days from disclosure of the report (unless such delay would cause his claim to become time-barred), to enable the parties to consider whether the claim is capable of settlement.

5.2 The Civil Procedure Rules Part 36 permit claimants and defendants to make offers to settle pre-proceedings. Parties should always consider before issuing if it is appropriate to make Part 36 Offer. If such an offer is made, the party making the offer must always supply sufficient evidence and/or information to enable the offer to be properly considered.

5.3 Where the defendant has admitted liability, the claimant should send to the defendant schedules of special damages and loss at least 21 days before proceedings are issued (unless that would cause the claimant's claim to become time-barred). 
To

Defendant

Dear Sirs

Re: Claimant's full name

Claimant's full address

Claimant's Clock or Works Number

Claimant's Employer (name and address)

We are instructed by the above named to claim damages in connection with an accident at work/road traffic accident/tripping accident

on day of (year) at (place of accident which must be sufficiently detailed to establish location)

Please confirm the identity of your insurers. Please note that the insurers will need to see this letter as soon as possible and it may affect your insurance cover and/or the conduct of any subsequent legal proceedings if you do not send this letter to them.

The circumstances of the accident are:-

(brief outline)

The reason why we are alleging fault is:

(simple explanation e.g. defective machine, broken ground)

A description of our clients' injuries is as follows:-

(brief outline)

(In cases of road traffic accidents)

Our client (state hospital reference number) received treatment for the injuries at name and address of hospital).

Our client is still suffering from the effects of his/her injury. We invite you to participate with us in addressing his/her immediate needs by use of rehabilitation.

He is employed as (occupation) and has had the following time off work (dates of absence). His approximate weekly income is (insert if known).

If you are our client's employers, please provide us with the usual earnings details which will enable us to calculate his financial loss.

We are obtaining a police report and will let you have a copy of the same upon your undertaking to meet half the fee.

We have also sent a letter of claim to (name and address) and a copy of that letter is attached. We understand their insurers are (name, address and claims number if known).

At this stage of our enquiries we would expect the documents contained in parts (insert appropriate parts of standard disclosure list) to be relevant to this action.

Please note that we have entered into a conditional fee agreement with our client dated in relation to this claim which provides for a success fee within the meaning of section 58(2) of the Courts and Legal Services Act 1990. Our client has taken out an insurance policy with [name of insurance company] of [address of insurance company] to which section 29 of the Access Justice Act 1999 applies. The policy number is and the policy is dated . Where the funding arrangement is an insurance policy, the party must state the name and address of the insurer, the policy number and the date of the policy, and must identify the claim or claims to which it relates (including Part 20 claims if any).

A copy of this letter is attached for you to send to your insurers. Finally we expect an acknowledgment of this letter within 21 days by yourselves or your insurers.

Yours faithfully 


\section{B Pre-action personal injury protocol standard disclosure lists}

\section{FAST TRACK DISCLOSURE}

\section{RTA CASES}

\section{SECTION A}

In all cases where liability is at issue -

(i) Documents identifying nature, extent and location of damage to defendant's vehicle where there is any dispute about point of impact.

(ii) MOT certificate where relevant.

(iii) Maintenance records where vehicle defect is alleged or it is alleged by defendant that there was an unforeseen defect which caused or contributed to the accident.

\section{SECTION B}

Accident involving commercial vehicle as defendant -

(i) Tachograph charts or entry from individual control book.

(ii) Maintenance and repair records required for operators' licence where vehicle defect is alleged or it is alleged by defendant that there was an unforeseen defect which caused or contributed to the accident.

\section{SECTION C}

Cases against local authorities where highway design defect is alleged.

(i) Documents produced to comply with Section 39 of the Road Traffic Act 1988 in respect of the duty designed to promote road safety to include studies into road accidents in the relevant area and documents relating to measures recommended to prevent accidents in the relevant area.

\section{HIGHWAY TRIPPING CLAIMS}

Documents from Highway Authority for a period of 12 months prior to the accident -

(i) Records of inspection for the relevant stretch of highway.

(ii) Maintenance records including records of independent contractors working in relevant area.

(iii) Records of the minutes of Highway Authority meetings where maintenance or repair policy has been discussed or decided.

(iv) Records of complaints about the state of highways.

(v) Records of other accidents which have occurred on the relevant stretch of highway.

\section{WORKPLACE CLAIMS}

(i) Accident book entry.

(ii) First aider report.

(iii) Surgery record.

(iv) Foreman/supervisor accident report. 
(v) Safety representatives accident report.

(vi) RIDDOR (Reporting of Injuries, Diseases and Dangerous Occurrences Regulations) report to HSE.

(vii) Other communications between defendants and HSE.

(viii) Minutes of Health and Safety Committee meeting(s) where accident/matter considered.

(ix) Report to DSS.

(x) Documents listed above relative to any previous accident/matter identified by the claimant and relied upon as proof of negligence.

(xi) Earnings information where defendant is employer.

Documents produced to comply with requirements of the Management of Health and Safety at Work Regulations 1992 -

(i) Pre-accident Risk Assessment required by Regulation 3.

(ii) Post-accident Re-Assessment required by Regulation 3.

(iii) Accident Investigation Report prepared in implementing the requirements of Regulations 4,6 and 9.

(iv) Health Surveillance Records in appropriate cases required by Regulation 5 .

(v) Information provided to employees under Regulation 8.

(vi) Documents relating to the employees health and safety training required by Regulation 11.

\section{WORKPLACE CLAIMS - DISCLOSURE WHERE SPECIFIC REGULATIONS APPLY}

\section{SECTION A - Workplace (Health Safety and Welfare) Regulations 1992}

(i) Repair and maintenance records required by Regulation 5 .

(ii) Housekeeping records to comply with the requirements of Regulation 9.

(iii) Hazard warning signs or notices to comply with Regulation 17 (Traffic Routes).

\section{SECTION B - Provision and Use of Work Equipment Regulations 1998}

(i) Manufacturers' specifications and instructions in respect of relevant work equipment establishing its suitability to comply with Regulation 5 .

(ii) Maintenance $\log /$ maintenance records required to comply with Regulation 6.

(iii) Documents providing information and instructions to employees to comply with Regulation 8.

(iv) Documents provided to the employee in respect of training for use to comply with Regulation 9.

(v) Any notice, sign or document relied upon as a defence to alleged breaches of Regulations 14 to 18 dealing with controls and control systems.

(vi) Instruction/training documents issued to comply with the requirements of regulation 22 insofar as it deals with maintenance operations where the machinery is not shut down.

(vii) Copies of markings required to comply with Regulation 23.

(viii)Copies of warnings required to comply with Regulation 24 .

\section{SECTION C - Personal Protective Equipment at Work Regulations 1992}

(i) Documents relating to the assessment of the Personal Protective Equipment to comply with Regulation 6.

(ii) Documents relating to the maintenance and replacement of Personal Protective Equipment to comply with Regulation 7. 
(iii) Record of maintenance procedures for Personal Protective Equipment to comply with Regulation 7.

(iv) Records of tests and examinations of Personal Protective Equipment to comply with Regulation 7.

(v) Documents providing information, instruction and training in relation to the Personal Protective Equipment to comply with Regulation 9.

(vi) Instructions for use of Personal Protective Equipment to include the manufacturers' instructions to comply with Regulation 10.

\section{SECTION D - Manual Handling Operations Regulations 1992}

(i) Manual Handling Risk Assessment carried out to comply with the requirements of Regulation 4(1)(b)(i).

(ii) Re-assessment carried out post-accident to comply with requirements of Regulation $4(1)(b)(i)$.

(iii) Documents showing the information provided to the employee to give general indications related to the load and precise indications on the weight of the load and the heaviest side of the load if the centre of gravity was not positioned centrally to comply with Regulation $4(1)$ (b)(iii).

(iv) Documents relating to training in respect of manual handling operations and training records.

\section{SECTION E - Health and Safety (Display Screen Equipment) Regulations 1992}

(i) Analysis of work stations to assess and reduce risks carried out to comply with the requirements of Regulation 2.

(ii) Re-assessment of analysis of work stations to assess and reduce risks following development of symptoms by the claimant.

(iii) Documents detailing the provision of training including training records to comply with the requirements of Regulation 6.

(iv) Documents providing information to employees to comply with the requirements of Regulation 7.

\section{SECTION F - Control of Substances Hazardous to Health Regulations 1999}

(i) Risk assessment carried out to comply with the requirements of Regulation 6.

(ii) Reviewed risk assessment carried out to comply with the requirements of Regulation 6.

(iii) Copy labels from containers used for storage handling and disposal of carcinogenics to comply with the requirements of Regulation 7(2A)(h).

(iv) Warning signs identifying designation of areas and installations which may be contaminated by carcinogenics to comply with the requirements of Regulation 7(2A)(h).

(v) Documents relating to the assessment of the Personal Protective Equipment to comply with Regulation 7(3A).

(vi) Documents relating to the maintenance and replacement of Personal Protective Equipment to comply with Regulation 7(3A).

(vii) Record of maintenance procedures for Personal Protective Equipment to comply with Regulation 7(3A).

(viii) Records of tests and examinations of Personal Protective Equipment to comply with Regulation 7(3A). 
(ix) Documents providing information, instruction and training in relation to the Personal Protective Equipment to comply with Regulation 7(3A).

(x) Instructions for use of Personal Protective Equipment to include the manufacturers' instructions to comply with Regulation 7(3A).

(xi) Air monitoring records for substances assigned a maximum exposure limit or occupational exposure standard to comply with the requirements of Regulation 7.

(xii) Maintenance examination and test of control measures records to comply with Regulation 9.

(xiii) Monitoring records to comply with the requirements of Regulation 10.

(xiv) Health surveillance records to comply with the requirements of Regulation 11.

(xv) Documents detailing information, instruction and training including training records for employees to comply with the requirements of Regulation 12 .

(xvi) Labels and Health and Safety data sheets supplied to the employers to comply with the CHIP Regulations.

\section{SECTION G - Construction (Design and Management) (Amendment) Regulations} 2000

(i) Notification of a project form (HSE F10) to comply with the requirements of Regulation 7.

(ii) Health and Safety Plan to comply with requirements of Regulation 15.

(iii) Health and Safety file to comply with the requirements of Regulations 12 and 14.

(iv) Information and training records provided to comply with the requirements of Regulation 17.

(v) Records of advice from and views of persons at work to comply with the requirements of Regulation 18.

\section{SECTION H - Pressure Systems and Transportable Gas Containers Regulations 1989}

(i) Information and specimen markings provided to comply with the requirements of Regulation 5.

(ii) Written statements specifying the safe operating limits of a system to comply with the requirements of Regulation 7.

(iii) Copy of the written scheme of examination required to comply with the requirements of Regulation 8.

(iv) Examination records required to comply with the requirements of Regulation 9.

(v) Instructions provided for the use of operator to comply with Regulation 11.

(vi) Records kept to comply with the requirements of Regulation 13.

(vii) Records kept to comply with the requirements of Regulation 22.

\section{SECTION I - Lifting Operations and Lifting Equipment Regulations 1998}

(i) Record kept to comply with the requirements of Regulation 6.

\section{SECTION J - The Noise at Work Regulations 1989}

(i) Any risk assessment records required to comply with the requirements of Regulations 4 and 5 .

(ii) Manufacturers' literature in respect of all ear protection made available to claimant to comply with the requirements of Regulation 8 . 
(iii) All documents provided to the employee for the provision of information to comply with Regulation 11.

\section{SECTION K - Construction (Head Protection) Regulations 1989}

(i) Pre-accident assessment of head protection required to comply with Regulation 3(4).

(ii) Post-accident re-assessment required to comply with Regulation 3(5).

\section{SECTION L - The Construction (General Provisions) Regulations 1961}

(i) Report prepared following inspections and examinations of excavations etc. to comply with the requirements of Regulation 9.

\section{SECTION M - Gas Containers Regulations 1989}

(i) Information and specimen markings provided to comply with the requirements of Regulation 5.

(ii) Written statements specifying the safe operating limits of a system to comply with the requirements of Regulation 7.

(iii) Copy of the written scheme of examination required to comply with the requirements of Regulation 8.

(iv) Examination records required to comply with the requirements of Regulation 9.

(v) Instructions provided for the use of operator to comply with Regulation 11. 


\section{Letter of instruction to medical expert}

Dear Sir,

Re: (Name and Address)

D.O.B. -

Telephone No. -

Date of Accident -

We are acting for the above named in connection with injuries received in an accident which occurred on the above date. The main injuries appear to have been (main injuries).

We should be obliged if you would examine our Client and let us have a full and detailed report dealing with any relevant pre-accident medical history, the injuries sustained, treatment received and present condition, dealing in particular with the capacity for work and giving a prognosis.

It is central to our assessment of the extent of our Client's injuries to establish the extent and duration of any continuing disability. Accordingly, in the prognosis section we would ask you to specifically comment on any areas of continuing complaint or disability or impact on daily living. If there is such continuing disability you should comment upon the level of suffering or inconvenience caused and, if you are able, give your view as to when or if the complaint or disability is likely to resolve.

Please send our Client an appointment direct for this purpose. Should you be able to offer a cancellation appointment please contact our Client direct. We confirm we will be responsible for your reasonable fees.

We are obtaining the notes and records from our Client's GP and Hospitals attended and will forward them to you when they are to hand/or please request the GP and Hospital records direct and advise that any invoice for the provision of these records should be forwarded to us. In order to comply with Court Rules we would be grateful if you would insert above your signature a statement that the contents are true to the best of your knowledge and belief. In order to avoid further correspondence we can confirm that on the evidence we have there is no reason to suspect we may be pursuing a claim against the hospital or its staff.

We look forward to receiving your report within weeks. If you will not be able to prepare your report within this period please telephone us upon receipt of these instructions. When acknowledging these instructions it would assist if you could give an estimate as to the likely time scale for the provision of your report and also an indication as to your fee.

Yours faithfully 


\section{THE 2007 REHABILITATION CODE}

\section{The 2007 Rehabilitation Code}

\section{$\underline{\text { Introduction }}$}

The aim of this code is to promote the use of rehabilitation and early intervention in the compensation process so that the injured person makes the best and quickest possible medical, social and psychological recovery. This objective applies whatever the severity of the injuries sustained by the claimant. The Code is designed to ensure that the claimant's need for rehabilitation is assessed and addressed as a priority, and that the process of so doing is pursued on a collaborative basis by the claimant's lawyer and the compensator.

Therefore, in every case, where rehabilitation is likely to be of benefit, the earliest possible notification to the compensator of the claim and of the need for rehabilitation will be expected.

\section{Introduction}

1.1 The purpose of the personal injury claims process is to put the individual back into the same position as he or she would have been in, had the accident not occurred, insofar as money can achieve that objective. The purpose of the rehabilitation code is to provide a framework within which the claimant's health, quality of life and ability to work are restored as far as possible before, or simultaneously with, the process of assessing compensation.

1.2 Although the Code is recognised by the Personal Injury Pre-Action Protocol, its provisions are not mandatory. It is recognised that the aims of the Code can be achieved without strict adherence to the terms of the Code, and therefore it is open to the parties to agree an alternative framework to achieve the early rehabilitation of the claimant.

1.3 However, the Code provides a useful framework within which claimant's lawyers and the compensator can work together to ensure that the needs of injured claimants are assessed at an early stage.

1.4 In any case where agreement on liability is not reached it is open to the parties to agree that the Code will in any event operate, and the question of delay pending resolution of liability should be balanced with the interests of the injured party. However, unless so agreed, the Code does not apply in the absence of liability or prior to agreement on liability being reached.

1.5 In this code the expression "the compensator" shall include any loss adjuster, solicitor or other person acting on behalf of the compensator.

\section{The claimant's solicitor}

2.1 It should be the duty of every claimant's solicitor to consider, from the earliest practicable stage, and in consultation with the claimant, the claimant's family, and where appropriate the claimant's treating physician(s), whether it is likely or possible that early intervention, rehabilitation or medical treatment would improve their present and/or long term physical and mental well being. This 
duty is ongoing throughout the life of the case but is of most importance in the early stages.

2.2 The claimant's solicitors will in any event be aware of their responsibilities under section 4 of the Pre-Action Protocol for Personal Injury Claims.

2.3 It shall be the duty of a claimant's solicitor to consider, with the claimant and/or the claimant's family, whether there is an immediate need for aids, adaptations, adjustments to employment to enable the claimant to keep his/her existing job, obtain suitable alternative employment with the same employer or retrain for new employment, or other matters that would seek to alleviate problems caused by disability, and then to communicate with the compensators as soon as practicable about any such rehabilitation needs, with a view to putting this Code into effect.

2.4 It shall not be the responsibility of the solicitor to decide on the need for treatment or rehabilitation or to arrange such matters without appropriate medical or professional advice.

2.5 It is the intention of this Code that the claimant's solicitor will work with the compensator to address these rehabilitation needs and that the assessment and delivery of rehabilitation needs shall be a collaborative process.

2.6 It must be recognised that the compensator will need to receive from the claimants' solicitors sufficient information for the compensator to make a proper decision about the need for intervention, rehabilitation or treatment. To this extent the claimant's solicitor must comply with the requirements of the PreAction Protocol to provide the compensator with full and adequate details of the injuries sustained by the claimant, the nature and extent of any or any likely continuing disability and any suggestions that may have already have been made concerning the rehabilitation and/or early intervention.

2.7 There is no requirement under the Pre-Action Protocol, or under this code, for the claimant's solicitor to have obtained a full medical report. It is recognised that many cases will be identified for consideration under this code before medical evidence has actually been commissioned or obtained.

\section{The Compensator}

3.1 It shall be the duty of the compensator, from the earliest practicable stage in any appropriate case, to consider whether it is likely that the claimant will benefit in the immediate, medium or longer term from further medical treatment, rehabilitation or early intervention. This duty is ongoing throughout the life of the case but is most important in the early stages.

3.2 If the compensator considers that a particular claim might be suitable for intervention, rehabilitation or treatment, the compensator will communicate this to the claimant's solicitor as soon as practicable.

3.3 On receipt of such communication, the claimant's solicitor will immediately discuss these issues with the claimant and/or the claimant's family pursuant to his duty set out above. 
3.4 Where a request to consider rehabilitation has been communicated by the claimant's solicitor to the compensator, it will usually be expected that the compensator will respond to such request within 21 days.

3.5 Nothing in this or any other code of practice shall in any way modify the obligations of the compensator under the Protocol to investigate claims rapidly and in any event within 3 months (except where time is extended by the claimant's solicitor) from the date of the formal claim letter. It is recognised that, although the rehabilitation assessment can be done even where liability investigations are outstanding, it is essential that such investigations proceed with the appropriate speed.

\section{Assessment}

4.1 Unless the need for intervention, rehabilitation or treatment has already been identified by medical reports obtained and disclosed by either side, the need for and extent of such intervention, rehabilitation or treatment will be considered by means of an assessment by an appropriately qualified person.

4.2 An assessment of rehabilitation needs may be carried out by any person or organisation suitably qualified, experienced and skilled to carry out the task. The claimant's solicitor and the compensator should endeavour to agree on the person or organisation to be chosen.

4.3 No solicitor or compensator may insist on the assessment being carried out by a particular person or organisation if [on reasonable grounds] the other party objects, such objection to be raised within 21 days from the date of notification of the suggested assessor.

4.4 The assessment may be carried out by a person or organisation which has a direct business connection with the solicitor or compensator, only if the other party agrees. The solicitor or compensator will be expected to reveal to the other party the existence of and nature of such a business connection.

\section{The Assessment Process}

5.1 Where possible, the agency to be instructed to provide the assessment should be agreed between the claimant's solicitor and the compensator. The method of providing instructions to that agency will be agreed between the solicitor and the compensator.

5.2 The assessment agency will be asked to carry out the assessment in a way that is appropriate to the needs of the case and, in a simple case, may include, by prior appointment, a telephone interview but in more serious cases will probably involve a face to face discussion with the claimant. The report will normally cover the following headings:-

1. The Injuries sustained by the claimant.

2. The current disability/incapacity arising from those Injuries. Where relevant to the overall picture of the claimant's needs, any other medical conditions not arising from the accident should also be separately annotated. 
3. The claimant's domestic circumstances (including mobility accommodation and employment) where relevant.

4. The injuries/disability in respect of which early intervention or early rehabilitation is suggested.

5. The type of intervention or treatment envisaged.

6. The likely cost.

7. The likely outcome of such intervention or treatment.

5.3 The report should not deal with issues relating to legal liability and should therefore not contain a detailed account of the accident circumstances.

5.4 In most cases it will be expected that the assessment will take place within 14 days from the date of the letter of referral to the assessment agency.

5.5 It must be remembered that the compensator will usually only consider such rehabilitation to deal with the effects of the injuries that have been caused in the relevant accident and will normally not be expected to fund treatment for conditions which do not directly relate to the accident unless the effect of such conditions has been exacerbated by the injuries sustained in the accident.

\section{The Assessment Report}

6.1 The report agency will, on completion of the report, send copies onto both the claimant's solicitor and compensator simultaneously. Both parties will have the right to raise questions on the report, disclosing such correspondence to the other party.

6.2 It is recognised that for this assessment report to be of benefit to the parties, it should be prepared and used wholly outside the litigation process. Neither side can therefore, unless they agree in writing, rely on its contents in any subsequent litigation.

6.3 The report, any correspondence related to it and any notes created by the assessing agency to prepare it, will be covered by legal privilege and will not be disclosed in any legal proceedings unless the parties agree. Any notes or documents created in connection with the assessment process will not be disclosed in any litigation, and any person involved in the preparation of the report or involved in the assessment process, shall not be a compellable witness at Court. This principle is also set out in paragraph 4.4 of the PreAction Protocol.

6.4 The provision in paragraph 6.3 above as to treating the report etc as outside the litigation process is limited to the assessment report and any notes relating to it. Any notes and reports created during the subsequent case management process will be covered by the usual principle in relation to disclosure of documents and medical records relating to the claimant.

6.5 The compensator will pay for the report within 28 days of receipt. 
6.6 This code intends that the parties will continue to work together to ensure that the rehabilitation which has been recommended proceeds smoothly and that any further rehabilitation needs are also assessed.

\section{Recommendations}

7.1 When the assessment report is disclosed to the compensator, the compensator will be under a duty to consider the recommendations made and the extent to which funds will be made available to implement all or some of the recommendations. The compensator will not be required to pay for intervention treatment that is unreasonable in nature, content or cost or where adequate and timely provision is otherwise available. The claimant will be under no obligation to undergo intervention, medical or investigation treatment that is unreasonable in all the circumstances of the case.

7.2 The compensator will normally be expected to respond to the claimant's solicitor within 21 days from the date upon which the assessment report is disclosed as to the extent to which the recommendations have been accepted and rehabilitation treatment would be funded and will be expected to justify, within that same timescale, any refusal to meet the cost of recommended rehabilitation.

7.3 If funds are provided by the compensator to the claimant to enable specific intervention, rehabilitation or treatment to occur, the compensator warrants that they will not, in any legal proceedings connected with the claim, dispute the reasonableness of that treatment, nor the agreed costs, provided of course that the claimant has had the recommended treatment. The compensator will not, should the claim fail or be later discontinued, or any element of contributory negligence be assessed or agreed, seek to recover from the claimant any funds that they have made available pursuant to this Code.

The Rehabilitation Code is endorsed by many organisations, including:

Association of British Insurers

Association of Personal Injury Lawyers

Bodily Injury Claims Management Association

Case Management Society of the UK

Forum of Insurance Lawyers

International Underwriting Association

Motor Accident Solicitors' Society

To download the code, go to www.iua.co.uk/rehabilitationcode 